\title{
The INTERIORITY of SLEEP \& POWER
}

Chloe Deanne Walbran 


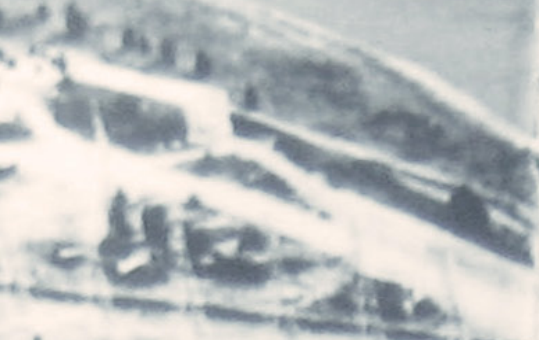

$x$

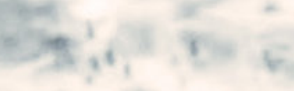

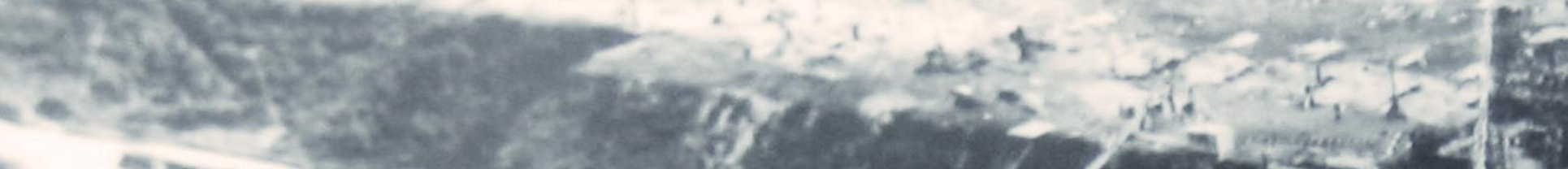
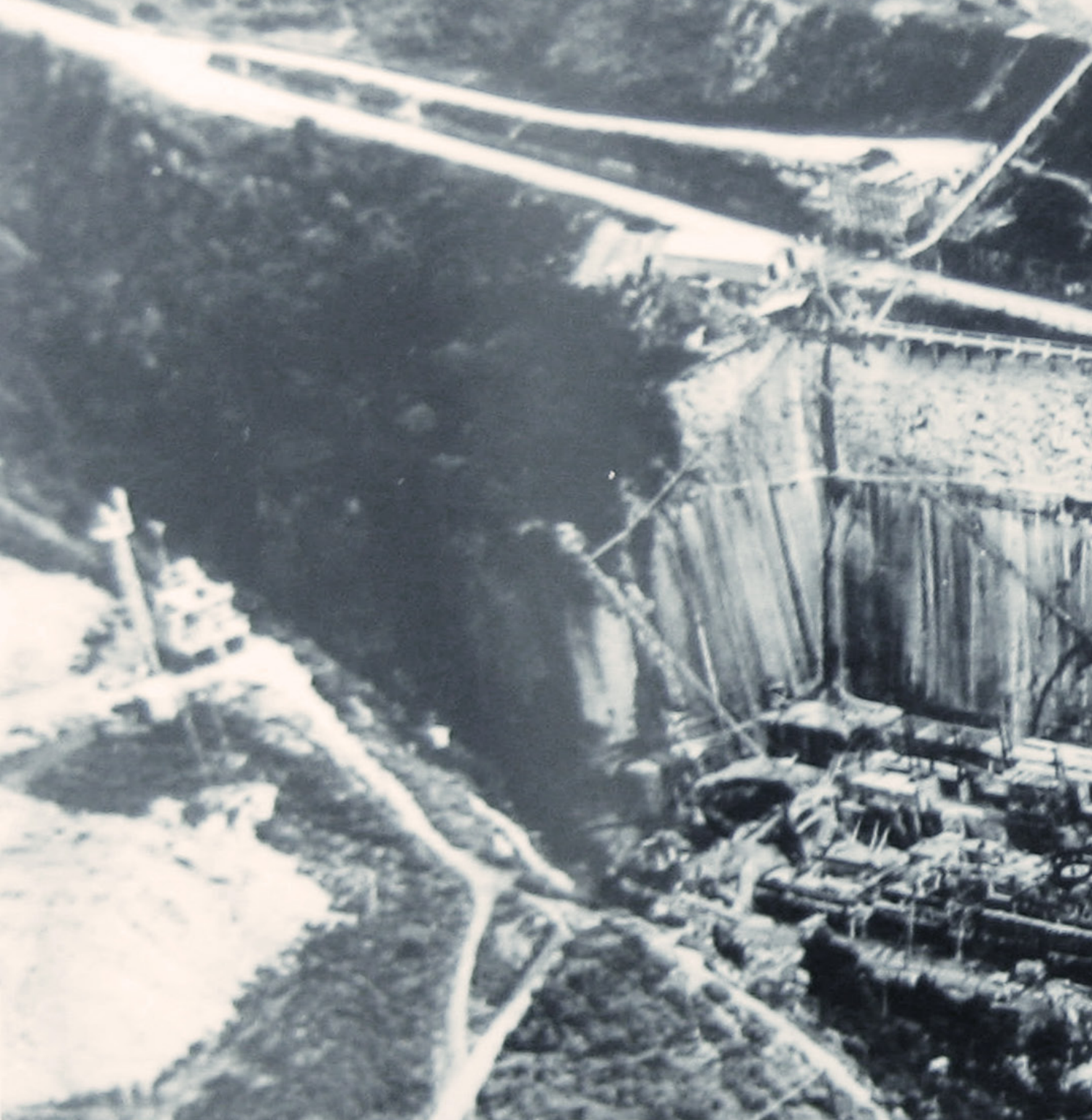

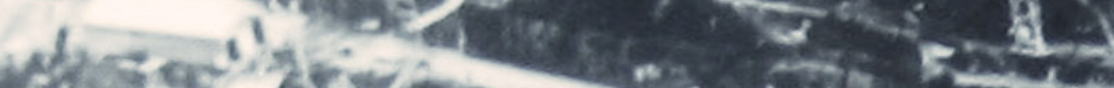

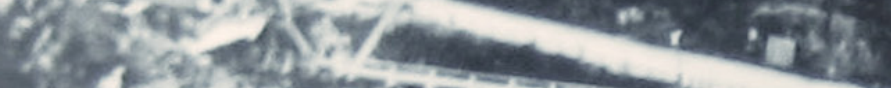
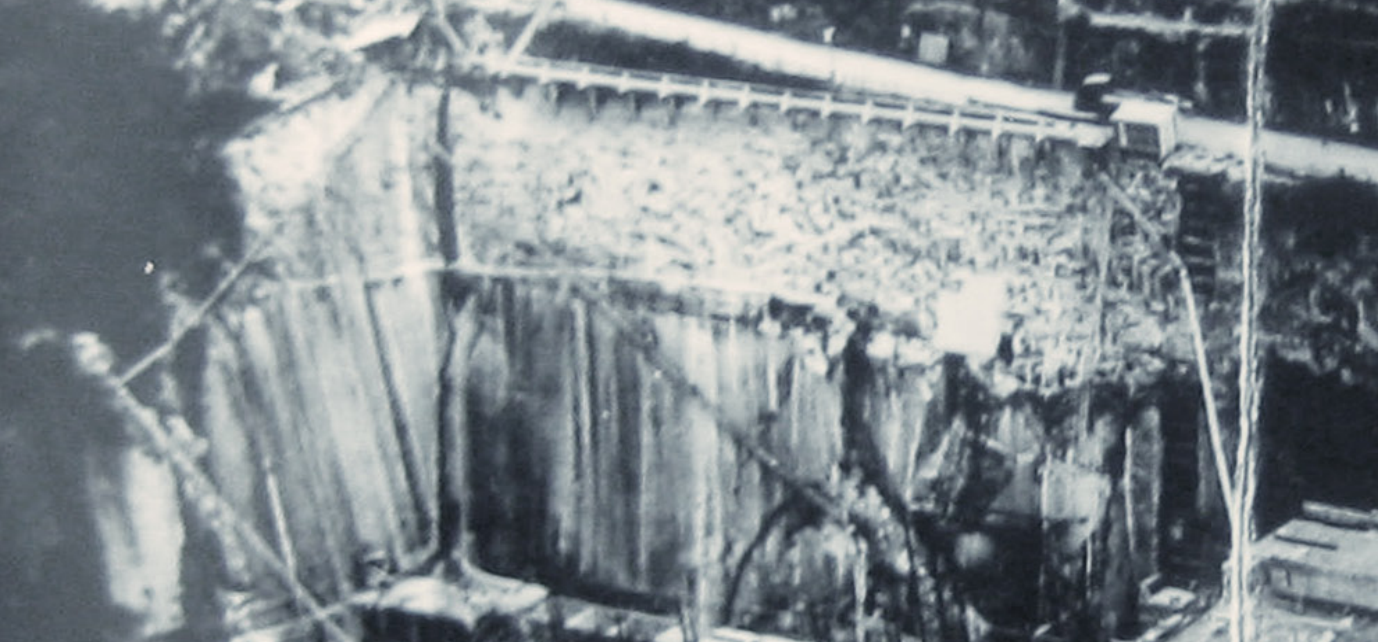

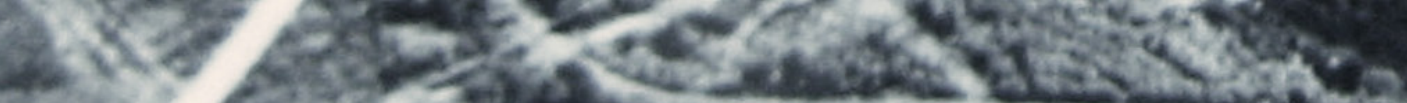

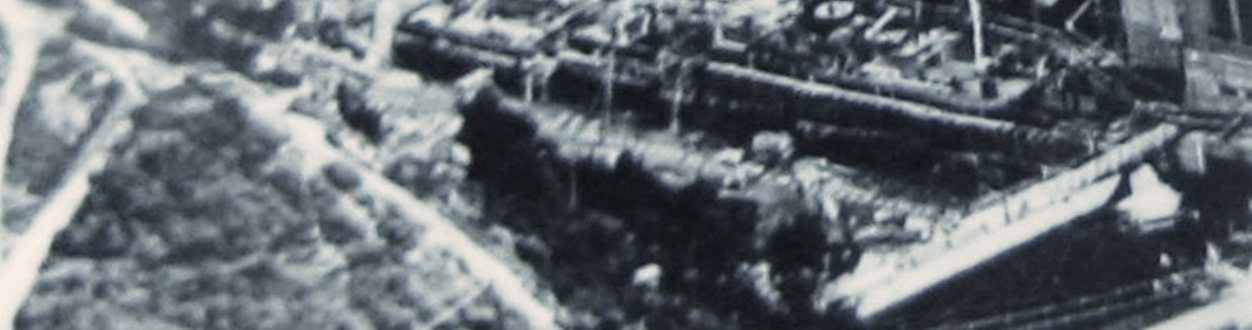


Whe

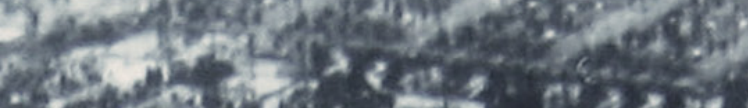

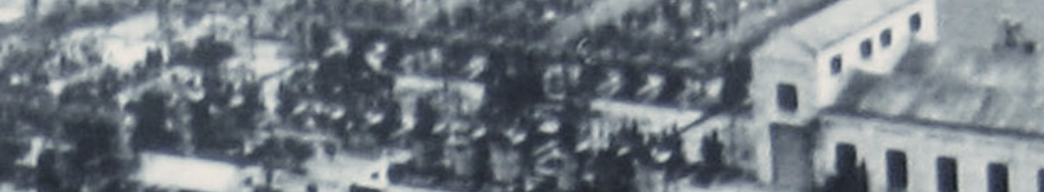

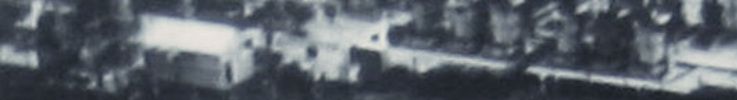

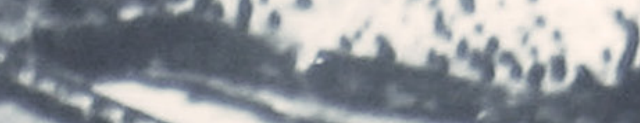

$$
\begin{aligned}
& \text { 4h }
\end{aligned}
$$

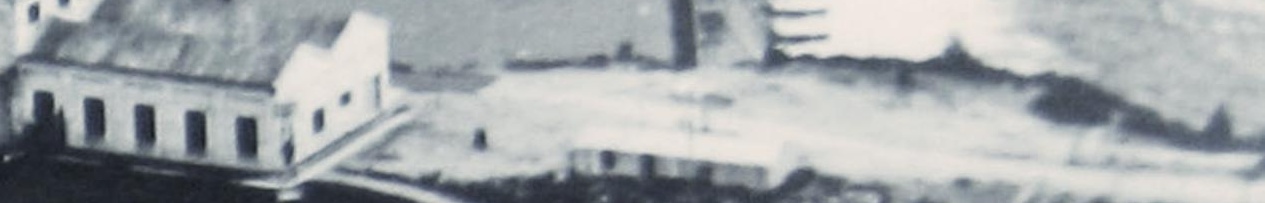

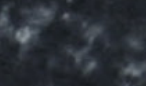

the

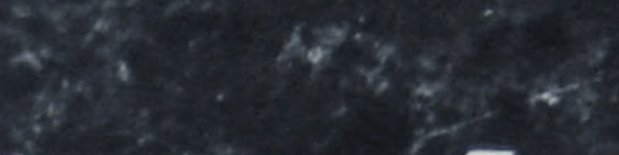
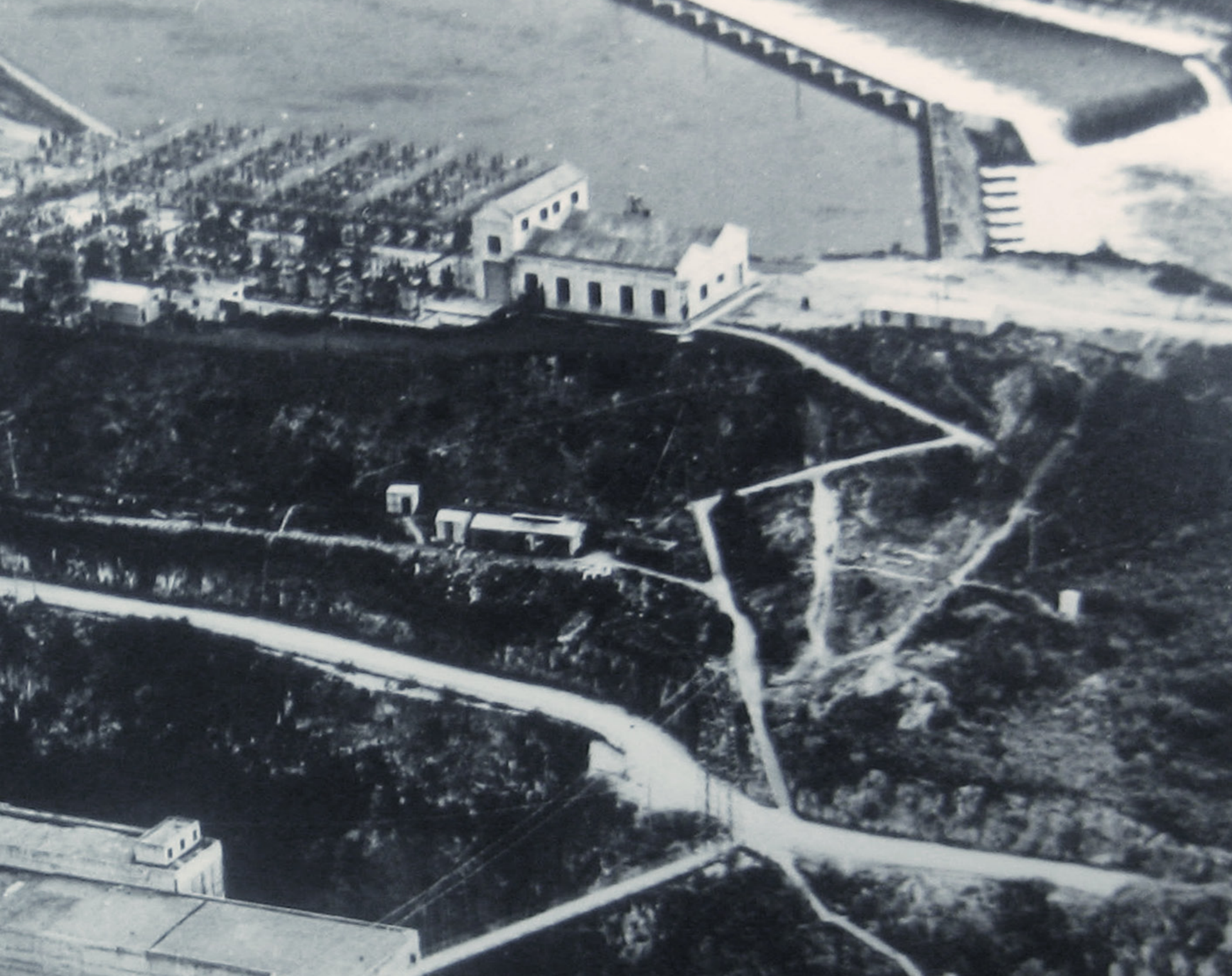

\section{1}

nity ars:

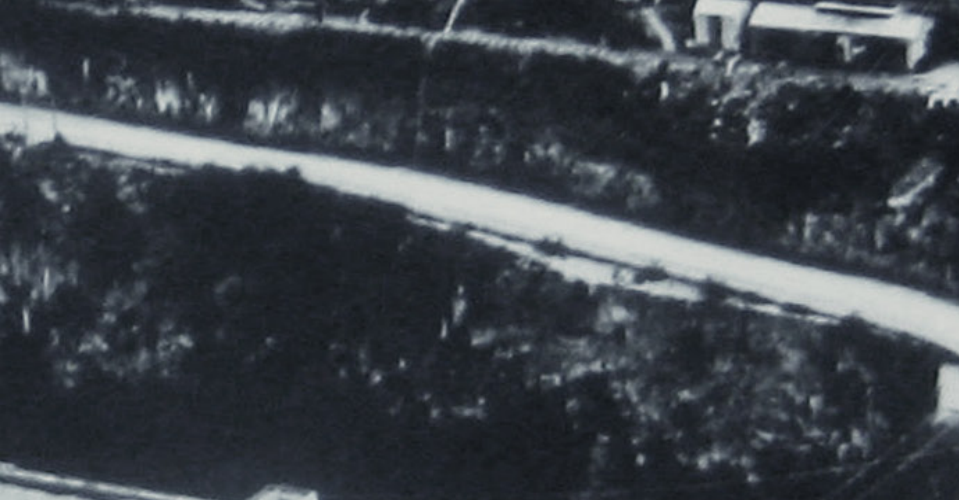

$2+\frac{1}{2}=2$
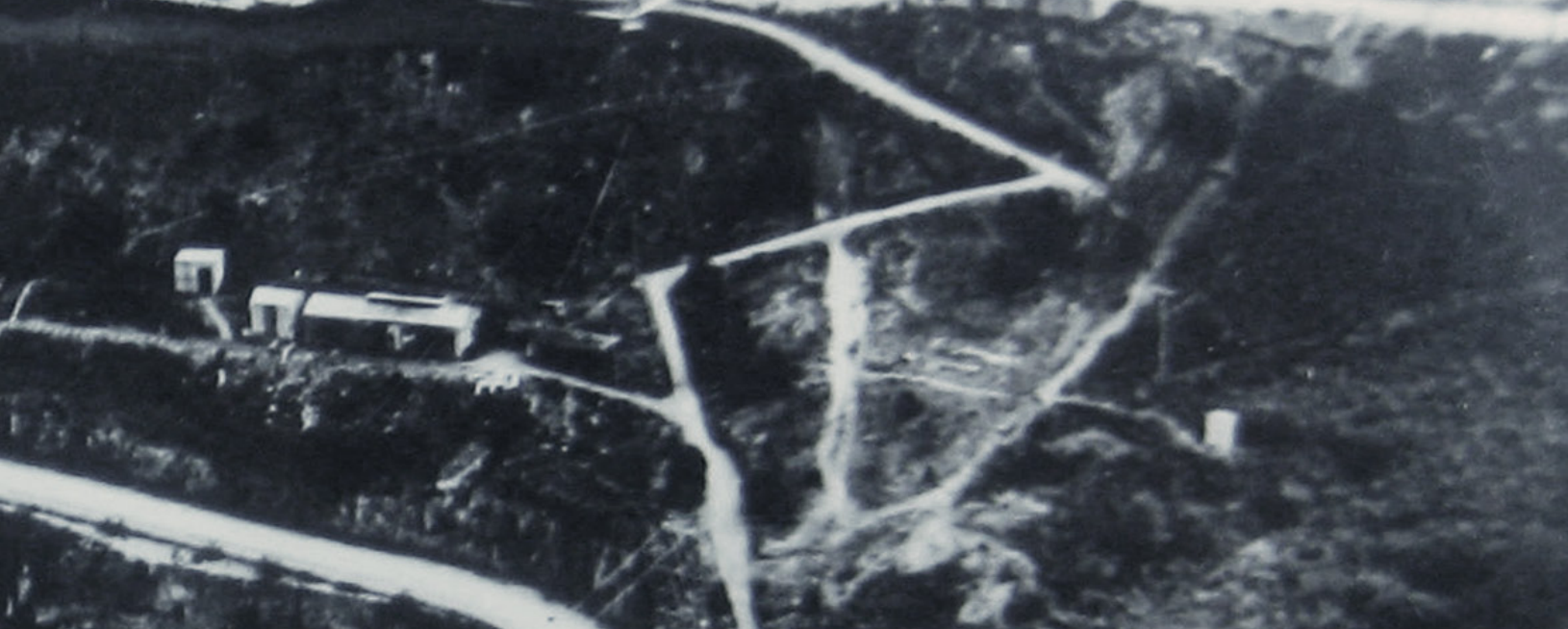

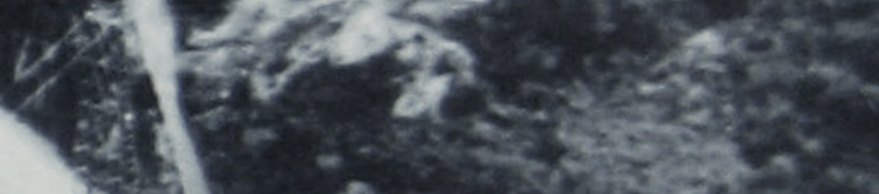

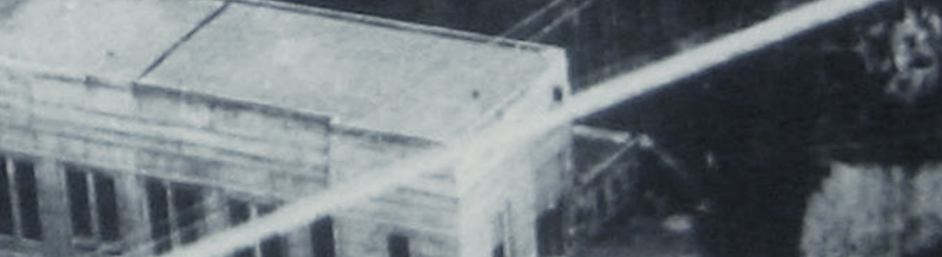

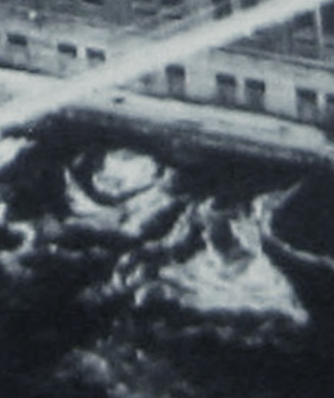

23
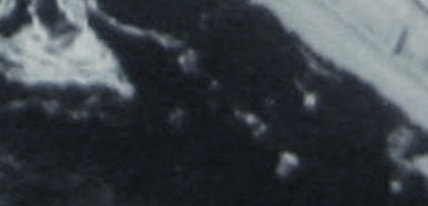

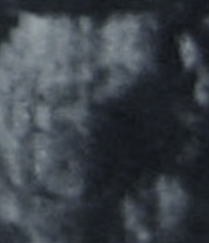

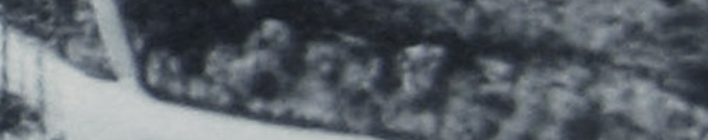
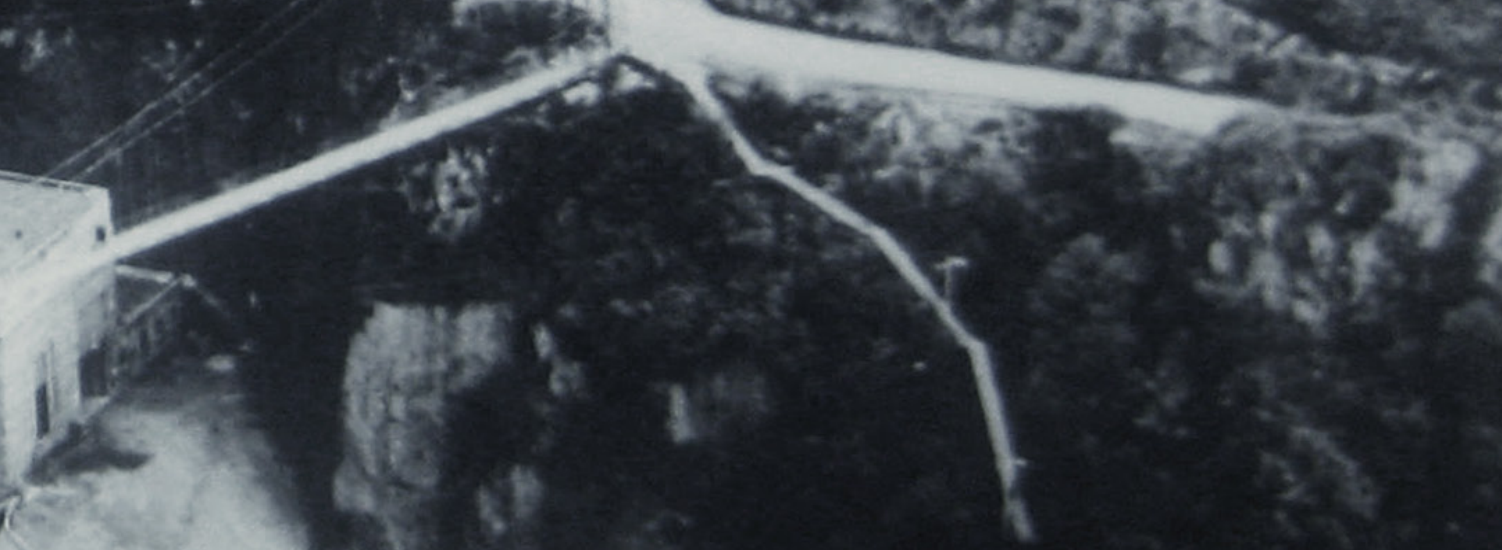



\title{
The INTERIORITY of SLEEP \& POWER
}

\author{
A 120-point thesis submitted to the \\ Victoria University of Wellington in \\ partial fulfillment of the requirements \\ for the degree of \\ Master of Interior Architecture
}

by Chloe Deanne Walbran

Victoria University of Wellington

School of Architecture, 2014 



\section{ACKNOWLEDGMENTS}

There are many people I would like to thank, not only for the duration of this thesis but for the five and one-half years I have been at university.

Thank you to Dr. Peter Wood for aiding me through my fi al year of university, for supporting whatever abstract idea I threw at him and helping transform them accordingly.

Thank you to all past lecturers. I would not be where I am today without the guidance (and stress!) you provided.

Thank you to Mighty River Power for taking the time to show me the ins and outs of my incredible historic site: Arapuni Hydro-electric Powerstation.

Lastly, to my fabulous family and friends for your help over the years, and for just 'being there' when I needed it. 



\section{ABSTRACT}

This thesis explores interior immensity through the framework that targets the human being's most inner self: the time human beings spend sleeping. The in-between state of sleep is left overlooked in architecture and leaves room for novel exploration. While spending time in a semi-conscious state, we can delve into the realms of the unknown.

The primary goal is to challenge the conventional interior space of backpackers in New Zealand by inhabiting the beautiful ugliness of an industrial site. The boundary between the individual and mechanical piece of architecture is explored through a whimsical intimacy.

A hydroelectric power station is the chosen apparatus. The power station allows a duality between operation and narration, between thematic qualities and program. The abnormalities hype the superimagination of the client, somewhat like experiencing a dream state, the most active and often fantastic aspect within the threshold of consciousness.

The thesis is grounded in three sections. I firstly explore the pragmatic site anomalies, the thematic qualities and their opportunities. I then move into conceptual exploration of the interior imagination while concluding with a fully functioning yet evocative design of sleep narration. The components of this thesis are largely visual. 



\section{CONTENTS}

\section{ACKNOWLEDGMENTS}

ABSTRACT

INTRODUCTION 1

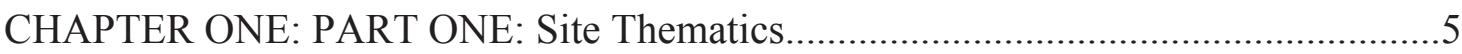

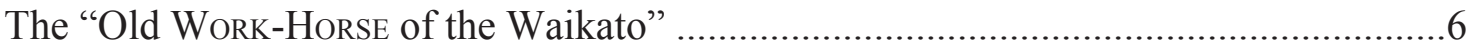

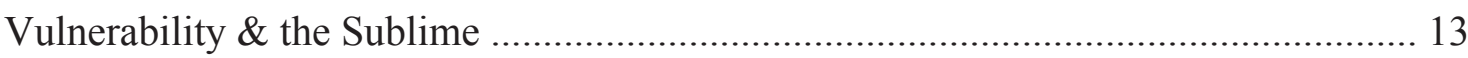

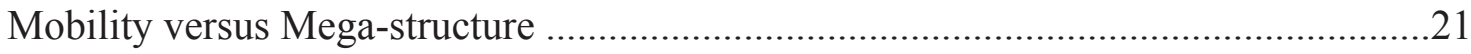

Mythology of the Power Station in POPULAR CULTURE …....................................27

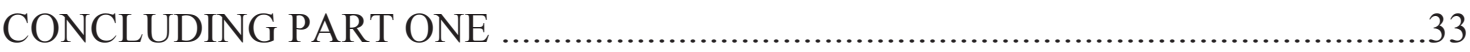

CHAPTER TWO: PART TWO: Narration and Program.............................................35

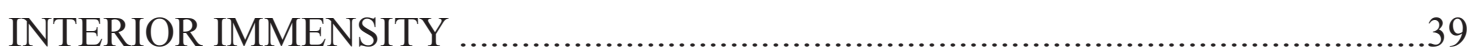

The Second Skin \& the Human Body: Dual Conditions ............................................40

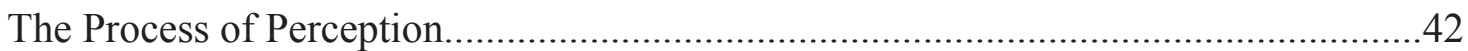

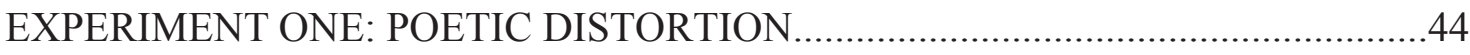

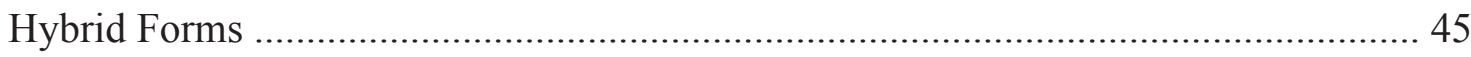

BOUTIQUE BACKPACKERS: Final Capsule Design..............................................58

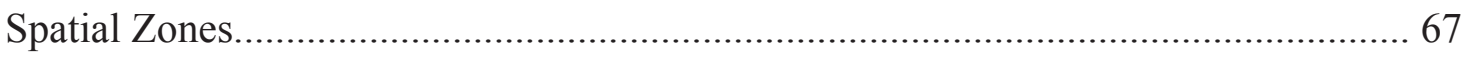

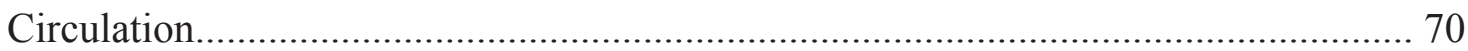

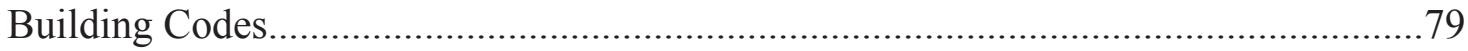

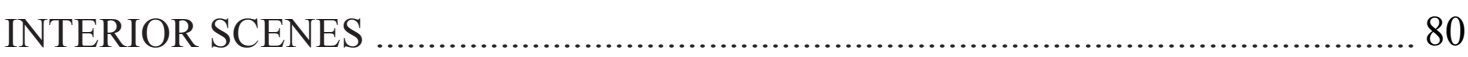

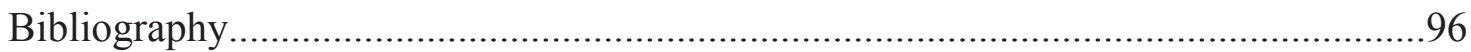




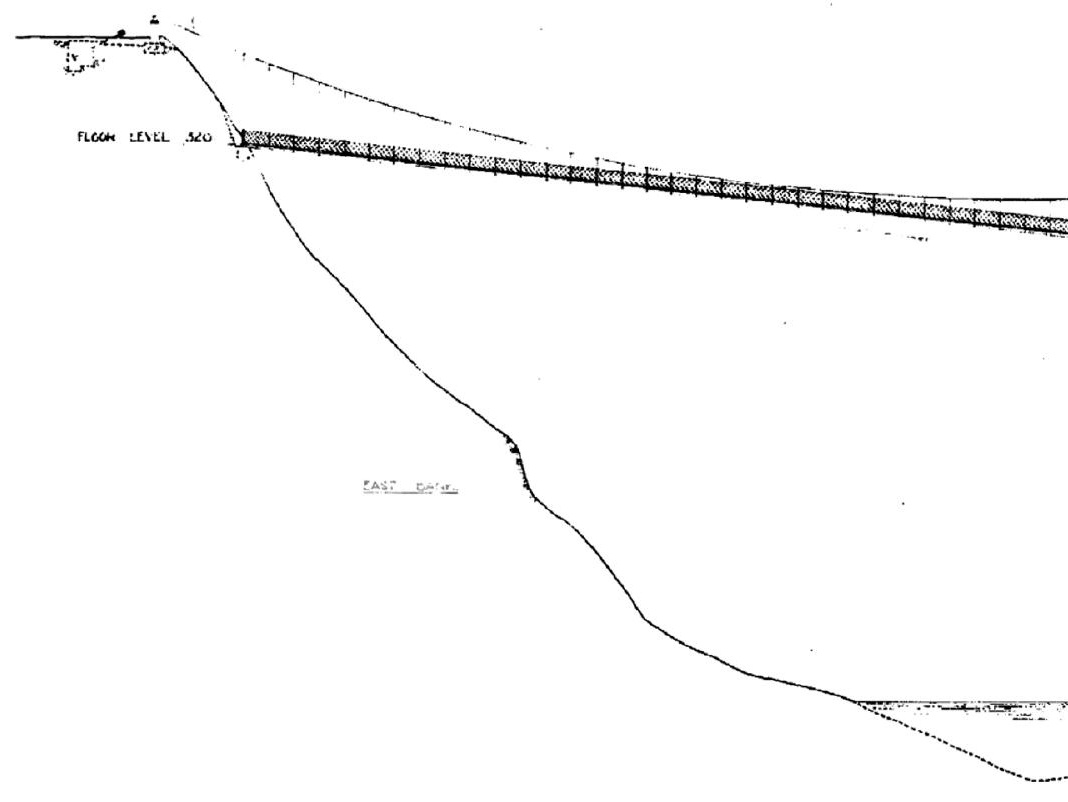




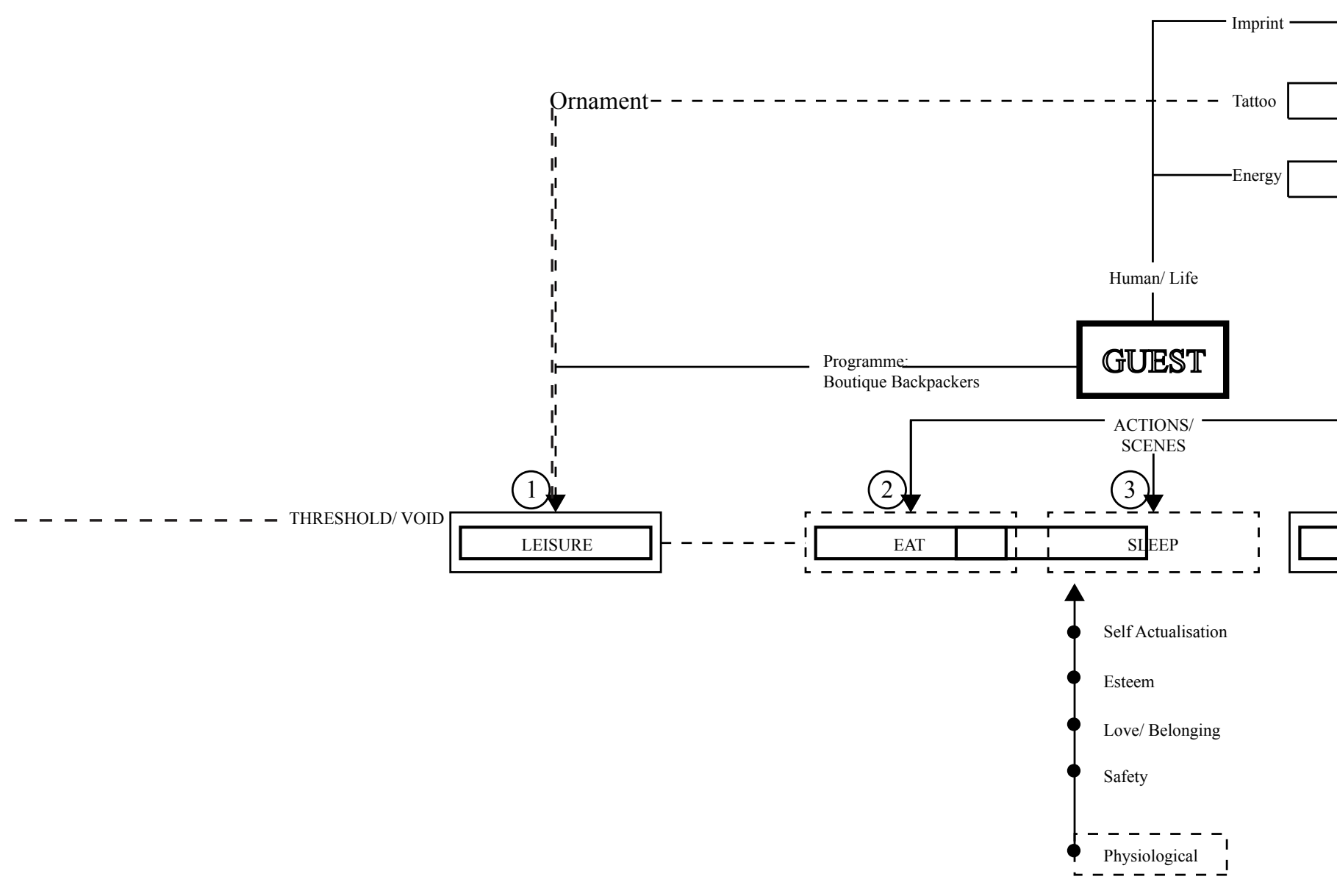




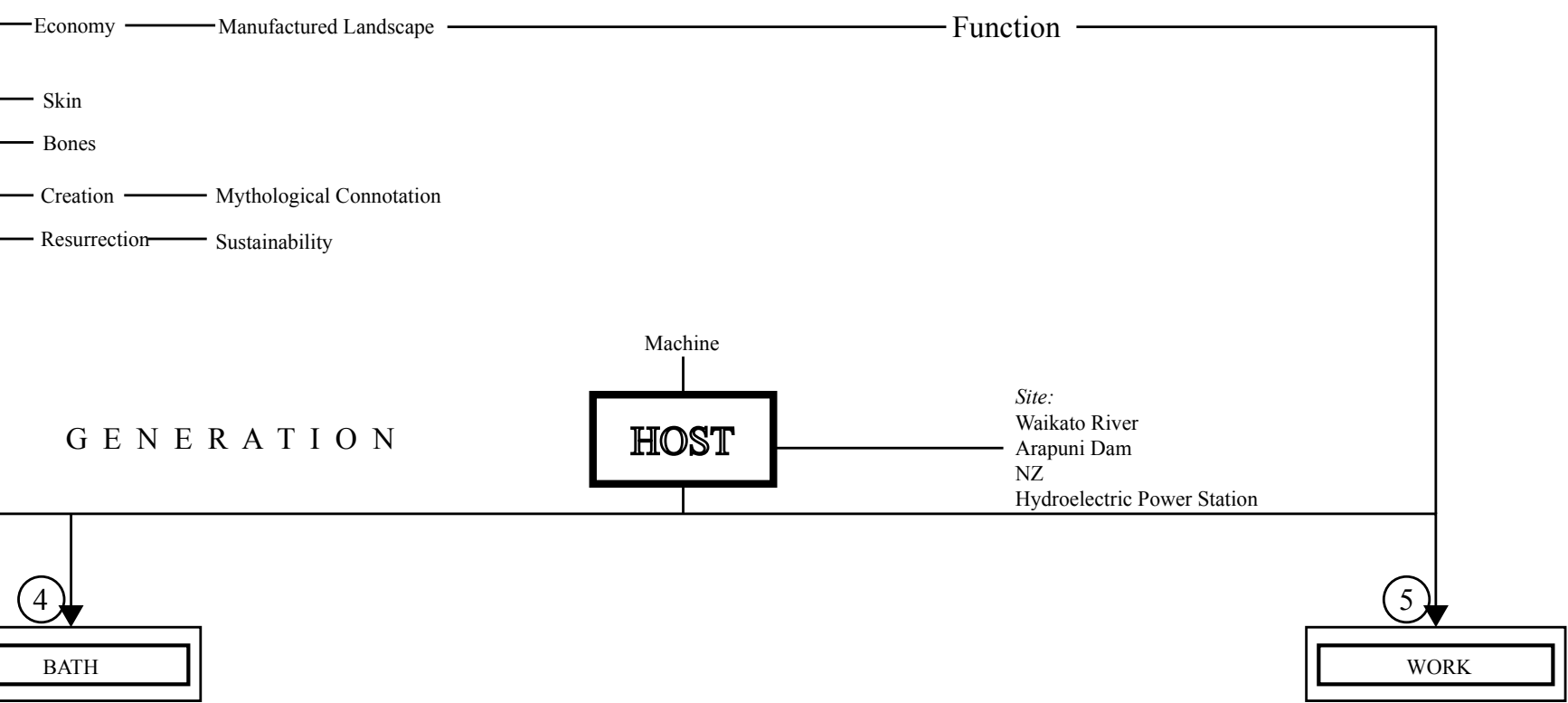

SOLID 


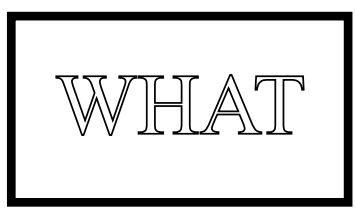

A highly contrived and artificial boutique backpackers. A destination of movement, a hyper-reality of the world that survives whilst living in a

psychological environment... an

interior... a series of events.

What happens if we essentially occupy a large machine to become a piece of interior architecture?

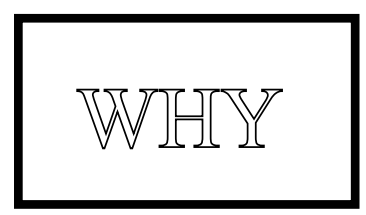

To study architecture and its opposite

The world of within - the capacities to affect rather than the definition of fixed moments or things such as geometries, order and artefact.

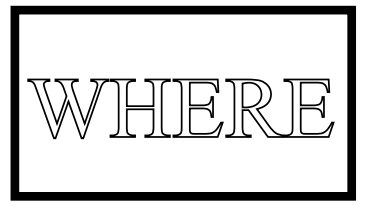

ARAPUNI

GORGE

Waikato River 


\section{INTRODUCTION}

Humans have an internal framework that actively programs our organs and tissues to prepare us for sleep at night or to be awake during the day. This 'clock', the circadian biological clock, is active in all types of life and is respectively a fundamental property of life. Although humans are day active (diurnal), we spend a third of our life in a state of absent consciousness. This most interior portion of life is left largely in the realms of the unknown for the most of us. The 'inbetween' state is important for life to run smoothly. Notably, this in-between state is largely overlooked by architecture and this leaves room for novel exploration, development of a pre-loved space, with its new intensions to be used in both literal and metaphorical darkness where the piercing of light tells us the time of day or signifies a moment in time. This pre-loved space will be the sublime territory of the inner-Waikato region: Arapuni Gorge Hydroelectric Power Station is a site of beautiful ugliness, situated in an alcove of New Zealand's famous river. One of nine spots of power generation along the river, this historic site is the perfect nodal point of new life and intervention, drawing attention to the abnormalities of such a wonderfully unnoticed piece of New Zealand: a new attraction in the form of an unconventional boutique backpackers, a new attraction of its own to the adventurous like-minded clients exploring New Zealand today.

This is the niche of life where our imaginations run wild, where it would seem nothing is happening; we are in fact dreaming, experiencing the most active and often fantastic aspect within the threshold of consciousness, the once predominant view of being somewhere between waking and death - what Freud theorised as the "safety valve" of the mind - a way of discharging instinctual energy (Gander 3). There is opportunity in the remarkable glory that lies within this safety valve, if people are willing to embrace and accept this unknown while living in their state of 'awakeness'.

The phenomenon of sleep has been extensively studied both visually and scientifically, reflecting psychological, physiological and sociological variables. Such variables are respectively important in the discipline of interior architecture design. Furthermore I believe sleep to be closely linked with interior immensity yet 
as an act itself neglected and shoved into the realms of the general unknown and replaced by the 'bed', centered on the grid of an architectural room. A successful interior world has the opportunity for the removal of any pre-conceived biases and the immersion into a fully engrossing, arti icially designed environment. This virtual reality or dream-like atmosphere can therefore be utilised with a desired intensity. The enclosed nature of Arapuni Power Station's interior space - both the interior of the machine hall and the greater interiority of the building dramatically excavated into the earth provides a platform to reach the desired intensity by pre-determining the cognitive experiences of the occupant via the ultimate manipulation of senses. We may also suggest from here that what is inside the walls of this complicated site, and what is inside ourselves, may have room to overlap.

The notion of the in-between alludes to both literal and theoretical thresholds and boundaries. Similarly sleep resides within the literal and poetic thresholds of consciousness. Perhaps we can use such precincts as ordering devices within the cyclic pattern of inwardness, in this 
case returning to the unconscious mind at the most inward point, where waking up concludes the temporal uncertain sense of existence.

This thesis analyses the variation in scale between the realms of an interior world. The proposition of 'betweeness' and 'inwardness' is idealised in depth through the natural reoccurrence of sleep. I explore how we can extend past collective public interiority, through the intimate, private realm and into the innermost realm of our secret 'self'. From here I postulate possible inter-crossings through visually evocative design - design that exploits the vast, limitless possibilities of the human imagination. I use a narrative of 'sleep' as a state of 'being' in an attempt to bridge the gap between scientific knowledge and poetic analysis.

The hydro-electric power station acts as a site of juxtaposition in the world of sleep and power. It gives the opportunity to discuss themes of gravity and its imaginative constrictions in today's logical world. Its surreal situation in the sublime landscape also provides perfect conditions to play with a desired intensity of immersion. The backpackers installed within is the nodal point within the state of transition the interior world possesses. The paradox of sleep presents an opportunity to delve into the literal and poetic thresholds of consciousness, and to design with the unlimited possibilities of the super-imagination in mind. 


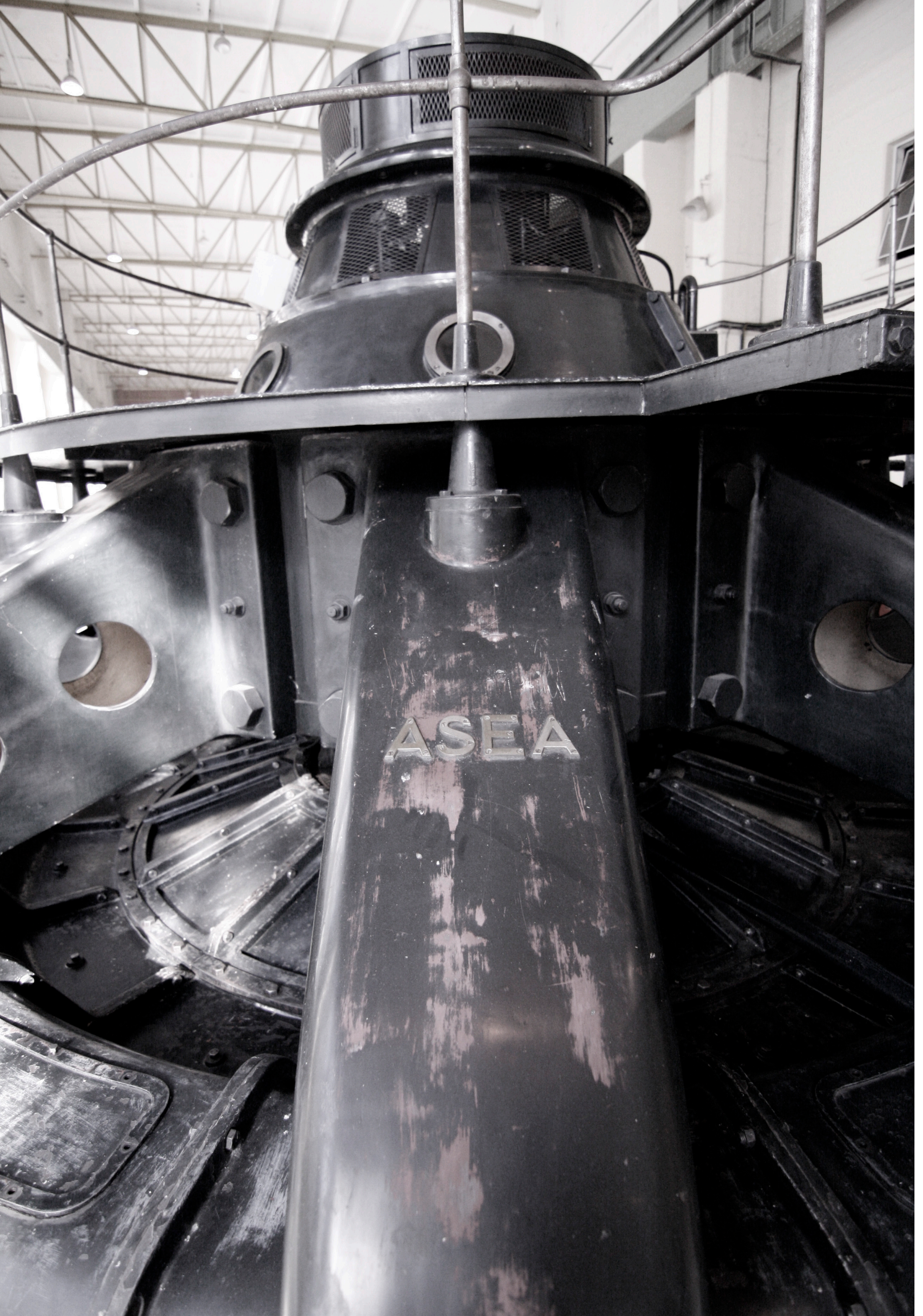


CHAPTER ONE: PART ONE

Site Thematics 


\section{The "Old}

\section{WORK-HORSE of the Waikato"}

Situated on the great beauty known as the Waikato River - the longest in New Zealand, stretching 354 kilometres from the great sources of rivers and streams running from the slopes of Mount Ruapehu and Mount Tongariro to the sea at Port Waikato lies Arapuni Power Station: the Old Work-horse of the Waikato.

"One could be forgiven, if when following the course of the Waikato River, one concluded that nature in her wisdom, had provided and prepared the way for man's needs in an age of technology which was to take place decades later"'(Southwood 4). 
The old grunting structure along with its smaller sister station Hora Hora were once household names, providing hydroelectric power to the northern half of the North Island.

Below: Arapuni Power Station South end completion 1946
We live in the 'age' of electricity, just like our ancestors lived in the age of steam. It is the foundation of great achievements. Science, space light, advanced medical knowledge, jet travel or just an easy life style are just a few products.

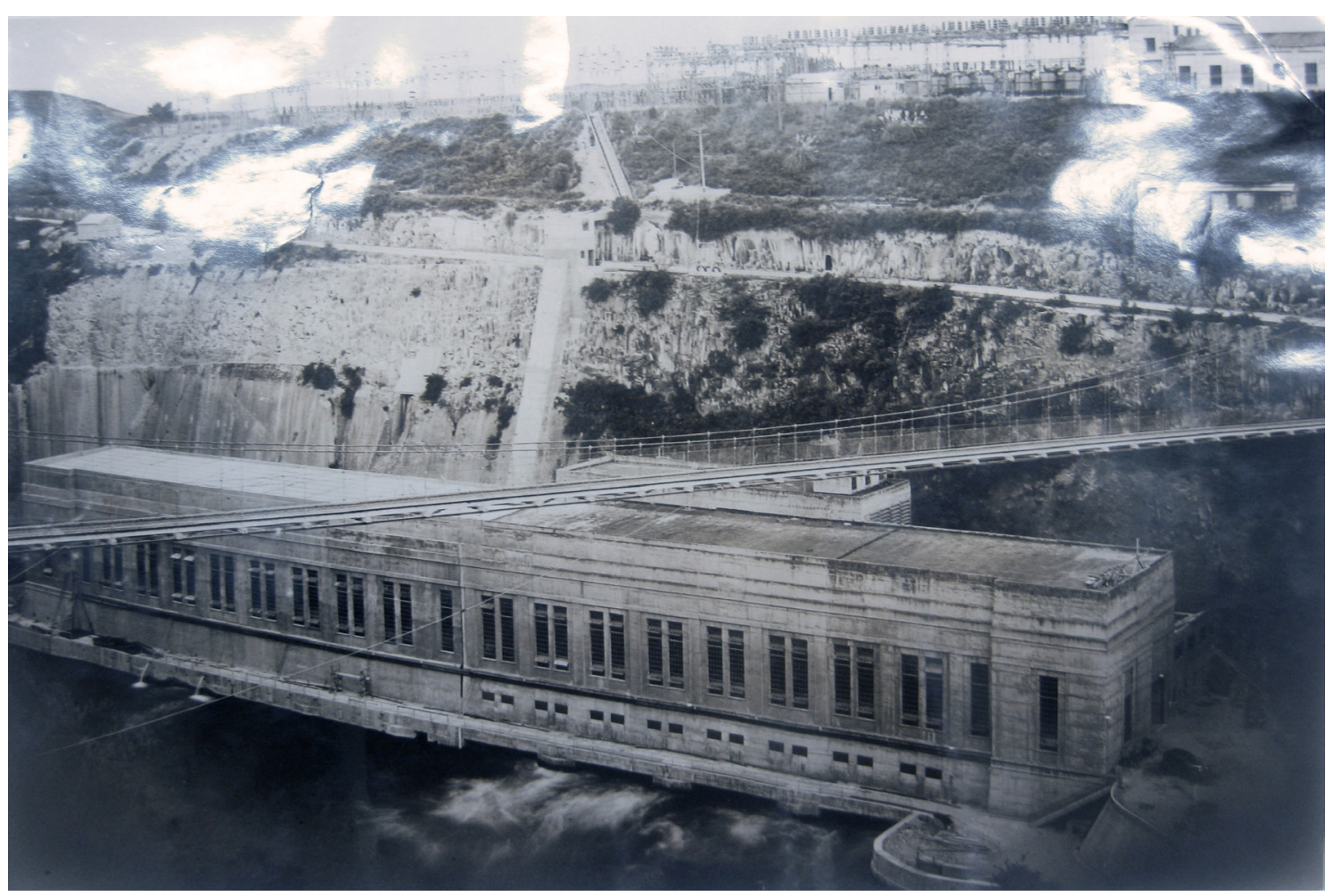




\section{WAIKATO RIVER H Y R O - E L E C T R I C}

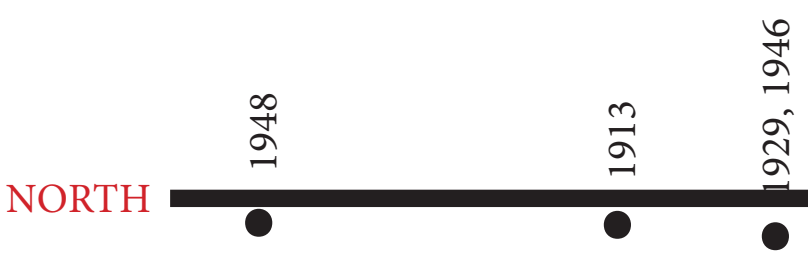

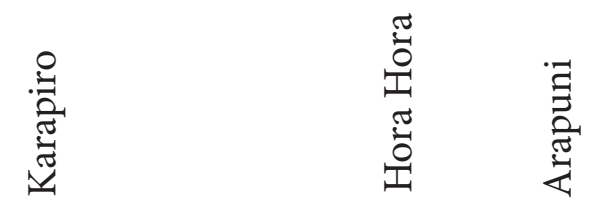

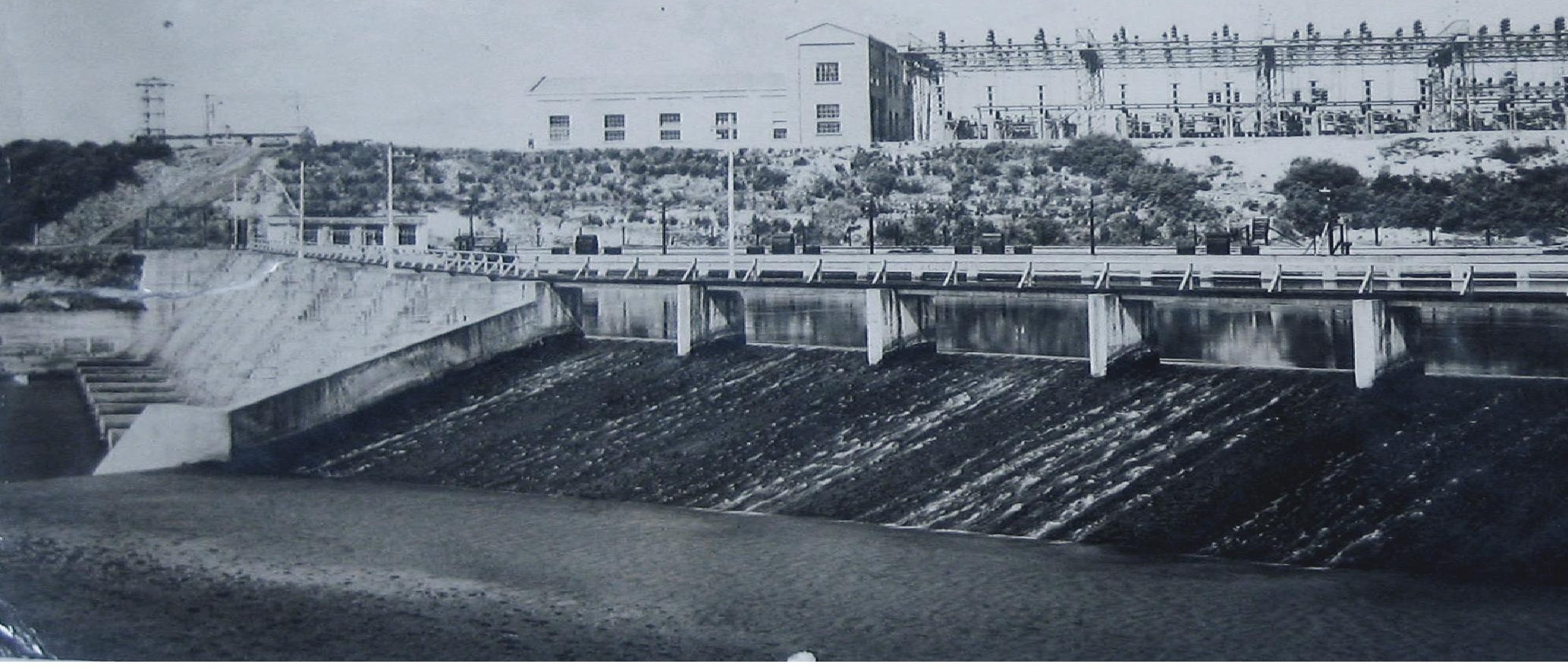




\section{POWER STATIONS}

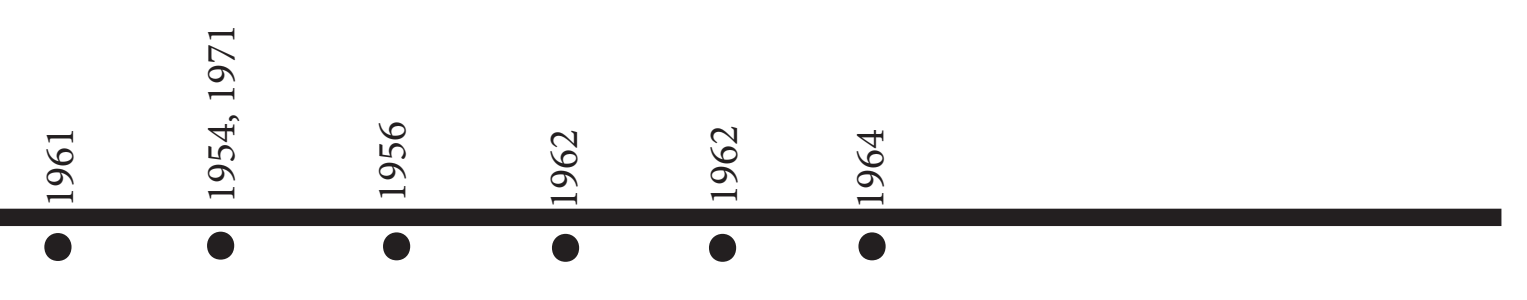

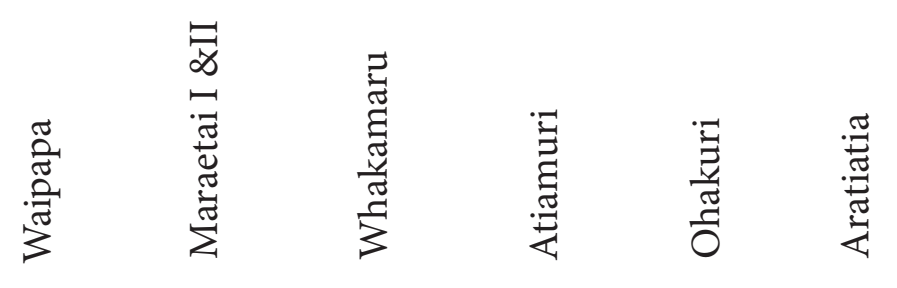

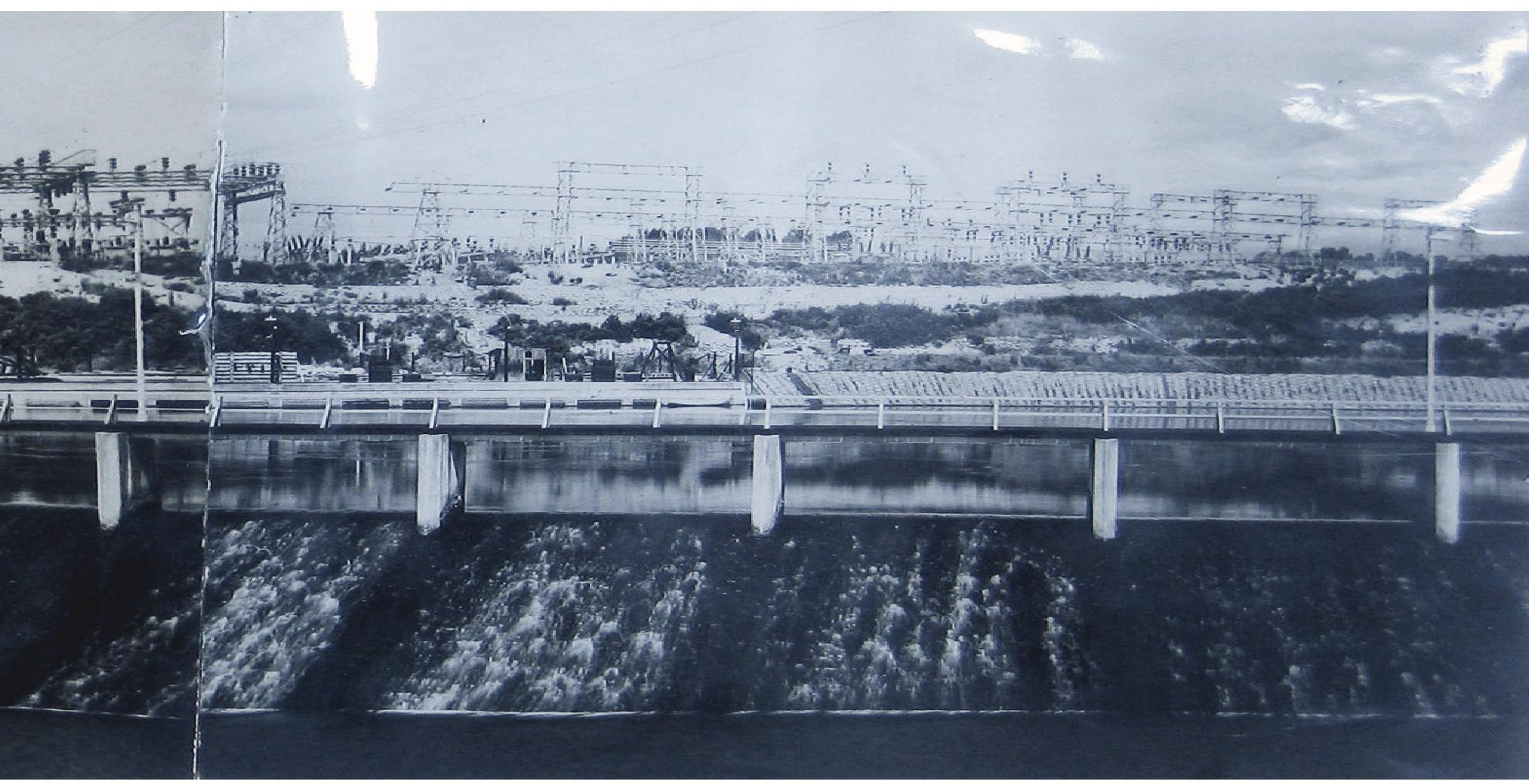

Photograph courtesy of Mighty River Power 


\section{ARCHITECTURAL DESCRIPTION:}

Although a building built for an industrial purpose, the Arapuni Powerhouse can be described as conforming to the International Style of the early 1930s. This is evident in the rectangular block form, which suggests the functional arrangement of spaces favoured by the Bauhaus, in its response to the machine age.

\section{Architectural Significance:}

I. In terms of materials used in the construction of the building and its advanced functional style, the building is a landmark in the construction of hydroelectric dams and in the industrial use of reinforced concrete.

II. The actual design was the work of the NZ Public Works Department and in this sense the building, and particularly the engineering solutions arrived at within it, such as the placement of the generators to minimise breakdown failures, are a credit to the engineers approximately eighty years ago. 
Historical Significance:

The Arapuni Dam project was first conceived in 1921 when a definite need for an increased power source for Auckland was recognised. The Minister of Public Works at the time, however, believed that there were insufficient funds for the project and the idea was shelved for two years. After a public outcry tenders were finally called for in 1923, and construction began in 1924. Thus, from the outset Arapuni was seen to be a very big project, surrounded by controversy, but nevertheless one which, for the first time, recognised the Waikato River as a major source of power generation.

In 1924 the science of hydroelectric power generation was still in its infancy, and therefore the practical engineering problems that had to be faced and overcome were largely of experimental nature. The British contractors, Armstrong Whitworth \& Co Ltd, clearly had difficulties in constructing adequate foundations for the powerhouse and this necessitated their retirement from the contract in 1927.

From this point on, the work was taken over by the Public Works Department until completion in 1929. It was the first such project taken on by the Public Works, and the efficiency with which it was completed was due in no small measure to the fact that Public Works engineers tackled the problems in a systematic manner. The powerhouse foundations, for instance, were constructed only after the engineers had solved the problem of diverting the river from its course through the construction of diversion tunnels. The credit for this systematic approach was in no small measure due to the expertise of the Engineer-in-Chief, Mr F. W. Furket; his judgement had ultimately been decisive in saving the project in 1927. The innovation of creating diversion tunnels and pumping plants enabled work to continue by properly draining the site. This method worked so successfully that the contract was completed on time with the first generator turning on the $4^{\text {th }}$ of June, 1929. This date therefore marks the first time in which a statebuilt hydroelectric dam came into service supplying power to the national grid. The science of hydroelectric power generation has, since this time, taken Arapuni as a model, the project being first in the country to employ eight generators and modern constructional techniques. 



\section{Vulnerability \& the Sublime}

Here is the duality of vulnerability and power. The power station clutches onto both simultaneously. As Francis Ponge, a French essayist and poet, so elegantly stated:

"I asked myself where had I left my goddesses and their knees? But right away all things mingled and I saw these goddesses sitting on mountains near Truyere, or in the caverns of Brommat. I heard the thirty tons of water per second tumbling down at Maregas. I imagined the millions of volts, the giant transformers, and I did not forget the danger; and as of that moment, it no longer seemed impossible for me to begin writing my hymn, writing a certain type of poetry. Did you know that men died the moment they so much as touched those Hindu princesses, those untouchables? Well, I find that rather to my liking" (Ponge 193).
Arapuni Power Station has a sense of vulnerability due to the dramatic isolation and exposure to harsh natural elements. It has been the cause of a series of substantial landscape alterations which place it in opposition with the powerful forces of natural gravitation and land formation. Human intervention is in effect a game of trial and error. It may be argued that error

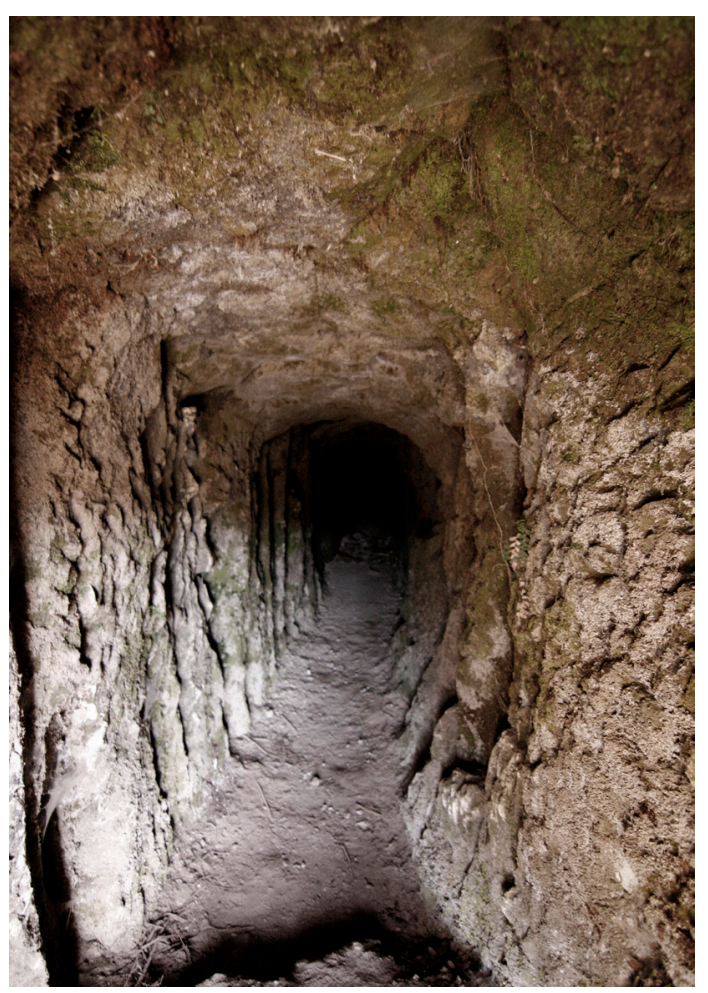

Photo by Author

Structural framework 
may be eradicated with the right structural engineering and scientific investigation into manipulating the landscape for beneficial purposes; however I feel it appropriate to make the assumption that if you are inserting human inhabitancy over 180 feet below a risen water level or directly through the core of an excavated gorge there has to be a risk factor of some

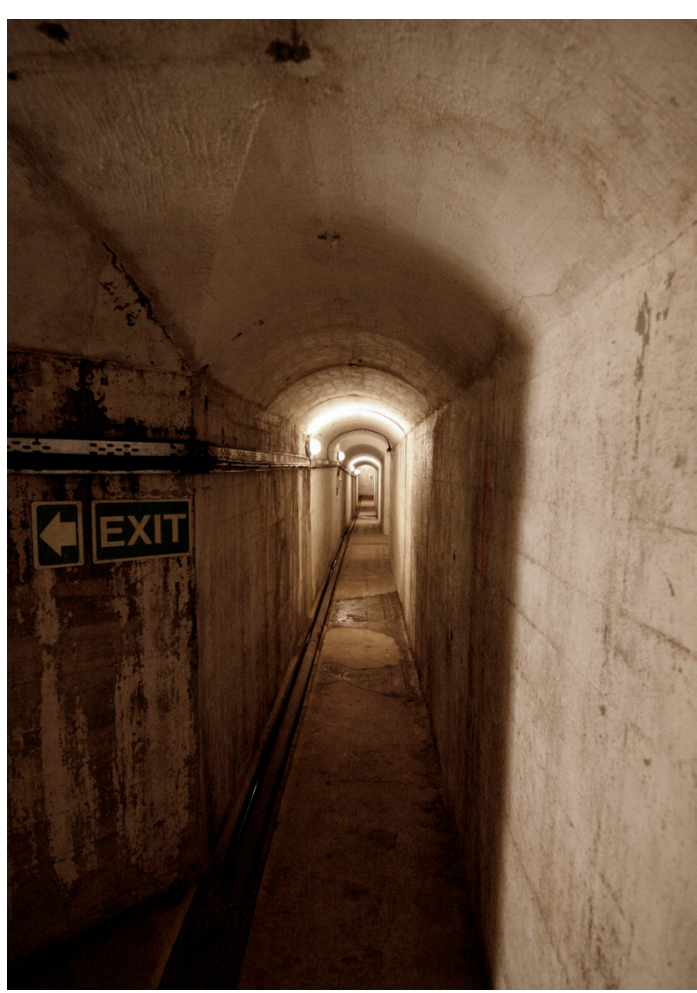

degree. (It should be recognised here that the former sister station of Arapuni, Hora Hora, is now completely submerged due to the insertion of dams upstream and rising water levels.)

Nonetheless, chiselling through 180200 feet of stone mass by hand is an impressive achievement and is hard to

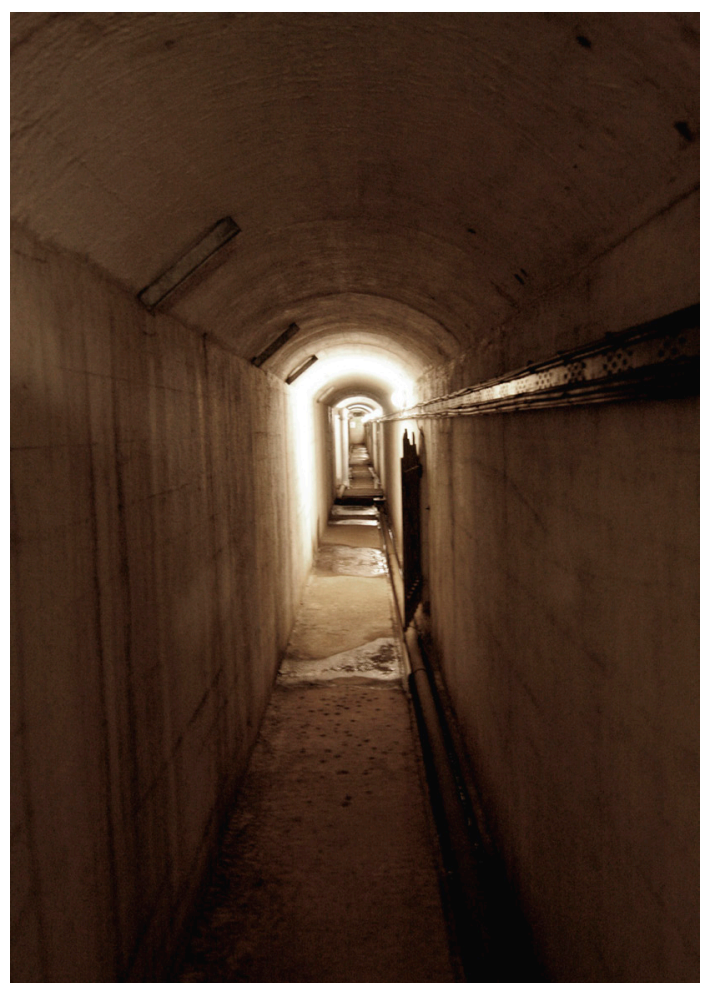

Photos by Author

Utility Tunnel 
fathom by today's standards. Perhaps we are just precious these days. Manual labour takes on a whole new meaning in modern life.

Introduced here is the extremity of the site. Edmund Burke is the first to admit that 'greatness of dimension' is a powerful cause of the sublime (Burke 72).

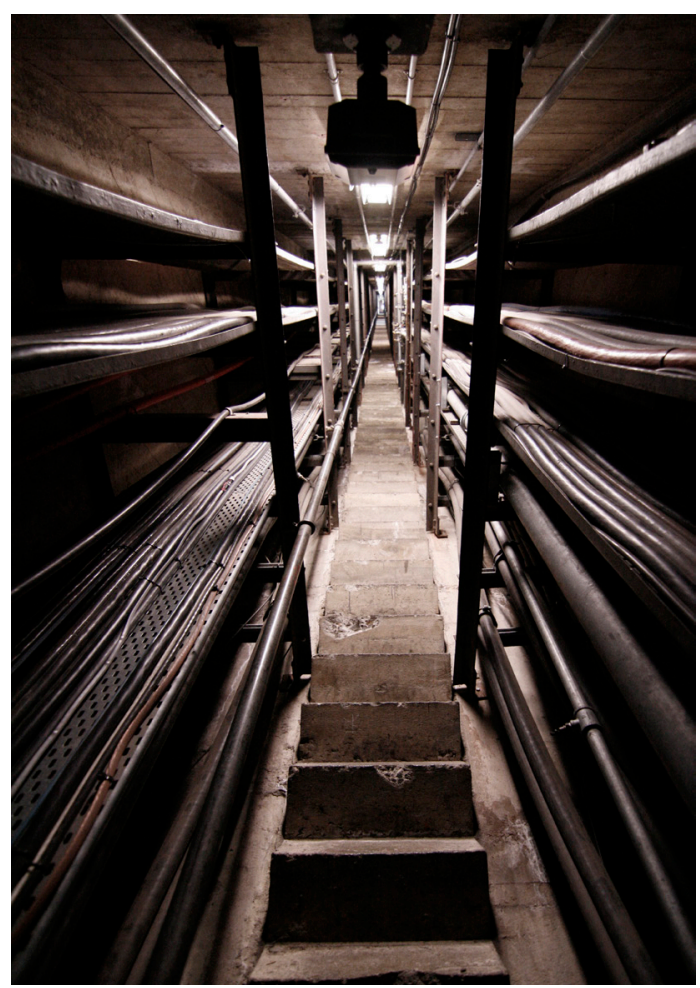

Photos by Author

Cable Tunnel.

Almost vertical stair
If greatness of dimension, vastness of extent, or quality has such a powerful effect on a person, where extension should be thought of in length, height, or depth, then Arapuni Gorge contributes in all respects. The suddenness of the site is beyond amazing. A two-minute walk from the road and you are presented with

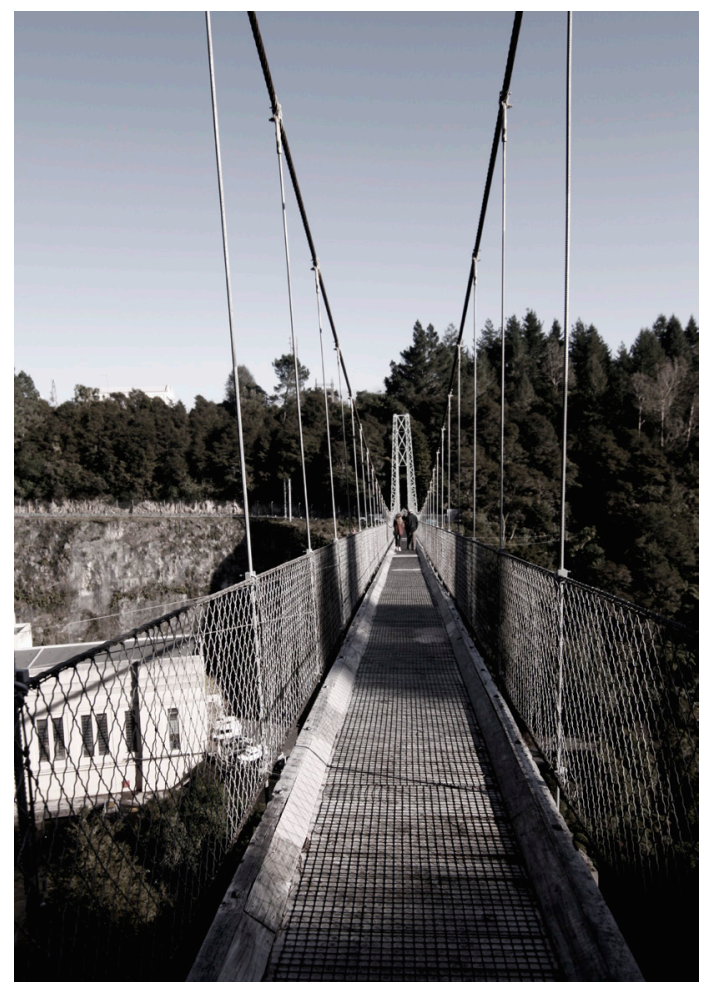

Photos by Author

Swing bridge access 
a world you had no idea existed, a world that may be perceived as dangerous and our guard rises against it. The threshold here is immensely sudden. Looking down at an immense depth has the biggest psychological effect on the human being. Accordingly, it is this effect you are greeted with on arrival. Walking across a swing bridge levitated above the vast

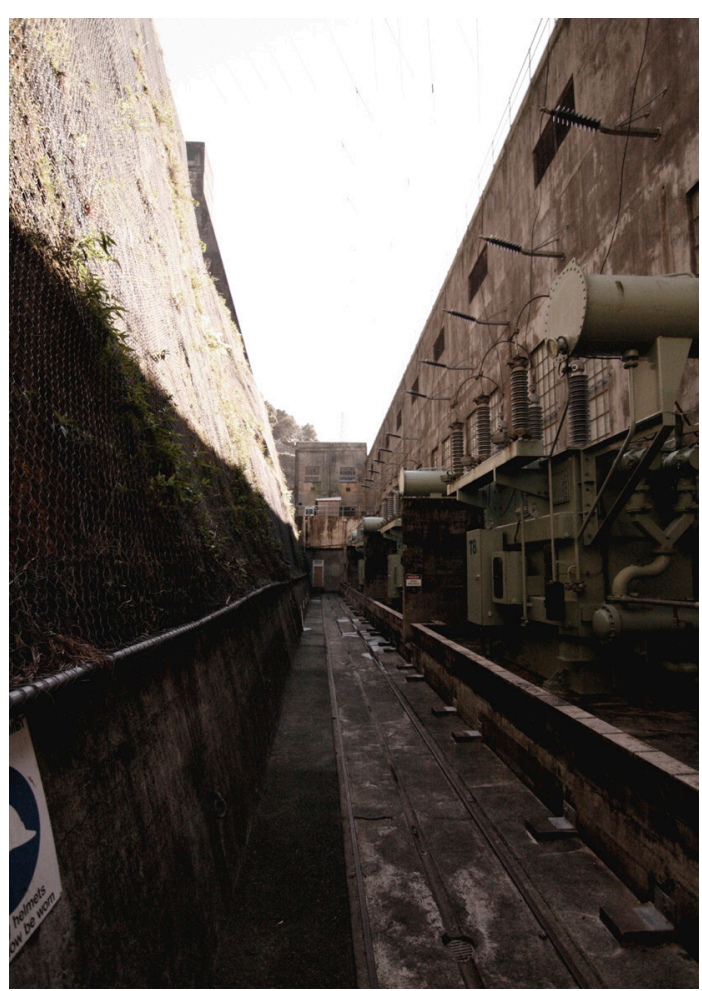

Photo by Author
Waikato River at 180 feet is nothing but intimidating. The difficult rugged excavation into the gorge is very close to perpendicular with the powerhouse perched 'unsteady' at the bottom. Such an immense force and magnitude of manual labour is entirely grand. The magnitude of the building itself promotes a greatness. The shear length with the uniform repetition of the vertical windows allows the imagination to rise to the idea of infinity and the promise of something more. In reverse nature, the extremities of the sublime occur also when seeing a human or animal in comparison to the prescribed backdrop. This is the 'extreme of littleness' working at its best.

We are presented with the sound of gushing water long before we see it, and the sound effect sits in the imagination long after. The excessive loudness in such serene surroundings is sufficiently overpowering. 
It is a site that is not originally designed solely for human use, a historic space that does not today comply with up to date building code requirements and generates intrigue and mystery. 


\section{On a side note:}

Can we claim the site to be of extreme vulnerability? From an economic point of view I think we could say that it was. The perspective of society having such a huge reliance on power passes a substantial level of responsibility on to the power station. There is a temporary nature asserted to technological development in the twentieth and twenty-first centuries, but I would consider it safe to say that electricity has a sense of permanence. The benefits of electricity outweigh the cons in modern society.

Vulnerability also relates to political power. This is evidenced in the opposite image where Arapuni Power Station has been camouflaged into the natural landscape during the period of WWII. If electricity generation is wiped out momentarily the effects on the country would be substantial. However in recent years, obviously in relation to the increase in technology advancements in the last fifty odd years, we have seen an epidemic of power stations developed around New Zealand ultimately sharing the risk factor of possible power outages. This statement is obviously proportional to the time period but relevant nonetheless. 


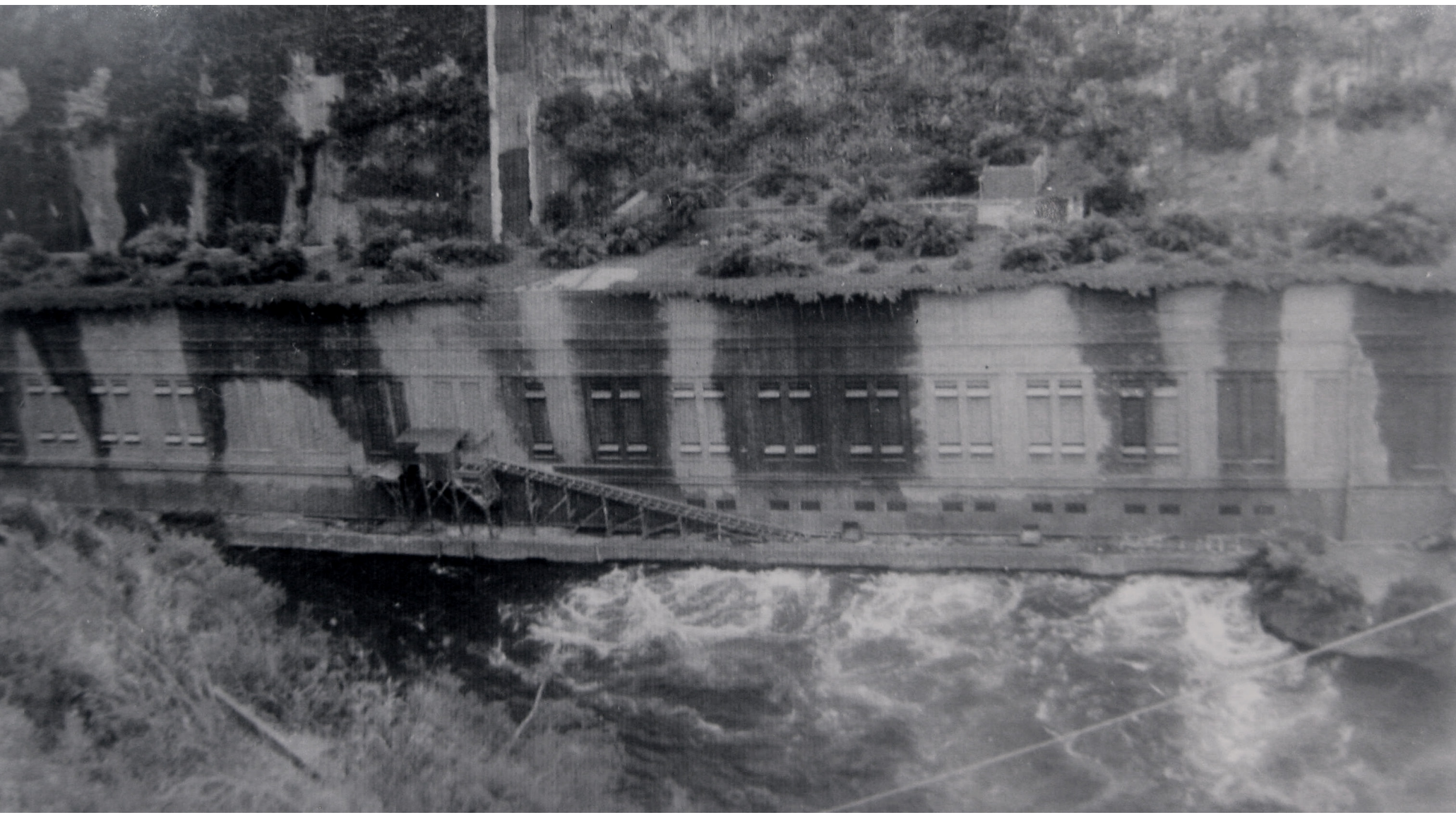

Photograph courtesy of Mighty River Power

Note: Protective planning in WWII 


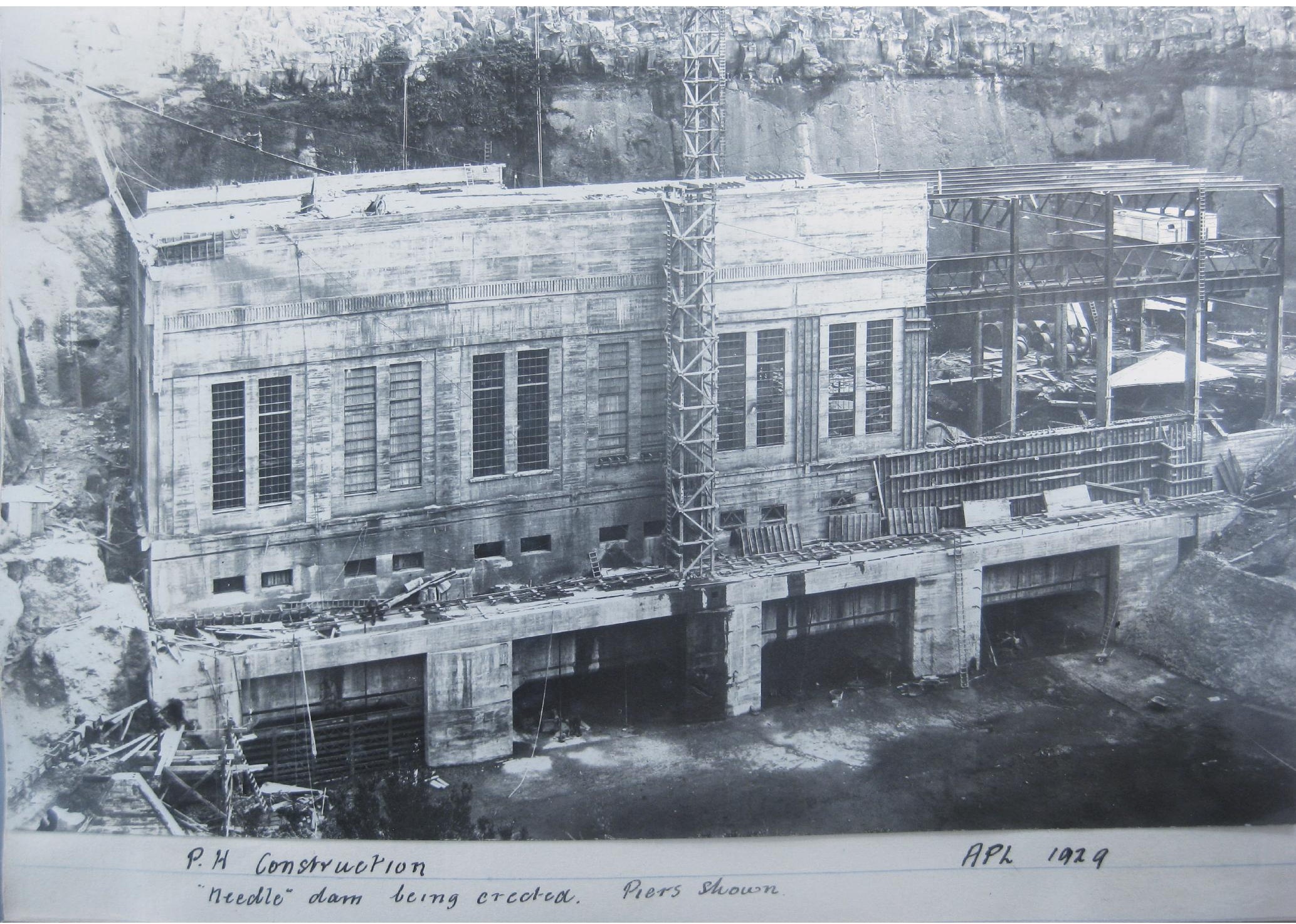

Photograph courtesy of Mighty River Power 


\section{Mobility}

\section{versus}

\section{Mega-structure}

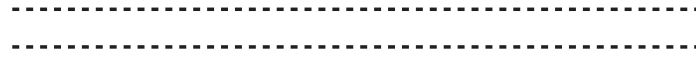

The duality of the linear form mimicking the International Style of the envelope and the inhabited machine entity leaves interesting dynamic negative space. It would be interesting to consider the building effaced in favour of the inhabited machine entity. Pieces of machinery, and the human body existing side by side within a restricted landscape. Somewhat intermingling, provoking an evocative sense of scale and hierarchy, giving identity to the unseen phenomenon of electricity - this being reflective of the surrounding natural elements also not visible to the human eye, instead revealed only through movement.

The power station may be compared to a network of machines. They are engineered rather than 'architected'. Each node within the larger network is essentially a piece of this specialised machine network - a factory of intangible production. From the 1990s onwards, the hydroelectric power stations on the Waikato River have been stripped of anything non-essential. Everything has a strict mechanical function and the coordination of the building is automated and run out of the head office in Hamilton 
central business district.

In the early 1900 s, just like the factory or industrial silo, it could be said the futuristic silhouette of the power station would typify an entire epoch of economic, technical and morphological analogies. Today, at the latter end of the timeline it can be concluded that the generation of power has made a substantial contribution to human society. The power station certainly gave birth to the foreshadowing effect of technical evolution. I do not think the power station should have a direct responsibility towards pollution or globalisation; however without this intervention the world would sit in a different position altogether.

There is a sense of elegance and sophistication to the power station that is not evident in other industrial structures of its kind. Despite its obvious relationship with industry and its reliance upon natural elements, the autonomous nature of its productivity allows the structure to somewhat detach itself from any negative attributes and be celebrated as a cultural entity with a unique realisation of a striving nation. This relationship is directly proportional to the scale of 
New Zealand and our collective respect towards a beautiful country.

It is interesting to make comparisons between large economies such as America and China, where on occasion the importance of the natural environment gets pushed aside to make way for the booming economy. China is essentially a site of integration where all extracted materials meet, disrupting the environment in pursuit of progress. When we harm the environment, we harm ourselves.

An interesting example found among the studies of Edward Burtynsky's photography of the 'manufactured landscape', where he aims to explore the aesthetic, social and spiritual dimensions of industrialism and globalisation through a depiction of industrial ugliness, is that of Three Gorges Dam in China. Edward Burtynsky states: "It looks like a bombed out landscape but it's an intentional onea need for power."

Three Gorges Dam is located on the Yangtze River within the Yiling District of Hubei Province. It is the world's largest capacity hydroelectric power station. The dam has a controversial identity.

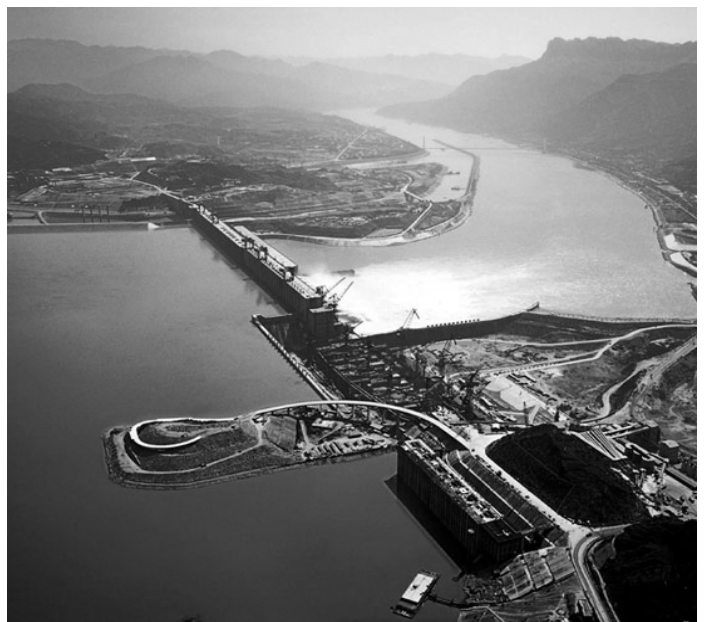

Three Gorges Dam, China 


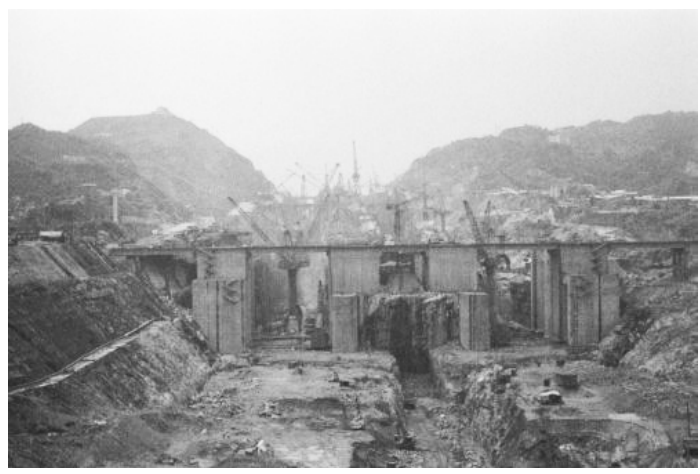

Three Gorges Dam, China

(Demolition/ Construction)
Economically the dam increases the river's shipping capacity making way for the expansion of production throughout the smaller towns in the district. The intervention reduces the potential for floods downstream by providing and controlling flood storage areas. The Chinese government regards the project as a historic engineering, social and economic success, moving toward limiting greenhouse gas emissions.

However, as Edward Burtynsky demonstrates via his photographs and documentary, the dam flooded archaeological and cultural sites and displaced more than 1.3 million people out of home with water levels rising upwards of 600 feet. It has also resulted in significant ecological changes including the increased risk of landslides. The documentary depicted locals physically demolishing their own homes to make way for construction. It is rather heart wrenching to watch this deconstruction where individuals were paid per brick to take their cities apart. It provokes the parallels between Arapuni Power Station where a town was established to aid construction and Three Gorges where thirteen cities and towns were 
demolished for the same reason. However the long-term effects may be somewhat proportional. Whether or not the individual's home was being demolished, it further provided work and income. It would be a stretch to claim that 1.3 million individual jobs were established as a result, and regardless would essentially be short-lived. The construction took approximately seventeen years. That has sublime qualities in itself.

I believe the power station includes certain aspects of what is essentially a relationship to the hypothetical environments proposed by various megastructuralist drawings. The interesting point here is the concept behind a threedimensional infinitely expandable urban environment. Can we really consider a power station an urban environment? Or would it perhaps be better articulated as an 'extension' of the urban environment. It certainly has played an integral role since the industrial revolution and the infrastructure required in setup, i.e. the dam, starts to affect the environment on a large scale. Ralph Wilcoxon defined the mega structure in 1968 as:

"Not only a structure of great size, but
. . . also a structure which requently is:

1 constructed of modular units; 2 capable of great or even unlimited extension; 3 a structural framework into which smaller structural units (for example, rooms, houses, or small buildings of other sorts) can be built or even 'plugged-in' or 'clipped-on' after having been prefabricated elsewhere; $4 \quad a$ structural framework expected to have a useful life much longer than that of the smaller units which it might support" (Wilcoxon 2). 



\section{Mythology of the Power Station in POPULAR CULTURE}

The program of the powerhouse in the last hundred years has demanded a new system of design solutions that combine both architectural and engineering principles. Today, there are eighty-two active power stations in New Zealand with fifty-nine being for hydroelectric generation and a further forty-two proposed. We can hypothetically adopt the power station to be somewhat of a representational installation.

As a unique and cultural architectural typology, through a general objective analysis as well as a metaphorical device, we can bridge the gap between operation and narration of power. We can define the powerhouse as a node within a wider typology of power generation. It defines the parameters of this typology as being developed under the functional demands of the machine age, the psychological pressure of controlling the active economy to a wider national scale while keeping up with a global market, all of which adds to the mythology of the powerhouse in popular culture.

Giving precedence to the powerhouse within the larger nodal network of electricity generation, as it relates to 
the past and present models of power design, prompts discussion of how this typology has and will inform the design of tomorrow.

"To conform ourselves to a style of life which has been ours since the electrical current was placed at our disposal, we shall immediately establish contact and suddenly throw light on our intensions" (Ponge 171).

Electricity is accepted in all areas of life. It is a permanent phenomenon that has manifested itself in each and every one of our refined states of life. It is not widely explored by the Architect; however it offers a compelling image of the urban environment's transformation over the last hundred odd years. When referring to a transformation I do not assume that electricity was discovered and generated within this timeframe; however, it does mark the development of power generation via the hydroelectric scheme in New Zealand, and furthermore, the advancing technological age. Francis Ponge claims:

"I cannot easily accept the idea that in the area of scientific knowledge, they were considerably inferior to us, I am slightly embarrassed when I have to accept the idea that modern man is in any way superior to the man of those epochs. Instinctively I challenge that claim" (Ponge 171).

The theory of electricity has a depth that is not only conceptual but also historical and intellectual. I feel in recent years the 'intellectual' side is somewhat obvious. With the ever-increasing technological advancements that aid efficiency in today's society comes a sense of devotion to science, the worship of modern life and technology, where large discoveries give the scientists a surreal image somewhat taking away from the devotional practices of the ancients. The mythologies regarding electricity generation have to some degree fallen into the background.

To the uneducated consumer electricity is just formulas on paper, but to the educated follower it becomes mystical, instilling fear and devotion.

"The great godesses are sitting, once again, undoubtedly conjured up by man, but he is terror stricken when he 
imagines them. They are called Angatrom, Light-Year, Nucleus, Frequency, Wave, Energy, Psi- Function, Uncertainty. Like the Summerian divinities, they too stagnate in a fantastic inertia but approaching them makes one dizzy. And on their aprons, written in abstract script, formulas are inscribed in advanced math" (Ponge 183).

Although the general public has participated in the growth of power stations in New Zealand and around the world through the ever-expanding phenomenon of advancing technology, whether it be through physical industry or the later computer / machine-aided generation, it is amazing how little contact and knowledge they would have regarding power generation and the mechanics of its generation. It would seem you just push a button and expect something to go. A small percentage of the population would have come into contact with power past its distribution in our homes and work places. There has been such a dramatic advancement in recent years that power can be generated through an automated system leaving the power station to run on its own. Our generation, although being technology savvy, has little knowledge of what a power station site entails; or until we find ourselves in the middle of a power outage we do not fathom our reliance on electricity.

However, just as the experience of the first electricity charged light bulb became generally known in the individual's household, the phenomenon of the power station installation has become universally recognisable through the medium of film and media. It is ironic that through such technology a large percentage of our generation has in fact encountered the power station without realising. Everyone has seen the heroic architecture of power stations, the mythic image of a powerful industrial immortalised structure set within the sublime backdrop of a prevailing river, a narrow gorge or a dynamic cityscape.

Whether it is through film or iconic media personalities using the power station as a promotional backdrop, we the ignorant users of electricity have subliminally been exposed to the hidden treasure of the power station.

An example of a power station in popular culture is the Battersea. The 
iconic structure has been featured as a shooting location for many films, television programmes, music videos and video games. The Battersea was built in London in the same period as Arapuni, with its first structure in 1936 and its additions in the 1950s, so there is a likely aesthetic comparison even though there are differences between coal powered design and hydro schemes. The 1936 film Sabotage directed by Alfred Hitchcock sets the scene of exaggerated masculinity where a gang of terrorists plot a series of attacks on London, while the recent Batman movie The Dark Knight uses the power station's stripped industrial interior as an abstract symbol of anxiety and isolation. The infamous Pink Floyd used the power station as a backdrop for their 1977 album Animals where they attached an inflatable pink pig to one of the heroic chimneys. This demonstrates the popular artistic culture of modern art; the rigid industrial structure in comparison to the organic fluidity of life. This, even if considered unintentional, exaggerates my own thoughts regarding the duality between both the manufactured and natural landscape. It is notable that the album launch party was simultaneously 

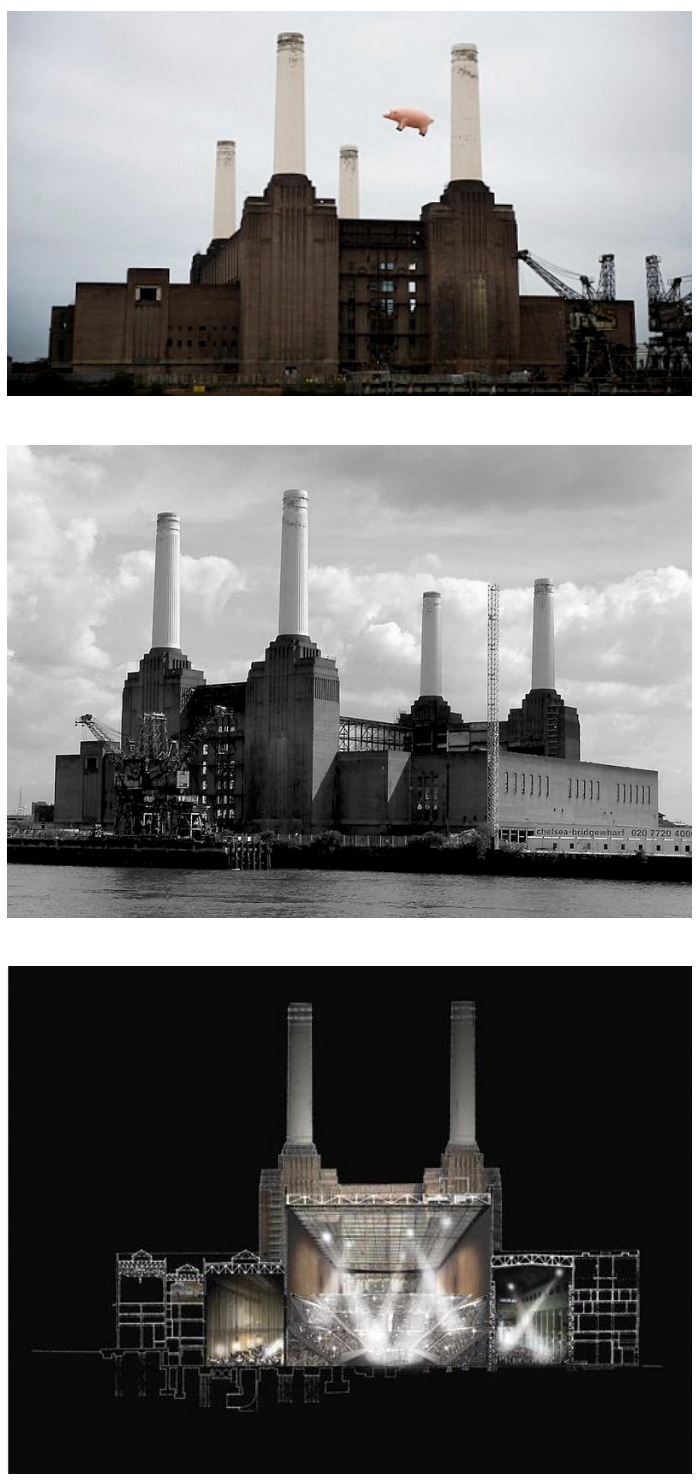

Battersea in Popular Culture 
held in the power station, which is appropriate for the time frame where industrial structure and aesthetic became popular within the arts scene - perhaps a take-off from the industrial loft apartment.

Noting the industrial structure as a popular aesthetic in the arts culture are numerous examples, two of which are:

- The Tate Modern in London, originally the Bankside Power Station designed by Sir Giles Gilbert Scott (along with the previously mentioned Battersea Power Station) in 1947 and later 1963 is now a modern art gallery re-designed by architects Herzog $\&$ de Meuron.

- Likewise, Rome's

Acea Power Plant (1912) is now Musei Capitolini Centrale Montemartini, yet another industrial archaeology converted into a museum.

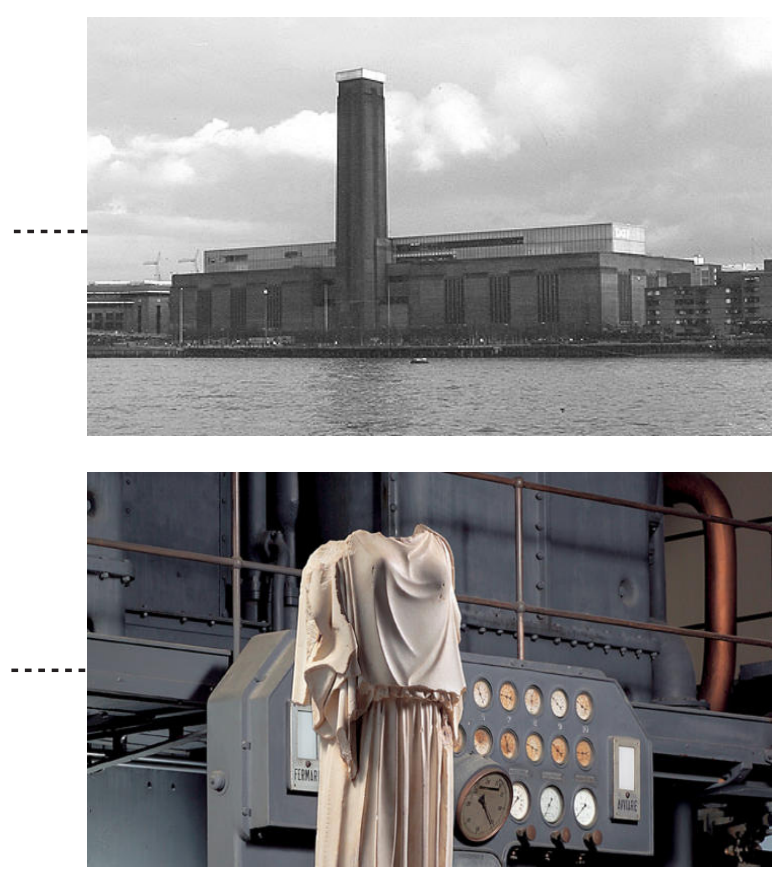




\section{CONCLUDING PART ONE:}

In terms of language, the powerhouse can only be understood as a static (for lack of a better word) enclosure before distribution; however, it is essentially a mobile structure tethered to the riverbed via a series of electrical cables and a series of flumes. The extent of this mobility ranges from the outer surroundings of the manufactured landscape within which the powerhouse is strategically inserted. Rather than thinking of the powerhouse as a piece of generic architecture, four walls and a ground and ceiling plane, let us consider the surrounding conditions as an interior space within the major site anomalies. The direction of water flow, the velocity of water flow, and the essential production of electricity give the powerhouse a sense of being alive the heart of the body that pumps life to the connected limbs. Unlike living existence, the power station never sleeps. The repetitive organisational structure of the turbines allows for momentary downtime where necessary, yet never at the same time. It is hard to fathom the concept of workload within the power station; unlike its siblings in the industrial scene of New Zealand, the power station may not run at full output but never stops generating that magic power humans rely on so dearly. Day merges into night with no break inbetween.
It is this simultaneous relationship between the flow of natural elements and the conflicting nature of what could be described as a partially static manufactured intervention that defines the complex identity of the powerhouse. There are interesting conflicts of form within the site, housing an element we cannot see or touch, however we know is there. The powerhouse acts both as a vehicle and a structure.

When considering the hydroelectric scheme, the powerhouse occupies a small plot of the riverbed and corresponding gorge, while strategically puncturing the land mass around it giving a de facto land mass to the wider grid of electricity usage in the north island. Unlike the structure of the powerhouse, the unseen phenomenon of electricity can move in and out of the built environment with a dominating sense of fluidity. The powerhouse remains stationary while the hypothetical surface fluctuates with demand.

From here I would like to introduce a new programme for this industrial archaeology that is not quite the popular museum, gallery or events venue.

Instead I am inserting human life into a mechanical structure.

[Welcome to Arapuni Unconventional Boutique Backpackers] 

CHAPTER TWO: PART TWO

Programme Narration 


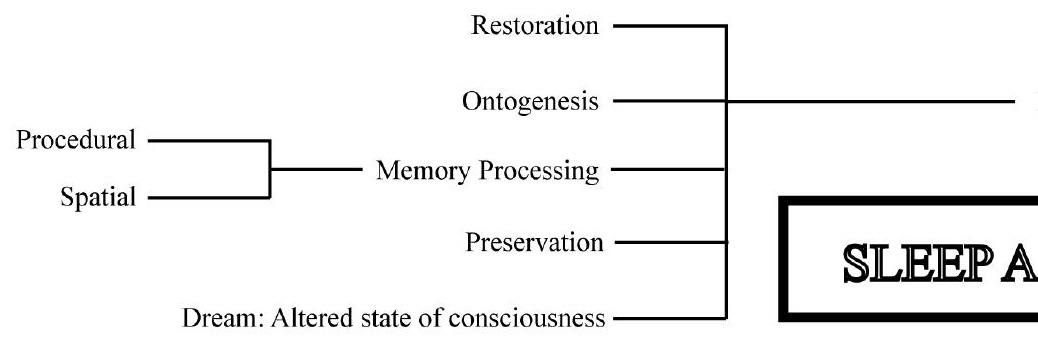

STRUC
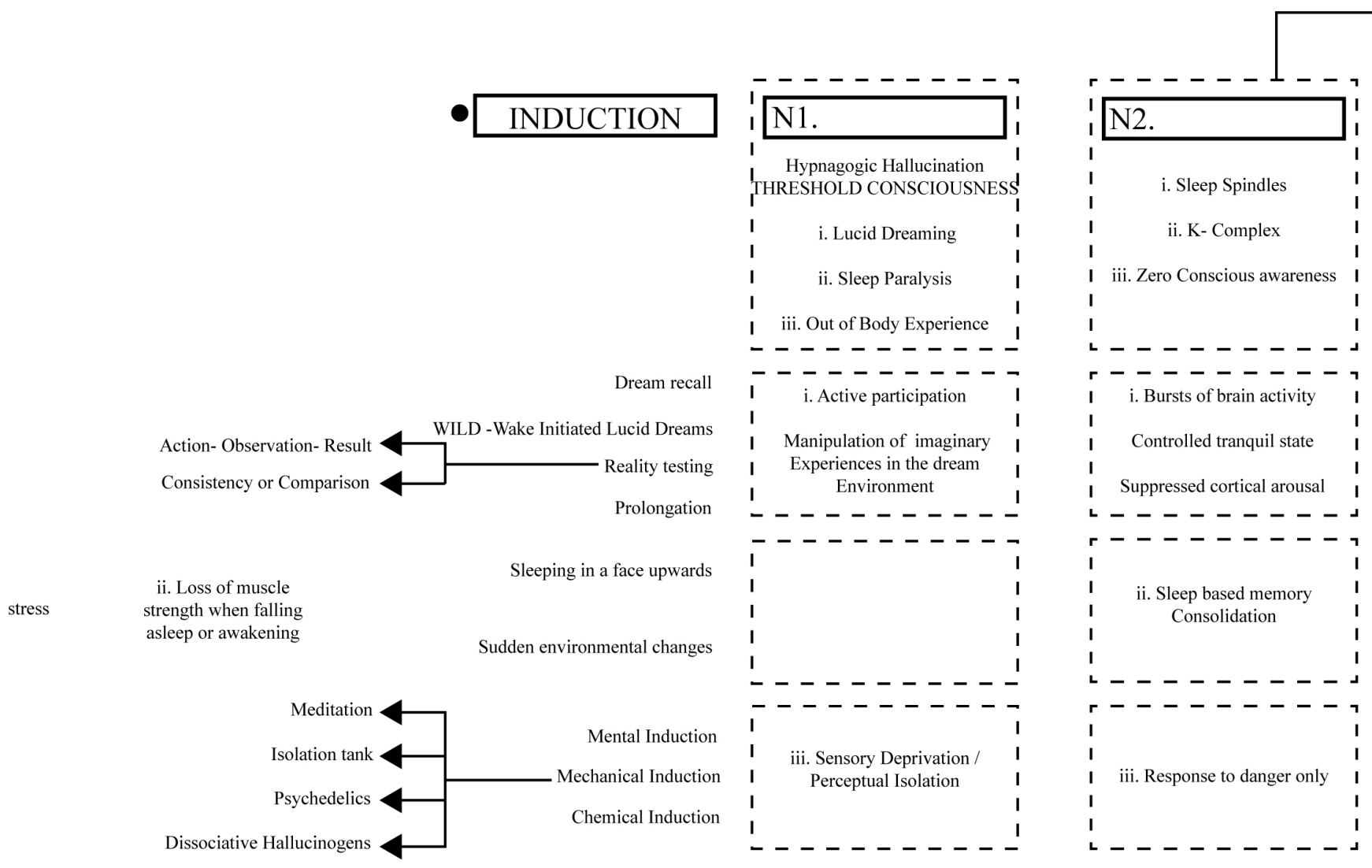


\section{$\mathbb{R C H} \Pi \mathbb{H E C T} \mathbb{R E}$}

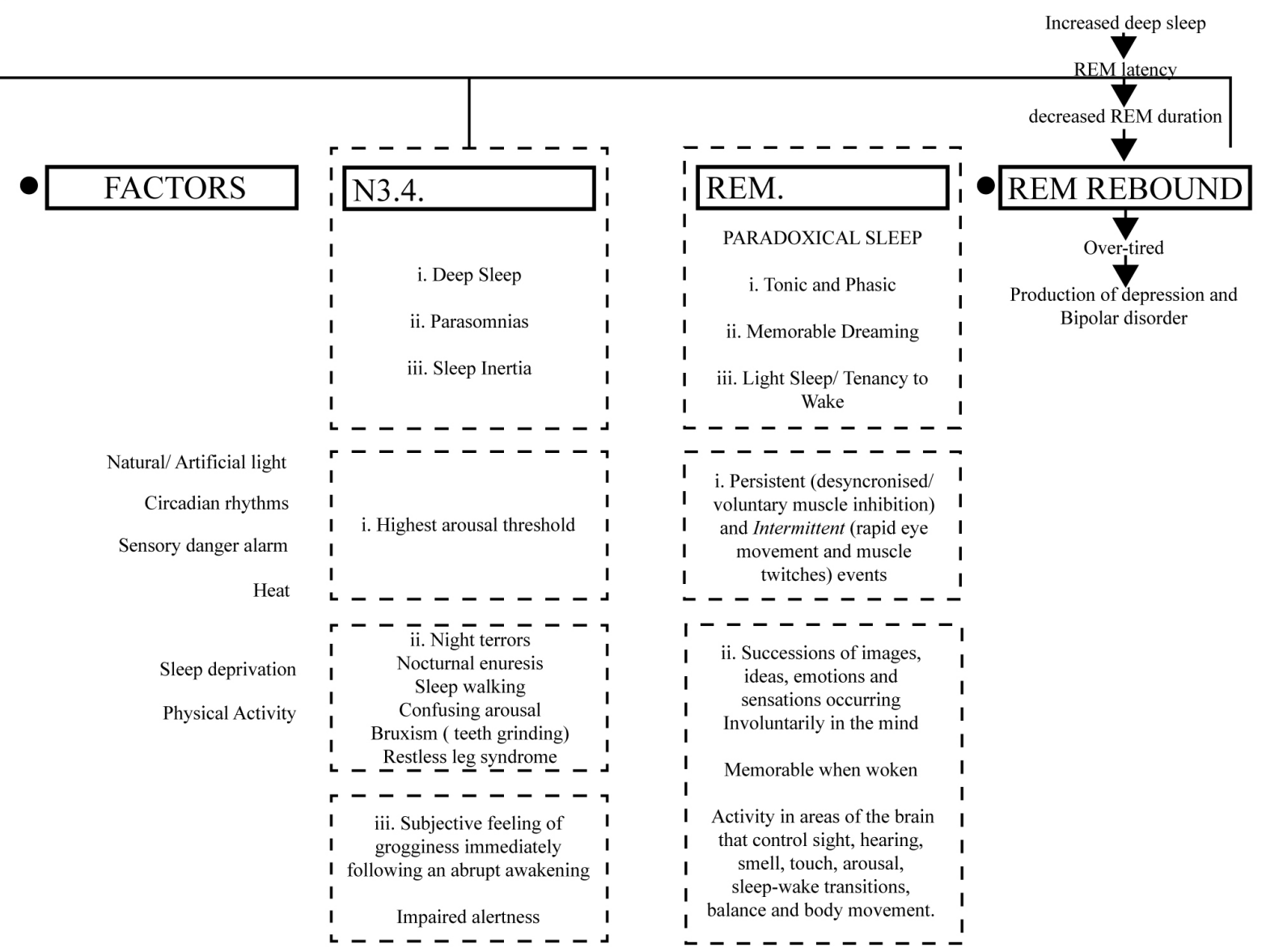


igoncili

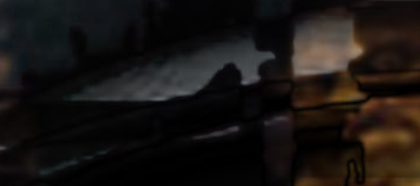

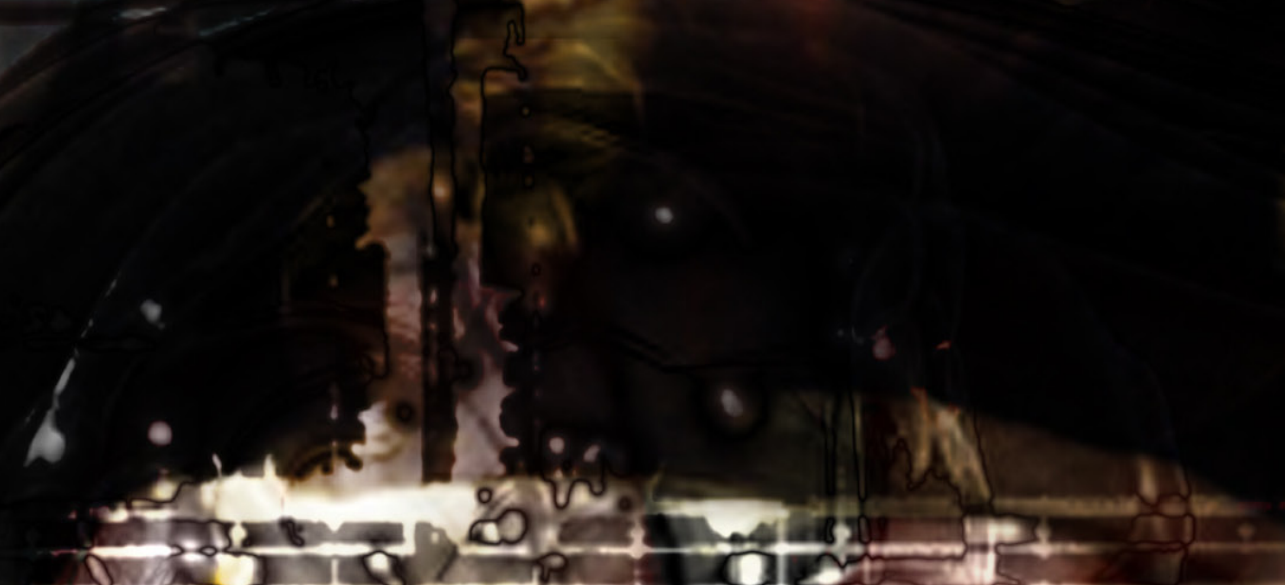

a.

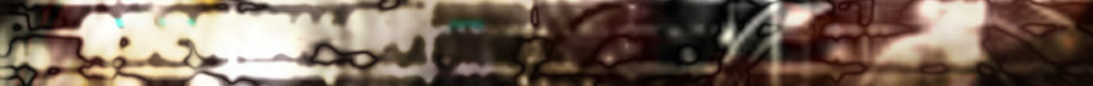

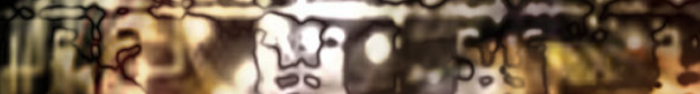

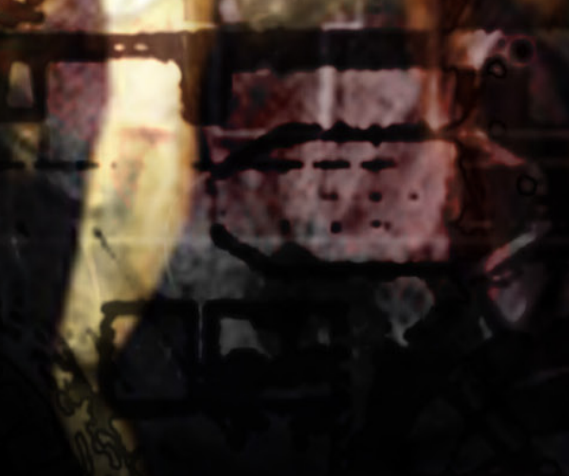
a. (a) an - a 


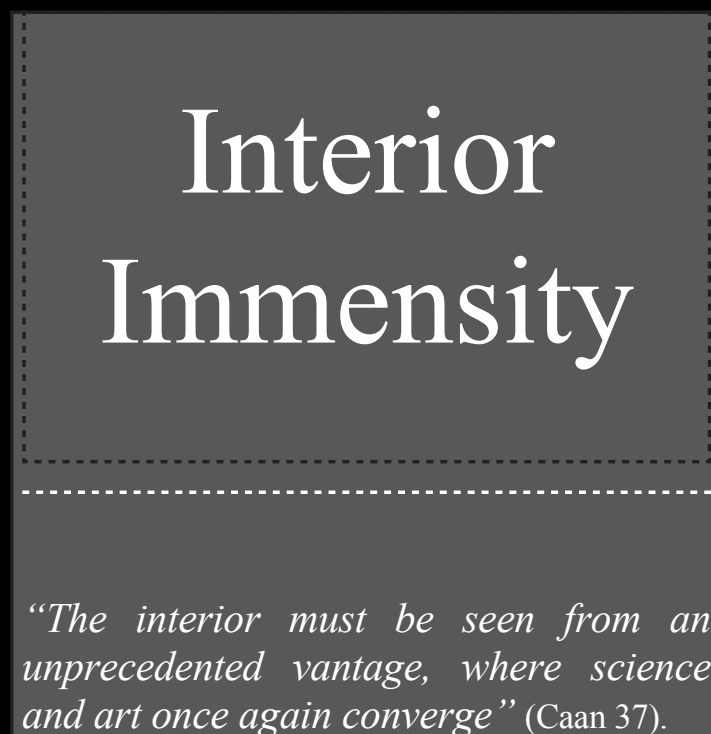

The interior realm has a most fundamental connection to human nature and human psyche. It is the mechanism to intimately connect with the human mind at both a conscious and unconscious level. Designing for the interior is designing for an enhanced human state. Conditions may be affected by the intersection of psychological, sociological and physiological influences. Unfortunately, in the twenty-first century, the intimacy of the interior has almost become lost in pushes towards mega-structures that house what Shashi Caan considers an "entire neighbourhood" (Caan 37). These lose any sense of individuality through such balanced and controlled environments. The controlled environment is what the interior world manipulates best. When using the 'thematics' of a site and an emotive narrative to dictate programme, the whimsical world of the interior will surface.

Pragmatic descriptions of design, although important in designing a fully functioning space, are restrictive of the intentional emotive relationship between the human, an object and an environmental setting. Humans should not be rendered as lifeless abstractions within a space, but used instead as common denominators for mediating space. 


\section{The Second Skin \& the Human Body:}

\section{Dual Conditions}

"The surface of a body is the limit of what is inside and outside. What belongs to this surface, and all that is placed beyond where one looks at or touches the body is exterior. Anything that is beyond the surface, in the depth of the body, is the interior" (Caan 40).

It is impossible to describe the interior world in strictly physical terms. To capture such intangible qualities is a primary goal and is continuously attempted. French philosopher Diderot maintains that the interior is not only a physical container but a device to encapsulate zones of human experience: physiologically and psychologically. The notion of interior space is reflective of both building / physical space and the human being, where the human being presents a complicit relationship. It is noted that the relationship between the interior and 
the human being is that of both inner self and outward personal projection. From here it is inevitable that what we project outwards and what is inside the physical walls of a design may begin to overlap (Caan 40).

The separation of boundaries between the realms of 'inside' and 'outside' is a 'second skin'. It defines how we perceive, and how we are perceived. It may lie outside of physical boundaries: a sense of identity in an atmospheric aura and extension of ourselves.

An interior space must then present itself as a crucial instrument. Accordingly, interaction with designed space can be assessed through this interiority.
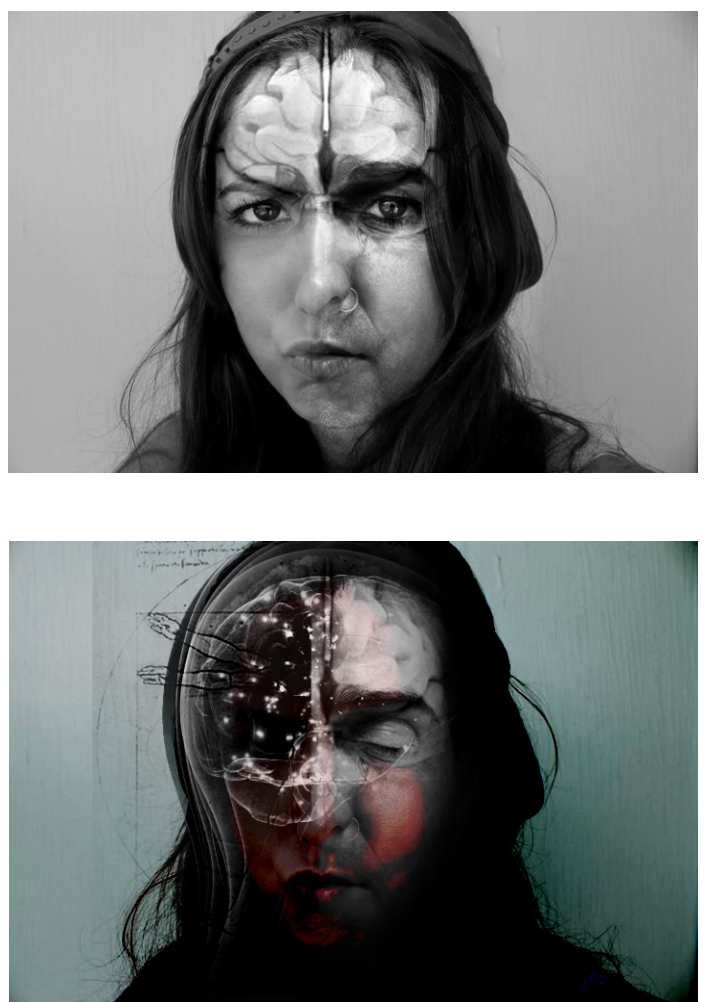


\section{The Process of Perception}

“...Between our interior selves and the exterior world lies a series of literal and perceived boundaries that we establish. These barriers do not stop at the outer limits of our bodies, and comprise our second skins, while more distant boundaries define urban space..." (Caan 41).

American poet Ralph Waldo Emerson saw the human body as having control over its surroundings, as an extension of 'ourselves'. The second skin is a projection of both our physical attributes and our psychological inwardness. Our ever-changing perception of surrounding space is affected in various ways as we behave differently with a space according to its association with the individual. For example, from work to home, or public to private, our perception of each noted space can just as easily be altered by intentional design decisions to shape and mould a space with psychological enhancements - enhancements that need to take into account Human variance. 
Likewise, this variance needs to take into consideration the scale of protection individual assert, whether they have the capability to intentionally reject and absorb the outside world and to what capacity. This correlation between space and internal being is beautifully noted by Bachelard in Poetics of Space:

"My house is diaphanous but it is not glass. It is more the nature of vapour. Its walls contract and expand as I desire. At times, I draw them close around me like protective armour. ... But at others, I let the walls of my house blossom out in their own space, which is infinitely extensible" (Bachelard 51).

Design influences self-perception and designed environments need to support us as a result. The problem is that design is increasingly based around a stereotypical, singular universal man - a universal building code that points to rigid, lifeless 'mega-structures' housing a neighbourhood of mass production and no unique variation to immerse within the individual client. Codes enforce limits and your house cannot breathe a life of its own if constrained.

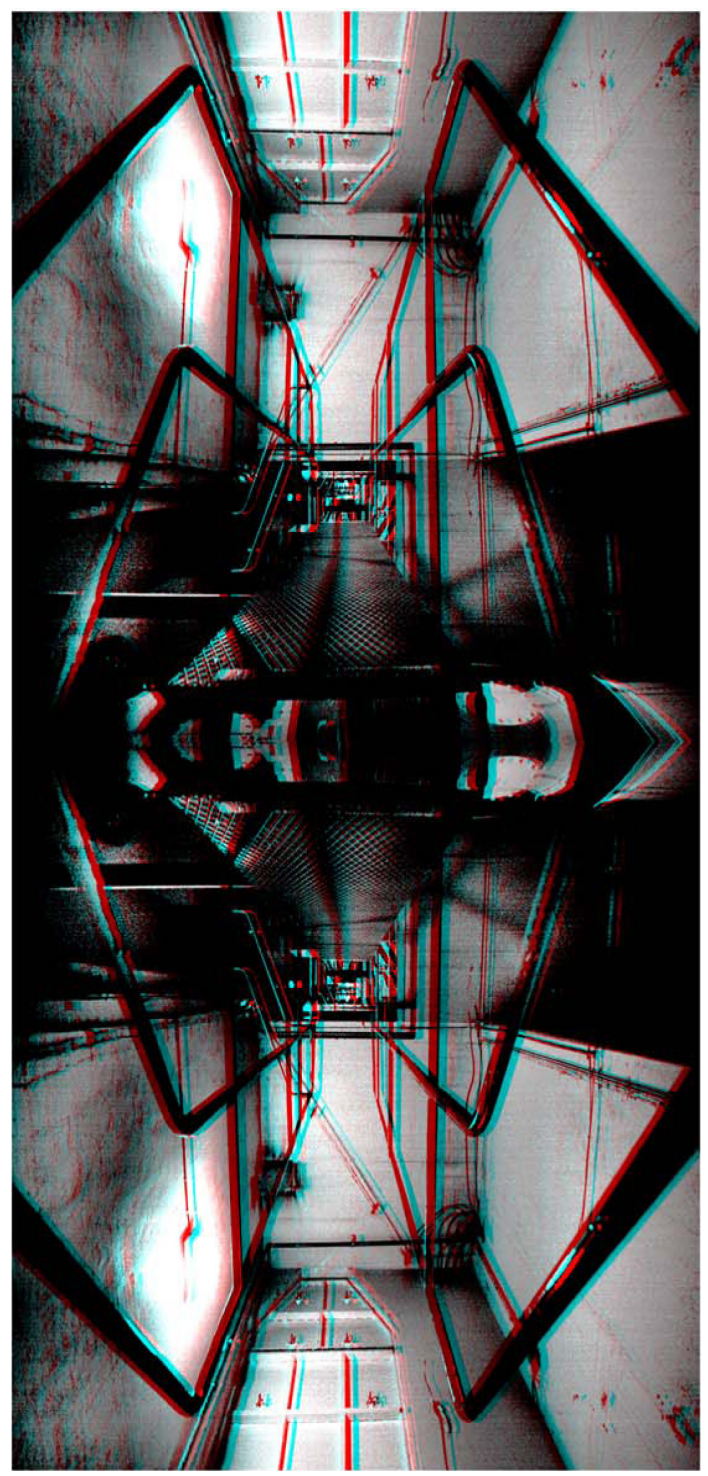

001

Distortion through refl ction.

3D experiment. (Find 3D glasses attached.) 
EXPERIMENT ONE: POETIC DISTORTION
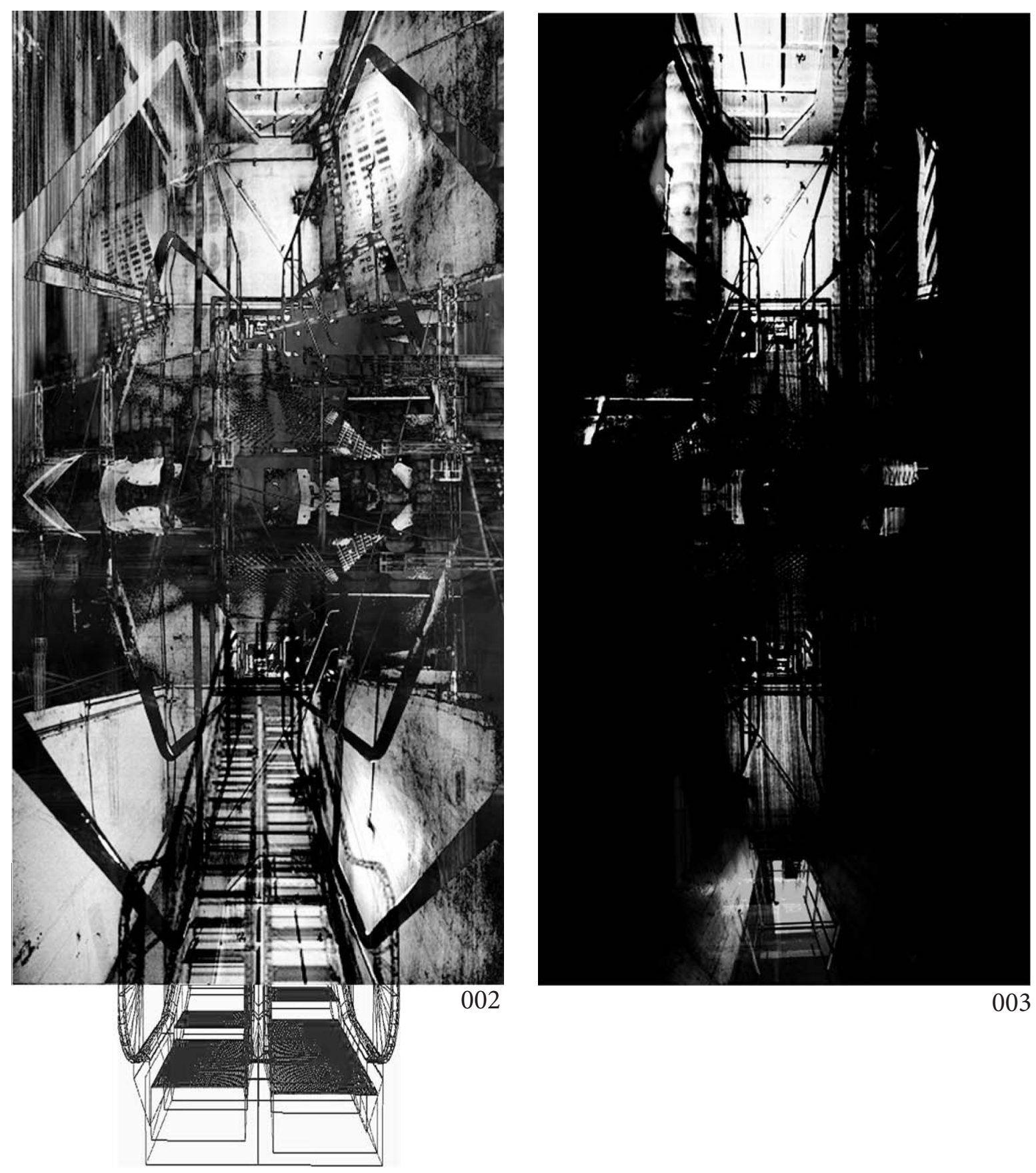


\section{Hybrid Forms}

Morphing is a term used to describe a process in which an object changes its form gradually in order to obtain another form markedly different in appearance, character, condition or function. In an adaptive design it can be used as a technique to conquer the difficulties of expression and identity of form. Architecture has distinctive qualities. It can be considered both dynamic and static. The manipulation of entities that are of elastic nature may be considered the design process. The design process is considered dynamic. It does not become static in nature until the design process is complete. It has essentially been frozen in a certain state to allow for construction and inhabitation. The presumption of a building may be that it is static; however, we can discuss this further and assume the identity of a building to be anything but static when considering the building as a blip on a continuum taken from the past and projected into the future. We can also consider the building as a connection within a diverse site context; when the site is built around the generation of power, how can it be considered static? 


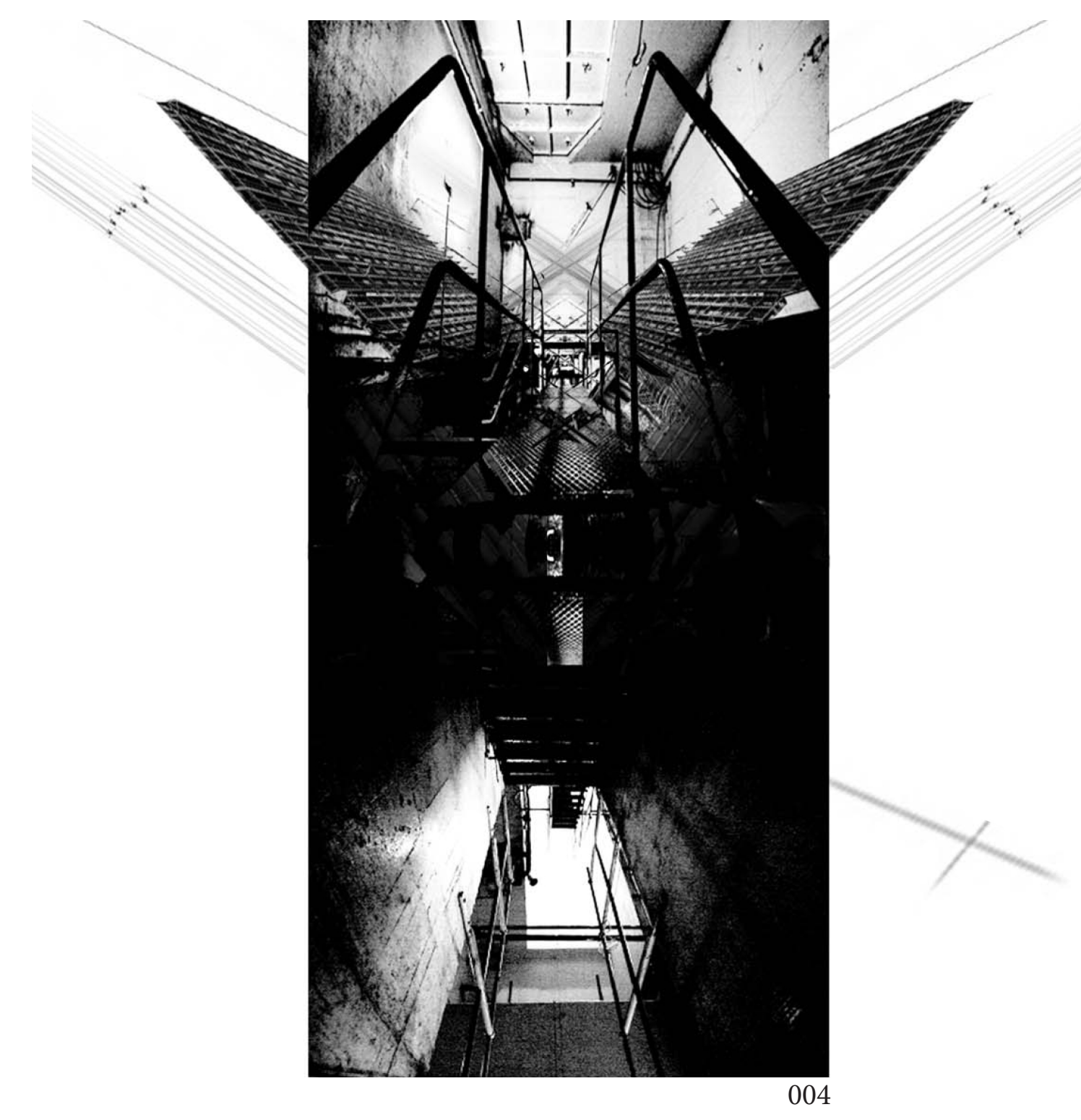




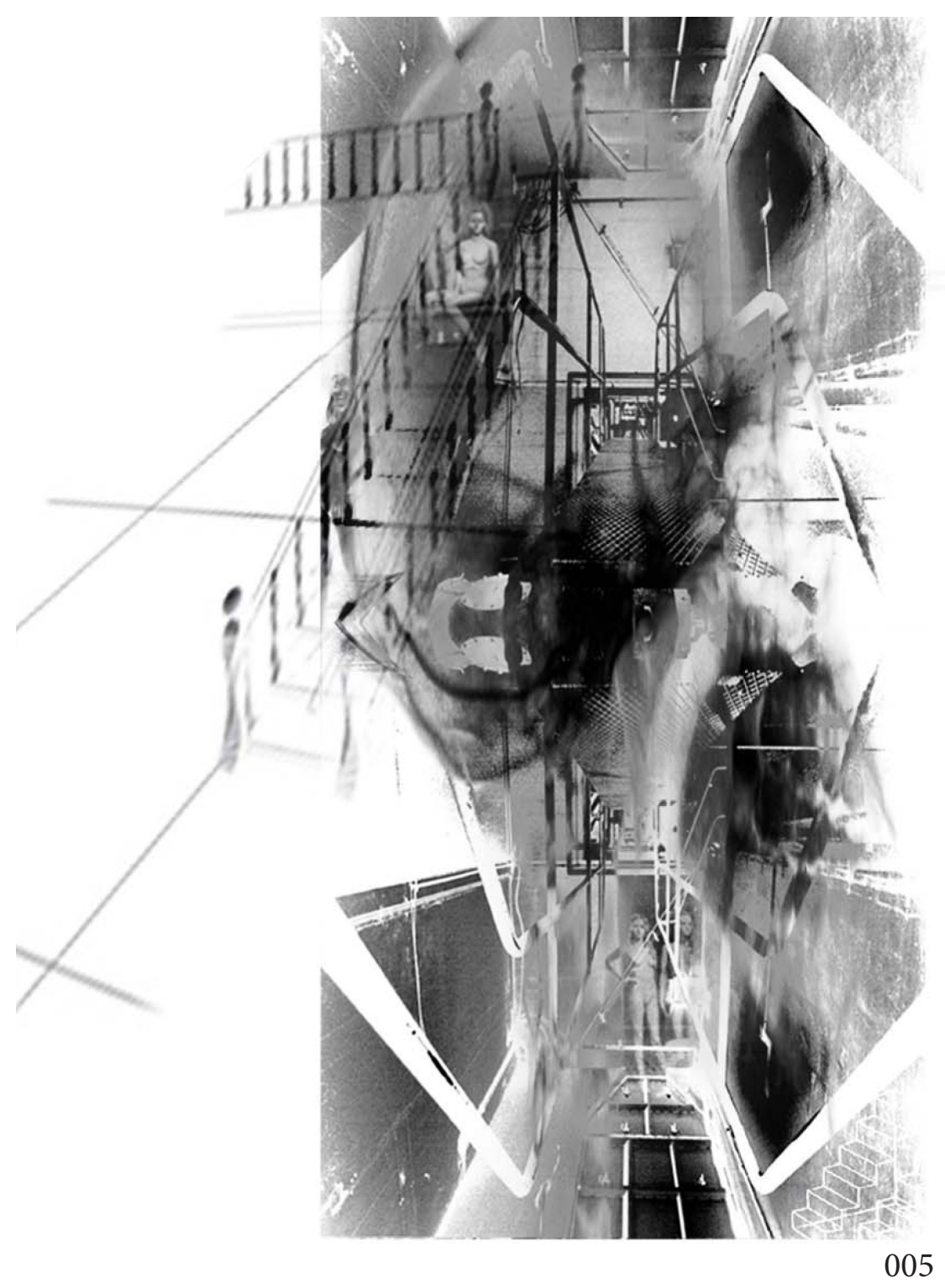




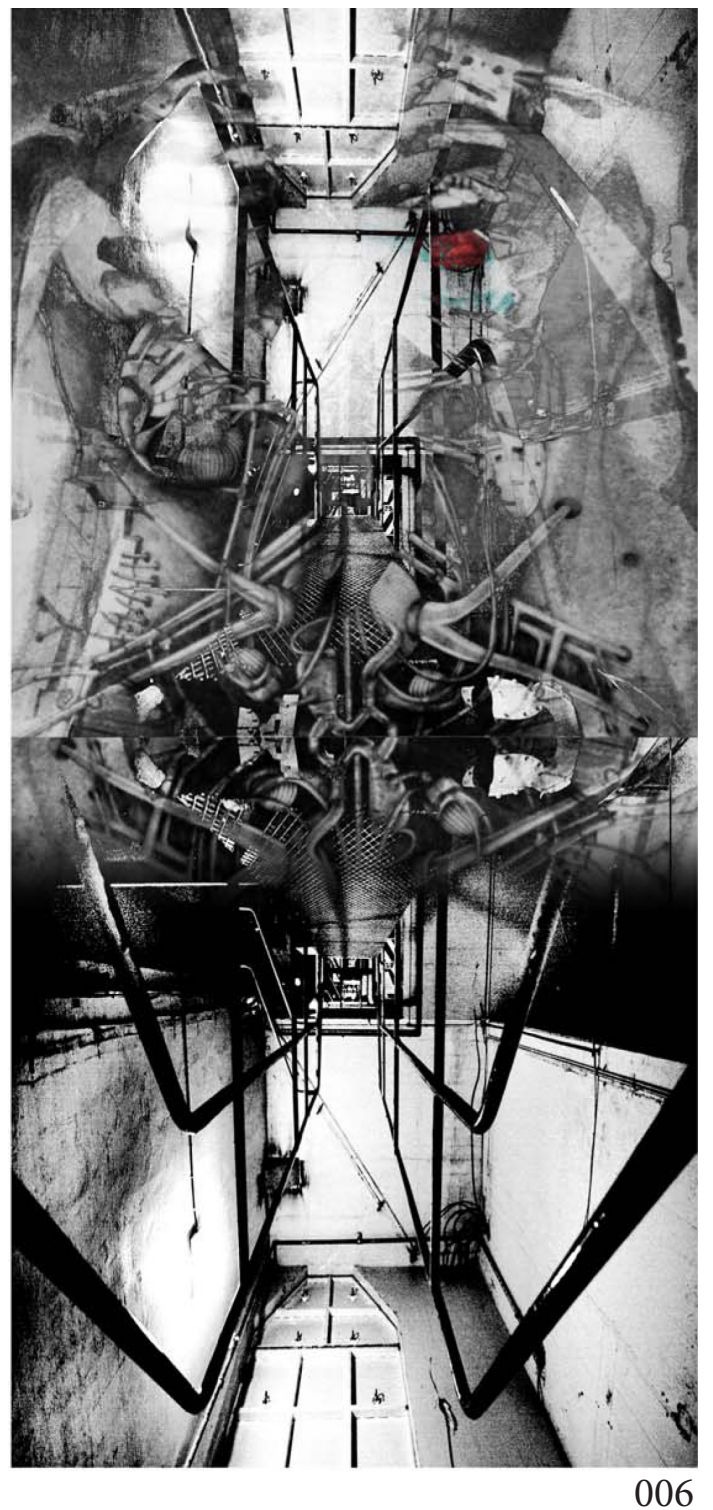




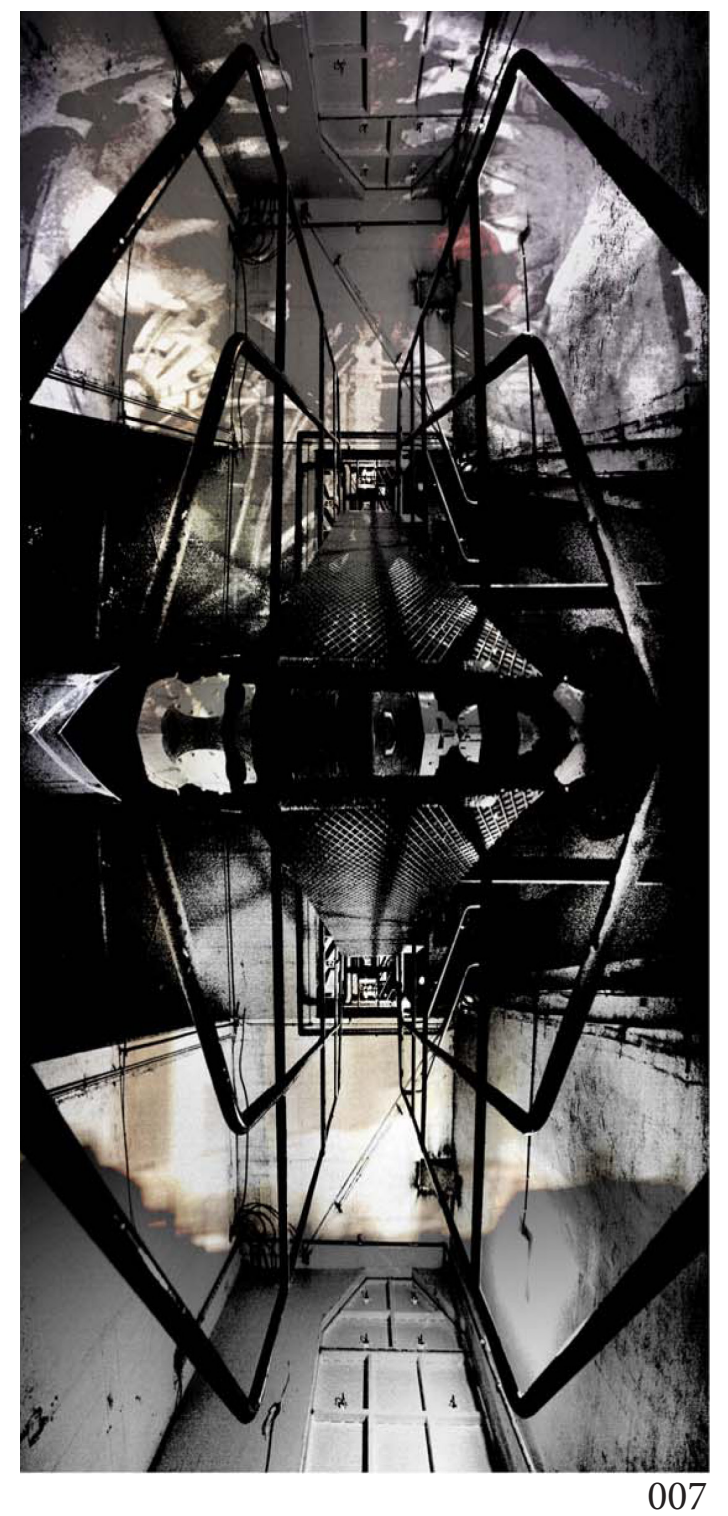


I am not specifically interested in change.

Architectural 'morphing' does not condone this state. The power station functions efficiently in its current state. I am rather interested in the possible outcomes where at one moment in time the past and future have the ability to overlap within the same form. Likewise, the opportunities in such a complex site are largely appealing for an interior intervention. As Kostas Terzidis claims, a design actively situated within the dynamic stages of production should involve transition, progress, continuity, interpolation, and evolution; the static result should convey expression, connotation, integration, combination, and bonding (Terzidis 29). To put it simply, the progression of the original structure to a modified form should be an articulated development of diversification between the fixed points of identification. When successful, the static result will demonstrate an abstract intension outside the realms of the literal primary meaning.

In this experiment of poetic distortion I have used photos (experiment one) I have taken on site and collaged them accordingly to generate varying atmospheric conditions. 
The application of morphing within architectural practice suggests geometrical and topological transitions. The process will affect the geometry of a distinct form but will preserve its 'topology', the properties that remain invariant under certain transformations such as bending, stretching and compression but not tearing or cutting. For this reason, morphing preserves the topological integrity of the objects involved. Architecturally, if I were to split one of the turbines actively functioning in Arapuni Powerhouse in two, and manipulate one half to exert itself towards an entirely different function altogether, it would no longer contribute to the running of the power station, and therefore lose its identity completely for a new one. If I were to use the strategy of morphing it could take on another function while still remaining active and is a completely manmade, artificial process following artificial rules.

This allows for this transaction between seemingly disparate entities to happen in a strategic way. The process will connect the 'unconnected', the unrelated and unalike, within the dynamic stage.
Once static, a type of morphing is the bond between this past and present state (Terzidis 57).

"Thus, it appears to be a process of magic or sorcery, and the effects often may look strange, awkward, or surprising" (Terzidis 58).

A recent theory of form in architecture has in fact focused on topological geometry

“...smooth spaces described by continuous yet differentiated systems resulting from curvilinear sensibilities that are capable of complex deformations in response to programmatic structural, economic, aesthetic, political, and contextual in uences" (Terzidis 23).

The viewer will always consider 'two' objects: the original (source) and the destination object (target). Theoretically the process only provides us with 'one' object, which is transformed from one original state into another. This destination object is called the "hybrid object". It essentially conveys characteristics of both parents involved in the transformation process. 
"This object actually is composed of the typology of the one object and the geometry of the other. It is an object in disguise. Although it is topologically identical to one parent, it resembles the geometry of the other parent" (Terzidis 58).

The hybrid object receives its structure from its parents through a formal method of estimating values that lie between two known points. It is considerably easier to use this process when dealing with isometric or structurally identical parent objects where a one-to-one correspondence applies between the parent sets. Heteromorphic parents, or two or more different forms, make the process more complicated. The process becomes more selective when deciding on elements between the sets. The crucial principle of this mapping process lies in the "preservation of the topological and geometrical properties of the hybrid form" (Terzidis 58). It must bear this relationship from the source to destination.

"For instance, in the case of a square being mapped to a triangle, the addition of a fourth point to the triangle preserves the topology of the square and yet, its disguised location preserves the geometrical appearance of the triangle" (Terzidis 58).
Hybrid design acts as an alternative to the standard build up design approach of today's architects. This is very convenient for the role of the interior architect. Due to the architectural nature of an interior space we do not often get the opportunity to start with a blank canvas. The hybrid design starts with complex constructs rather than building towards them, essentially imposing a new condition or configuration on a design. There is opportunity from here to explore the proposition of contrasting design agendas: find the state where the design is frozen in mid-transformation, mimicking the past while alluding to the future.

The archetypal ideas and values related to the themes of the original design should not be lost. Traditionally these values are understood through abstract organisational themes within the configuration of the site.

"Enclosure, balance, direction, rhythm, hierarchy and symmetry are depicted through the use of Euclidean shapes and geometrical con igurations" (Terzidis 58).

The symbolic manifestation of the hybrid form will be challenged through the selection of the parent objects. If these parent objects take on the appearance of the previously quoted parties, 
hybridisation will occur within these archetypal shapes. Dramatic differences in contrasting parent objects allow for a striking hybrid form to surface.

I have used this hypothetically for spatial arrangement of my design. The gravitational force of the penstocks and the repetitive nature of the turbines have given me space to transform zones of residence.

"For instance, morphing a foursquare parti into a circle is not about four shapes that merge into one, but rather about the concept of hard, sharp, and equilateral changing into soft, smooth, and concentric" (Terzidis 58).

For Arapuni Power Station to attain its original identity and remain first and foremost a site of electricity generation, deformation must be kept at bay. To ensure identity is not lost within a secondary function interpolation will force the intervention to oscillate between the identifiable shapes of its parents. Comparison can therefore be made at any time. This formal ancestral relationship is considerably important as it becomes a device for conveying change through form itself rather than direct contrast.

"The value of mutation is important since it represents a deviation from the ordinary, the common, and the predicted" (Terzidis 60).

If a design did not require the exploration of the alternative, why would we need an architect's creative mind. Controversial interpretations are healthy.

"What appears to be a monster also may be worshiped as a god" (Terzidis 60). 


\section{BOUTIQUE BACKPACKERS}

\section{First Conceptual Design}
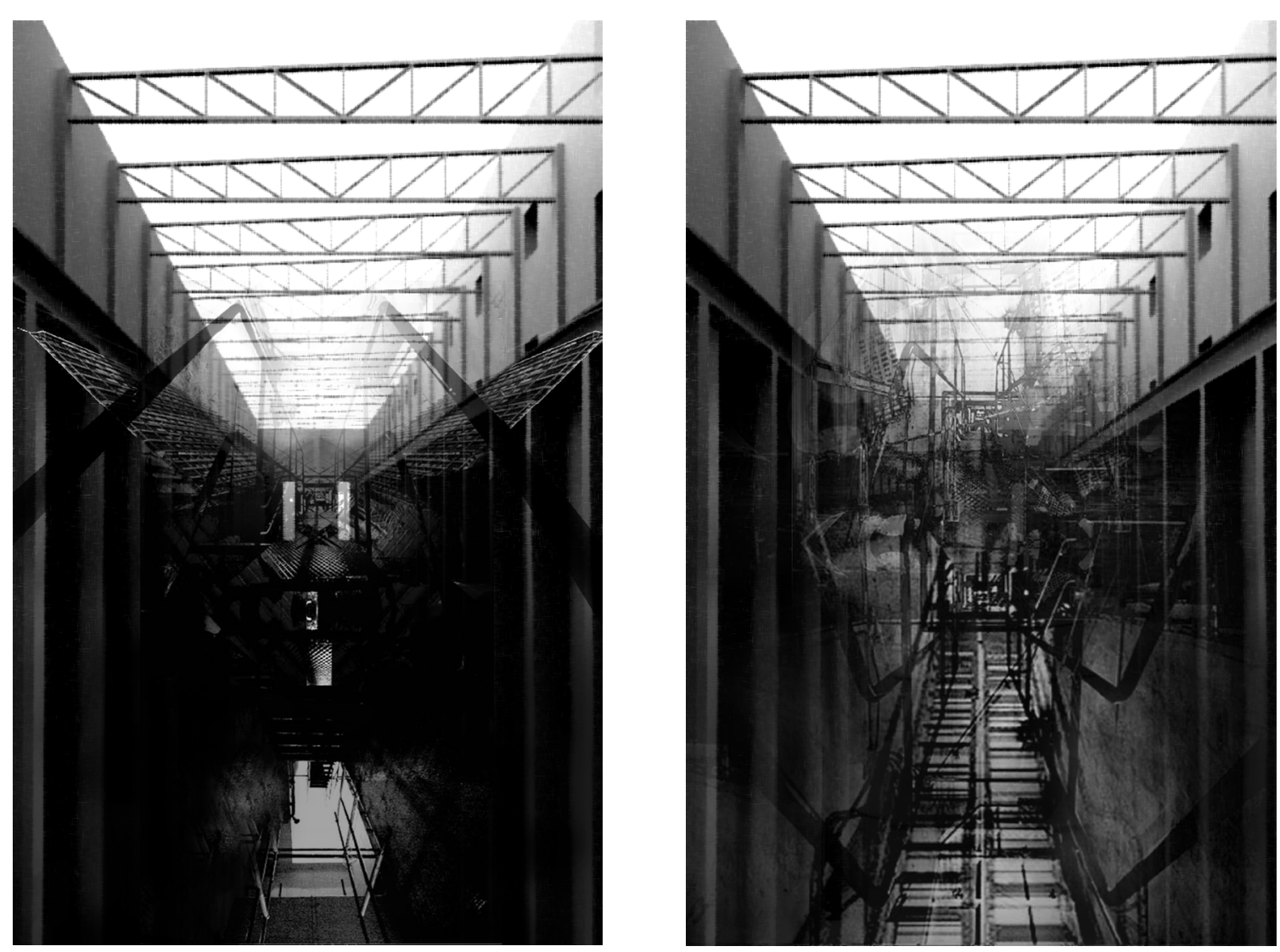

Conceptualised atmospheric capsules (Part of experiment one) 

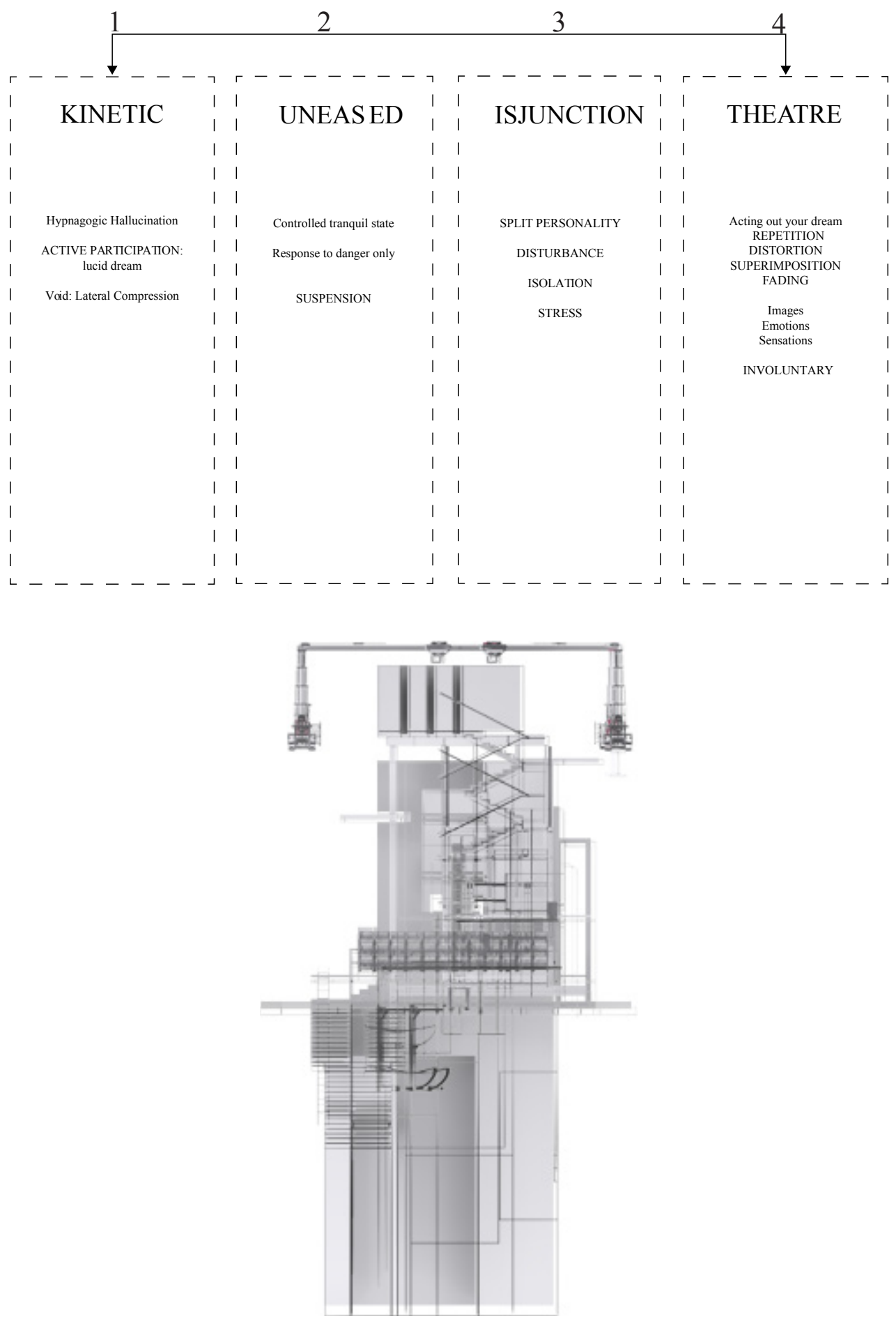


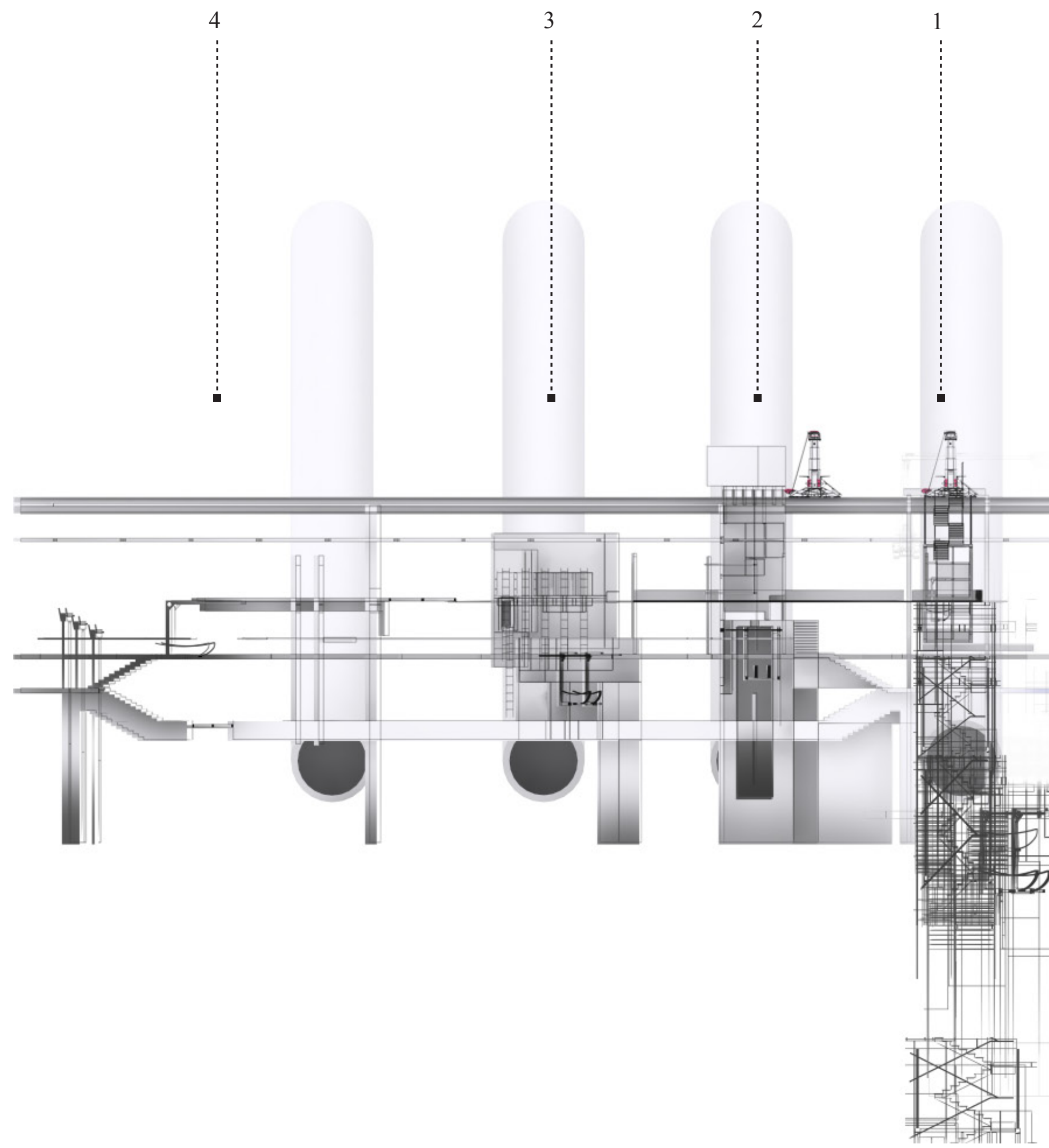




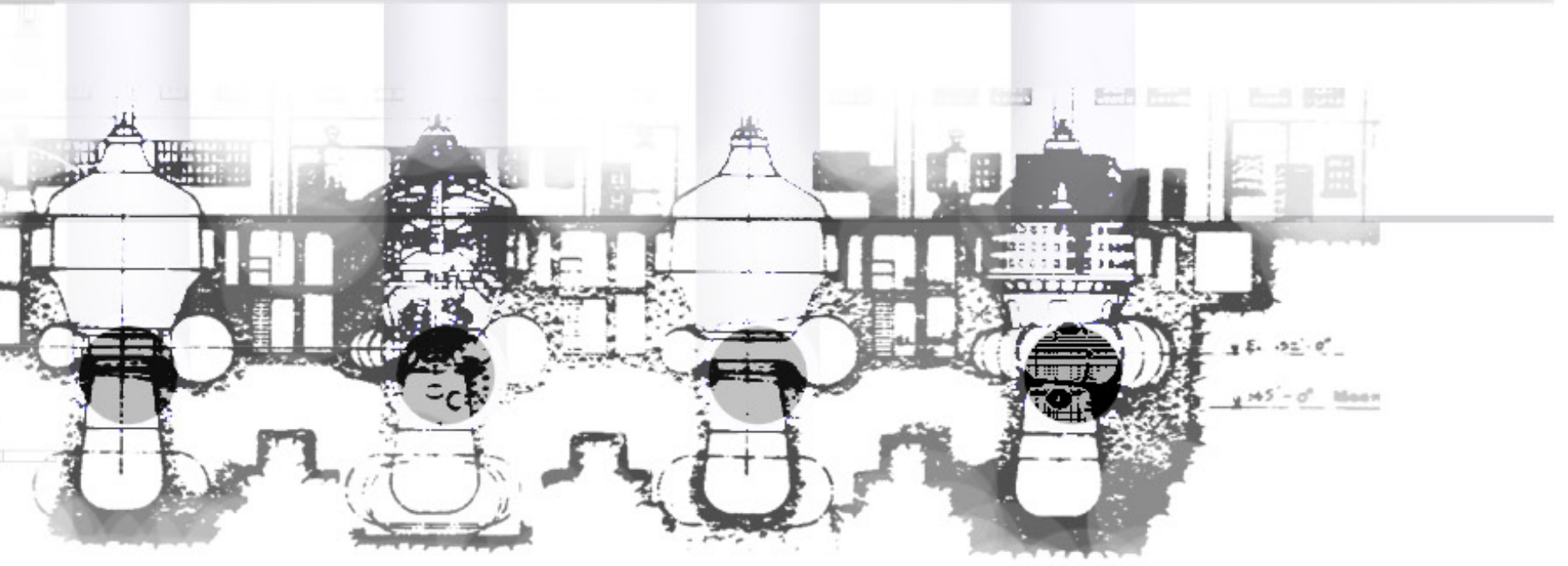

First Design Plan - Scrapped 


\section{BOUTIQUE BACKPACKERS}

\section{Final Capsule Design}

We have opportunities here for the repetitive approach to transform through public / private spaces and focal nodes of attachment, responding to what is happening behind, in front, in-between and at the end.

There is a transformation from the transparent at the front with the beautiful windows, to the solid behind as you work your way back into the land.

At all times you rest fully submerged in the sublime surrounding conditions. Although your mind races and your imagination runs wild, you are still at ease.

You remain within your capsule as a freestanding element of your surroundings. You have the extreme support of a solid original industrial protective shell. 


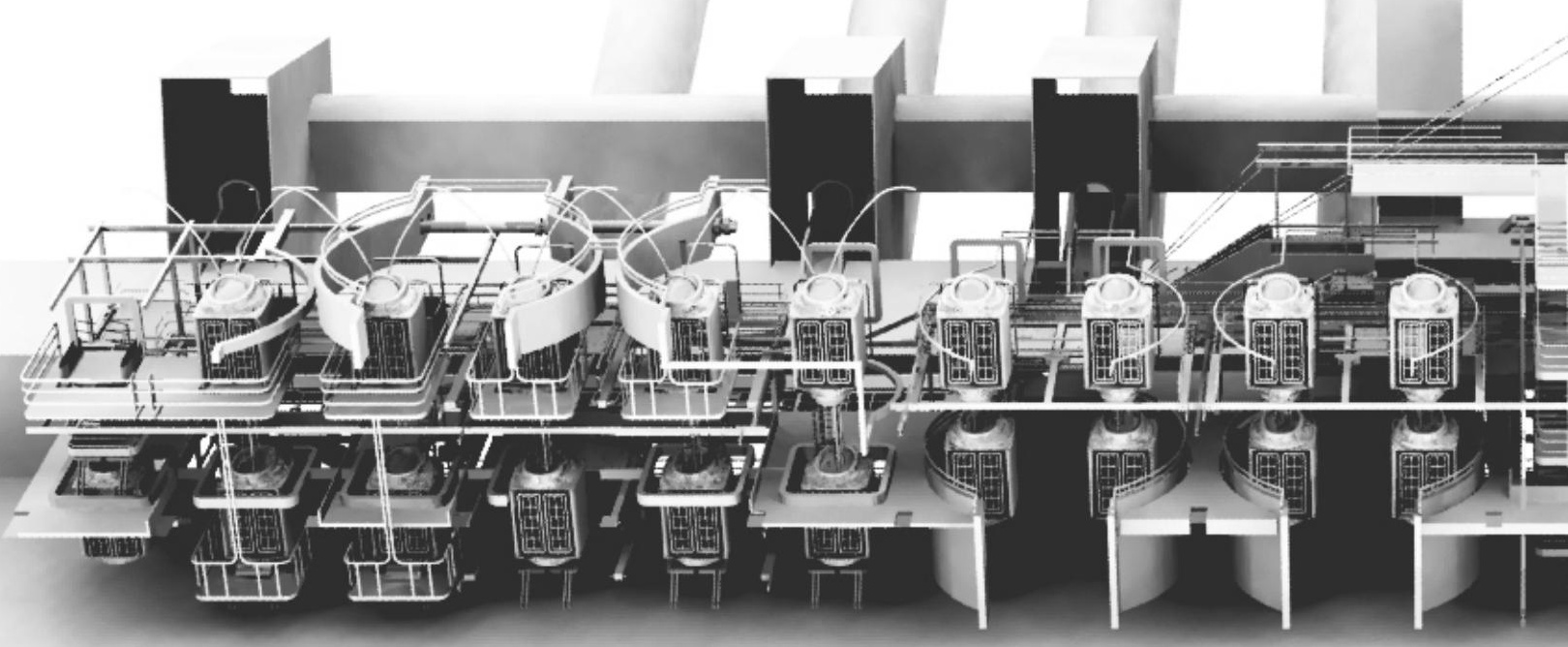




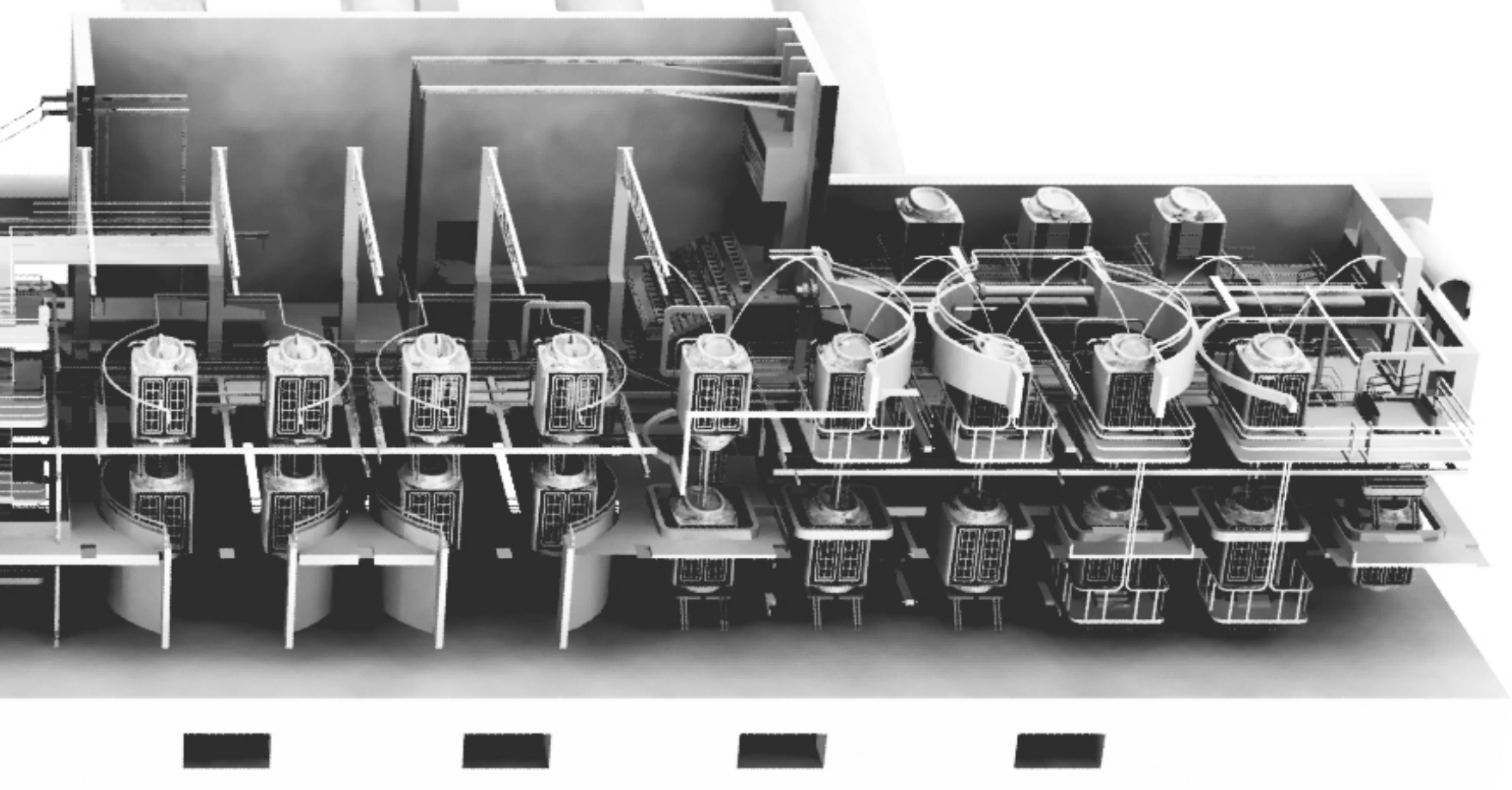



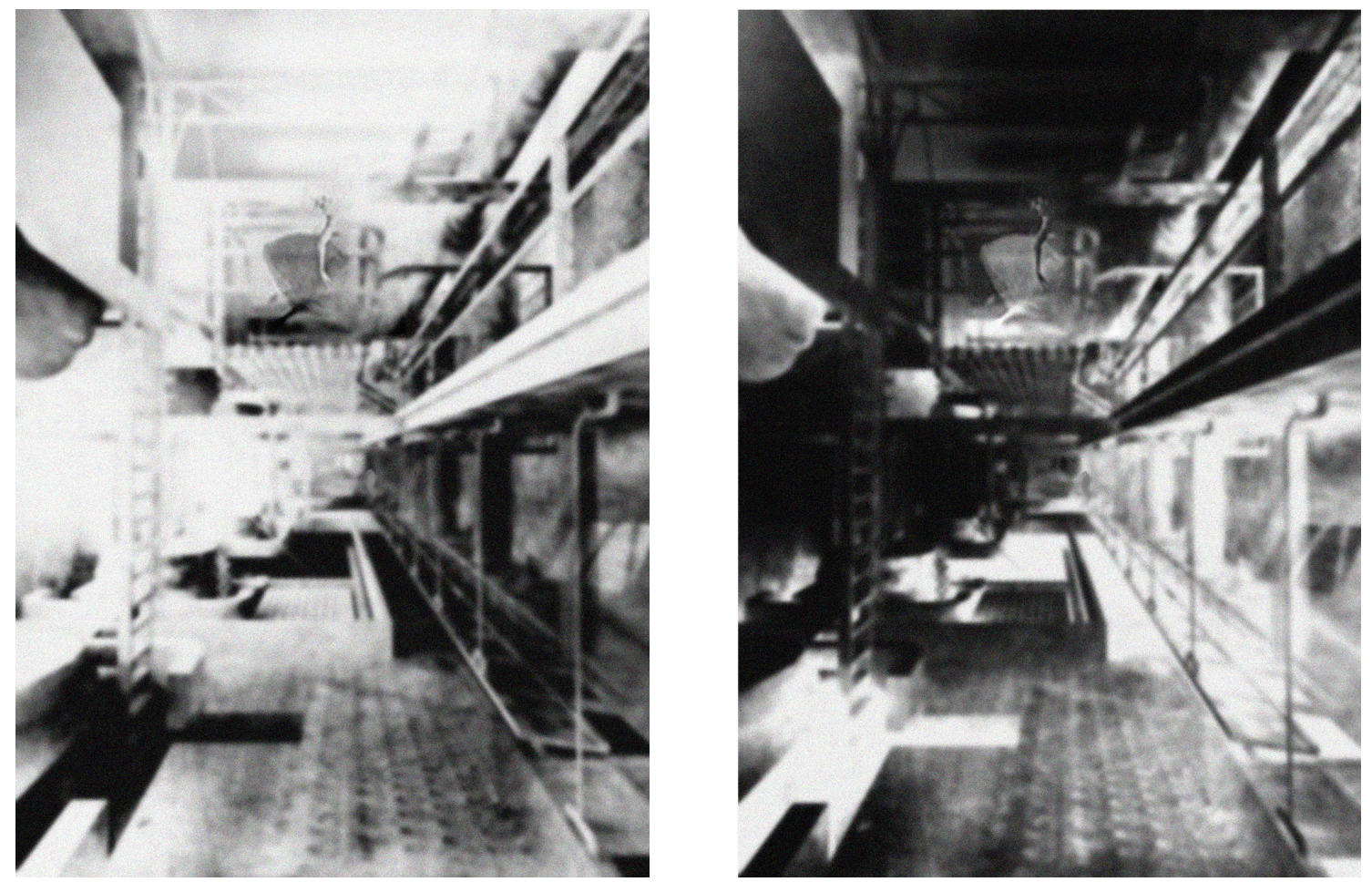

Conceptualised 'sleep state' renders of interior spaces 

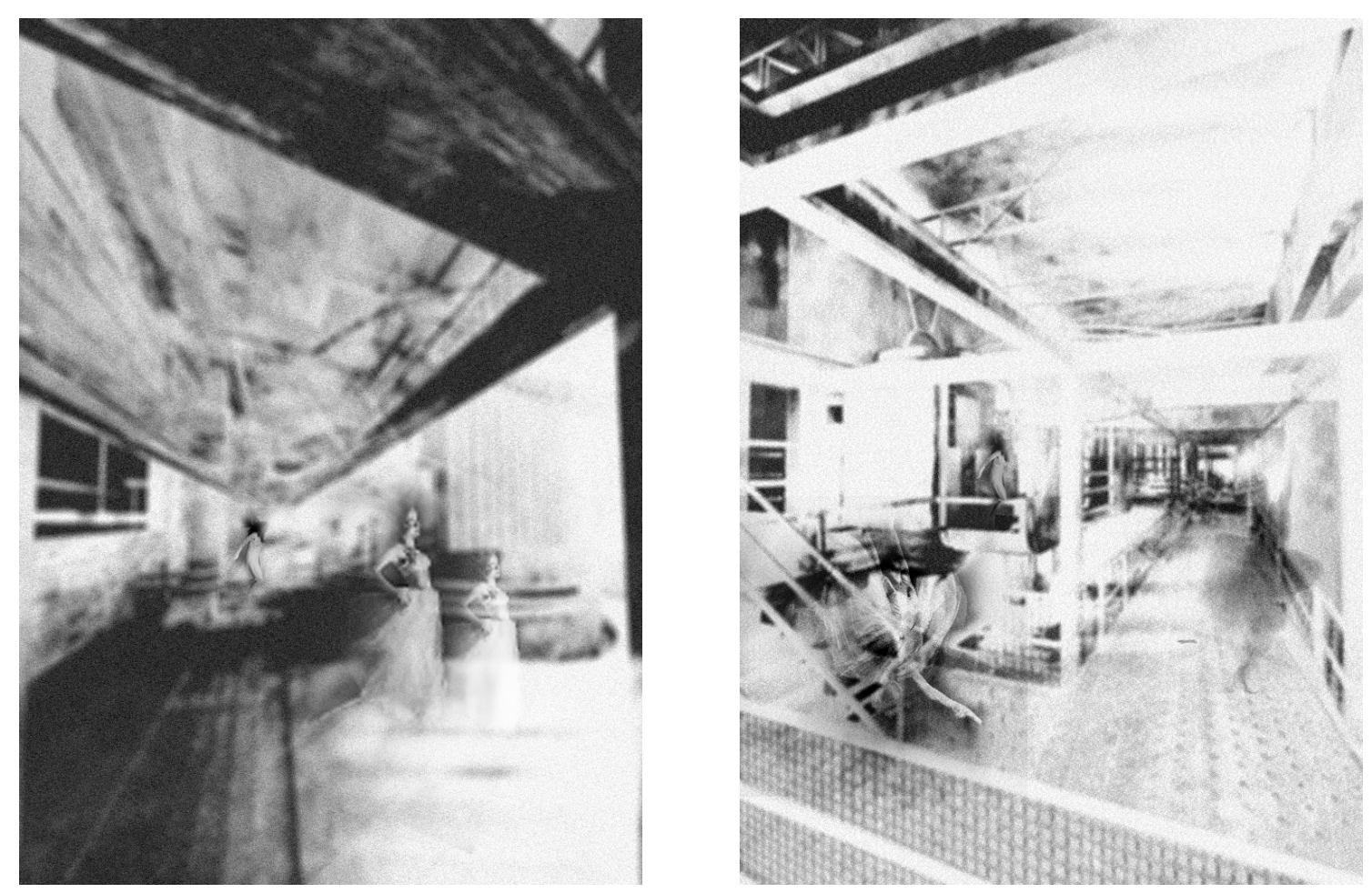

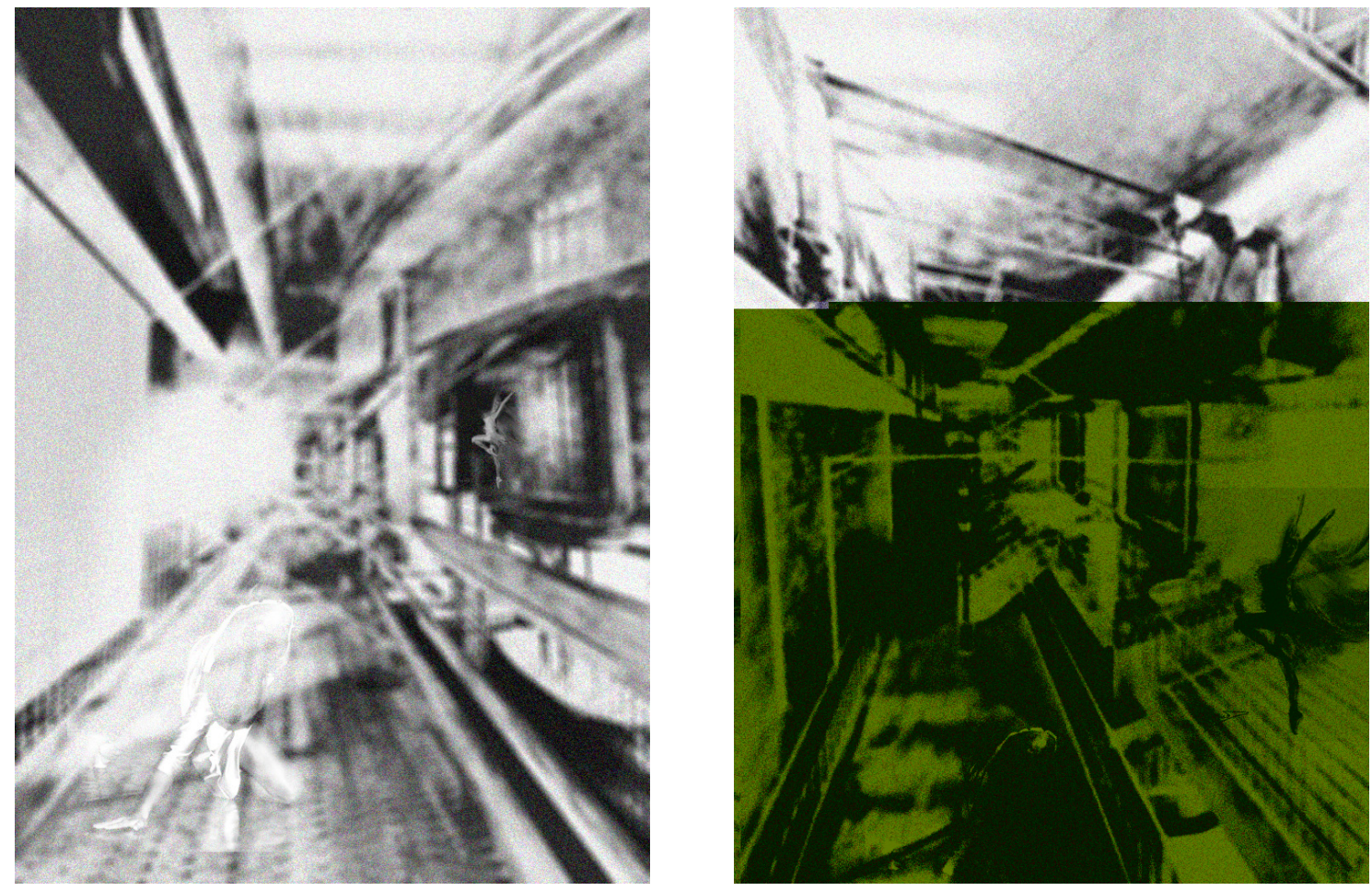

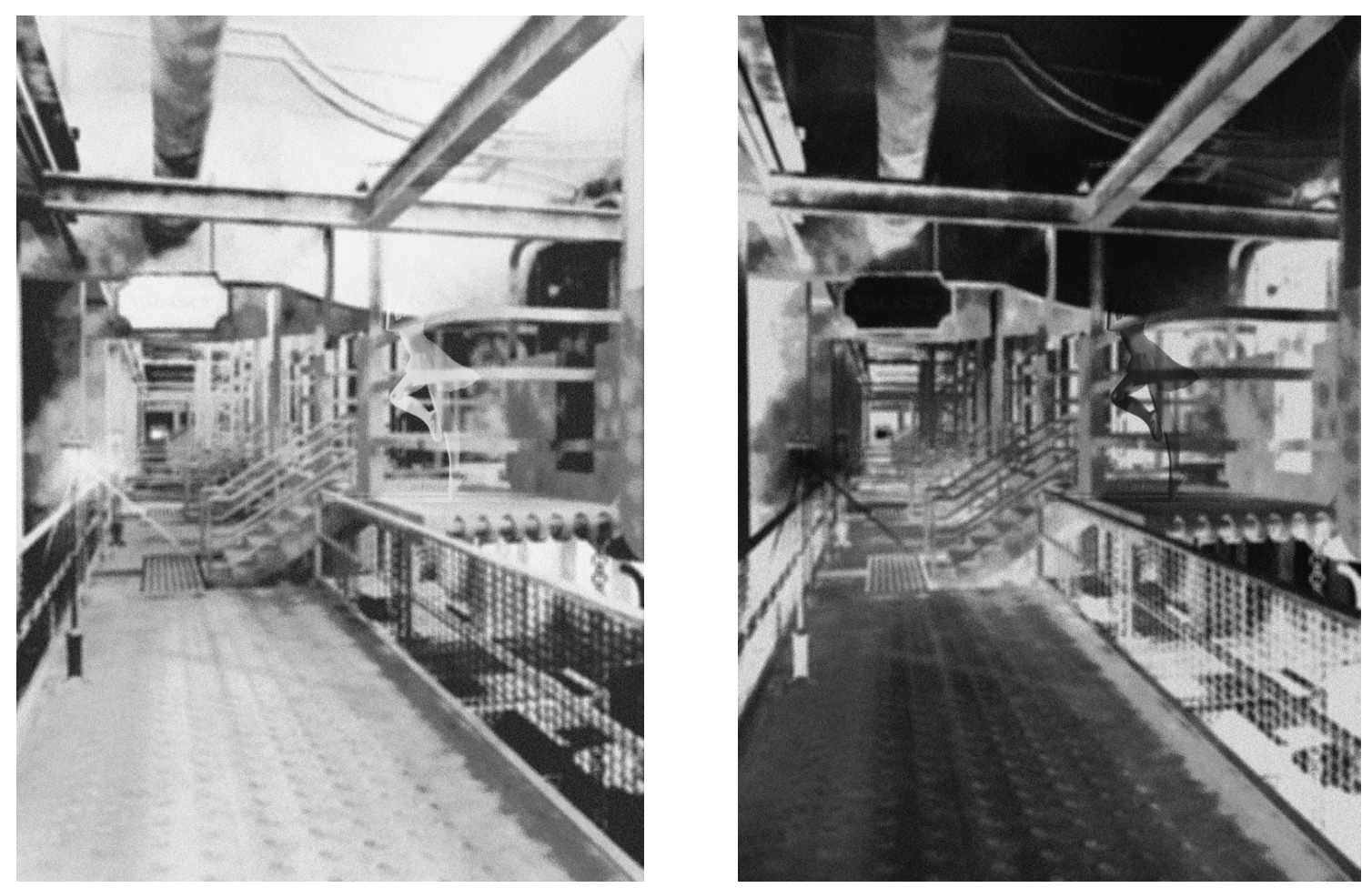

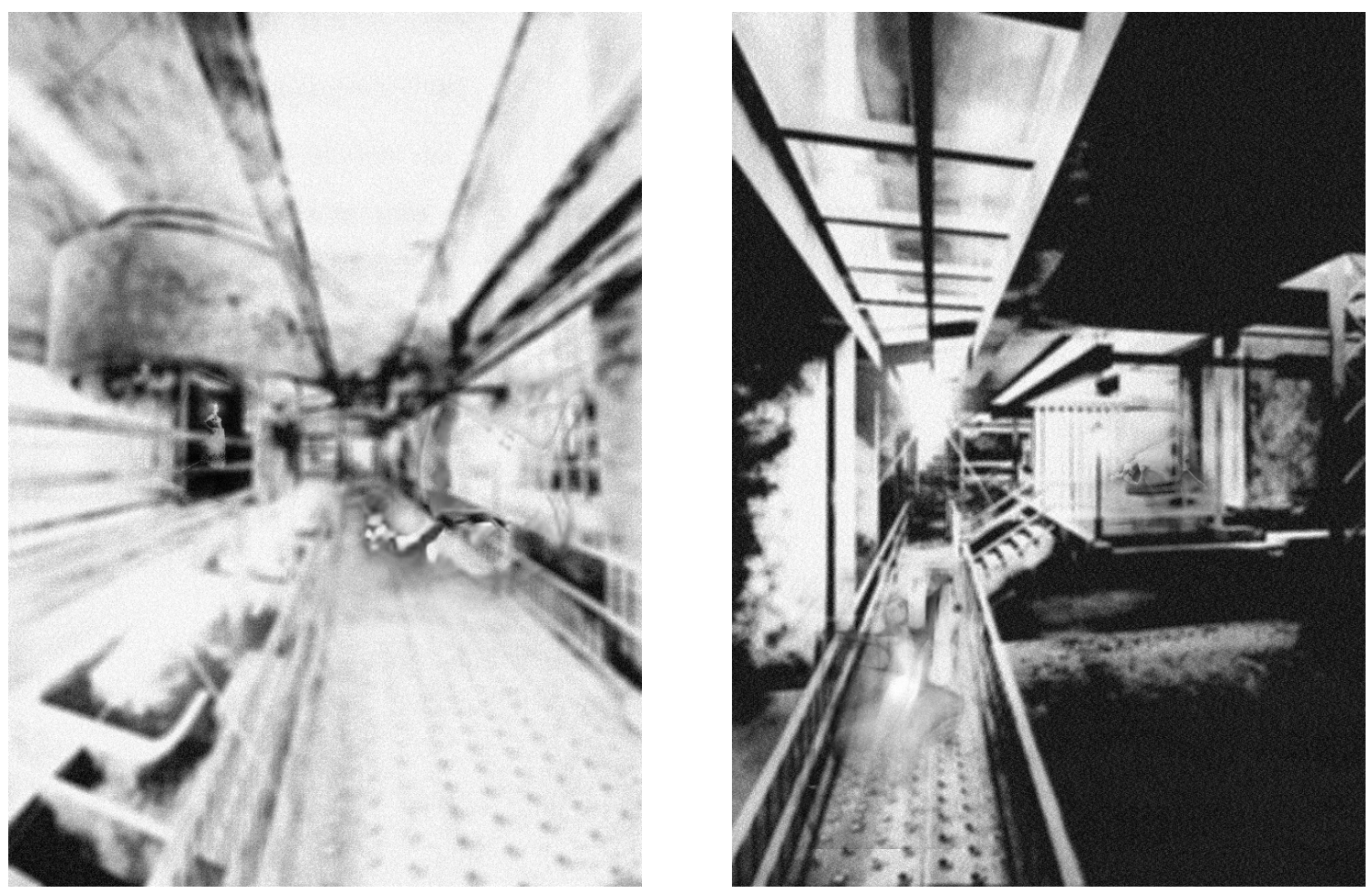


\section{Spatial Zones}

It is important to design with spatial zones in mind.

"Architectonic space owes its definition to the mass of the wall, which bounds the space from without. By contrast, the space that we experience and relate to ourselves gets its definition from the activity of our various faculties, determine its boundaries from within" (Van der Laan 11).

We have metaphoric voids and solids which are differentiated between what we carve out of natural space and how we experience the reciprocal built space. This artificial 'space' negates a sense of emptiness - or on the other hand, a sense of fullness - as we look out into the emptiness of nature.
Human interaction becomes important within this architectonic space. If intentional designed space were removed then we would just be human abstractions dotted on a plane with 'distance' between us. Likewise, if humans were removed from this plane then designed space would have little meaning, perhaps just a structure stripped of any symbolism, a pointless binary obstruction. Even in the dark we have a sense of life surrounding us, so once again it can be experienced atmospherically rather it can be experienced atmospherically rather
than through visual recognition. Obviously, "space is more than the void and air defined by four walls" (Caan 45) and if we consider hypothetically defined environments we can understand human interaction further.
There are four zones of distance proposed by the founder of the anthropological study of human space, proximities, Edward T. Hall. They consist of intimate space, personal space, social distance and public space (Caan 45). Each zone has been defined by a mathematical distance generated by the transmittance of sensory information, but embedded are social and cultural narratives. Hall is adamant that this central positiong within the buit culcult the due to the strong influences space can have on occupants, whether it is to support them or merely impress. 


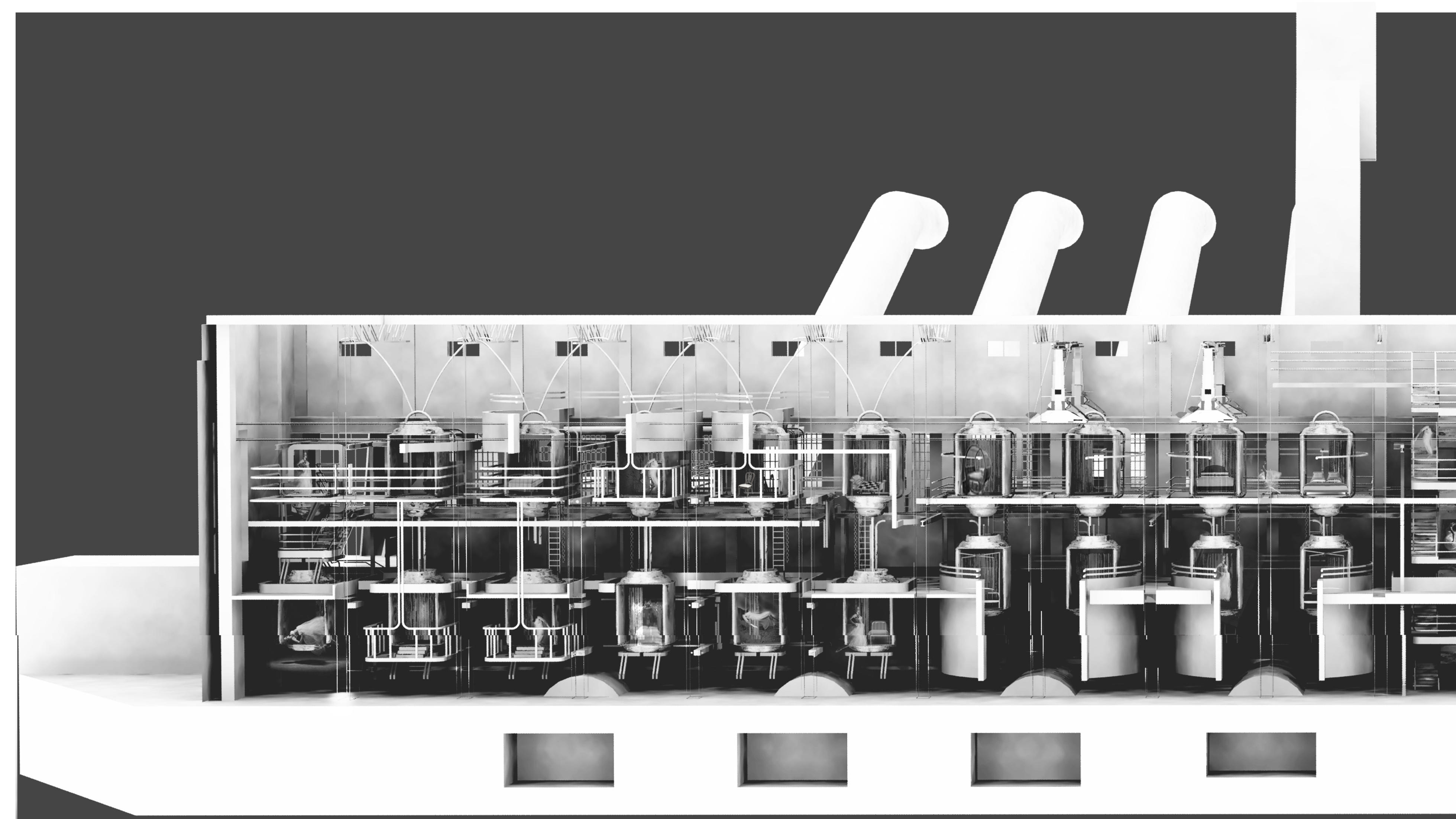




\section{CIRCULATION AND DESIGN BREAK-UP}

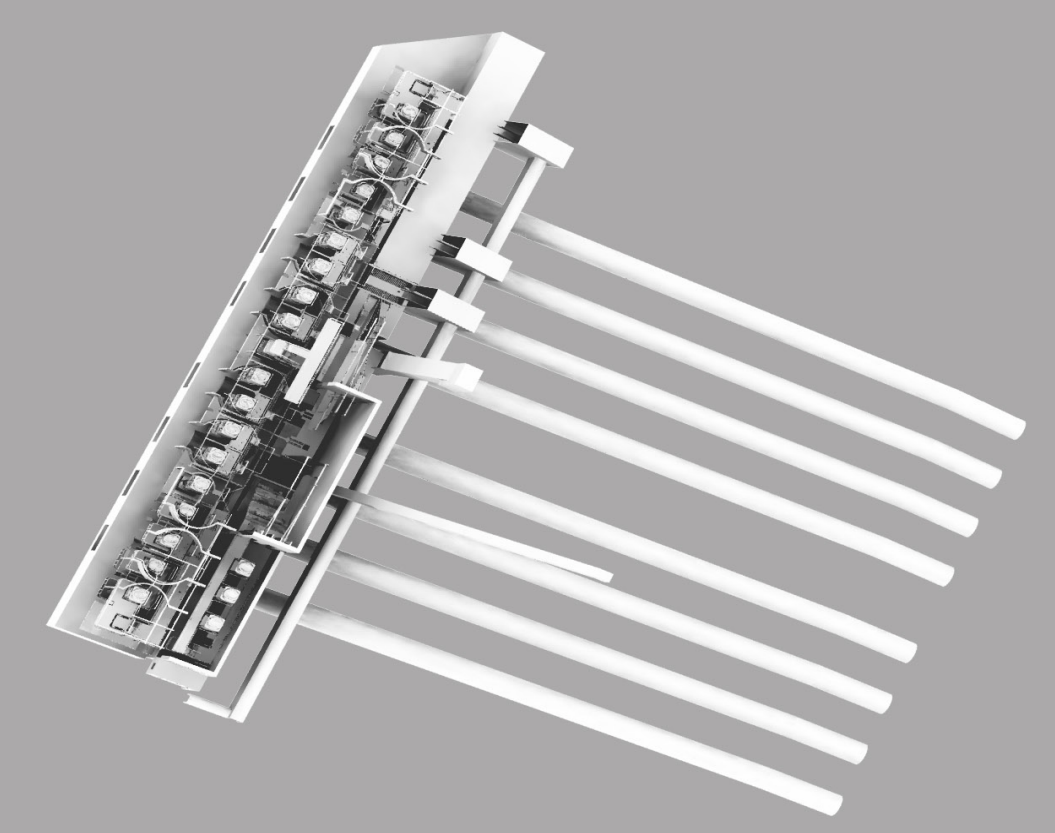




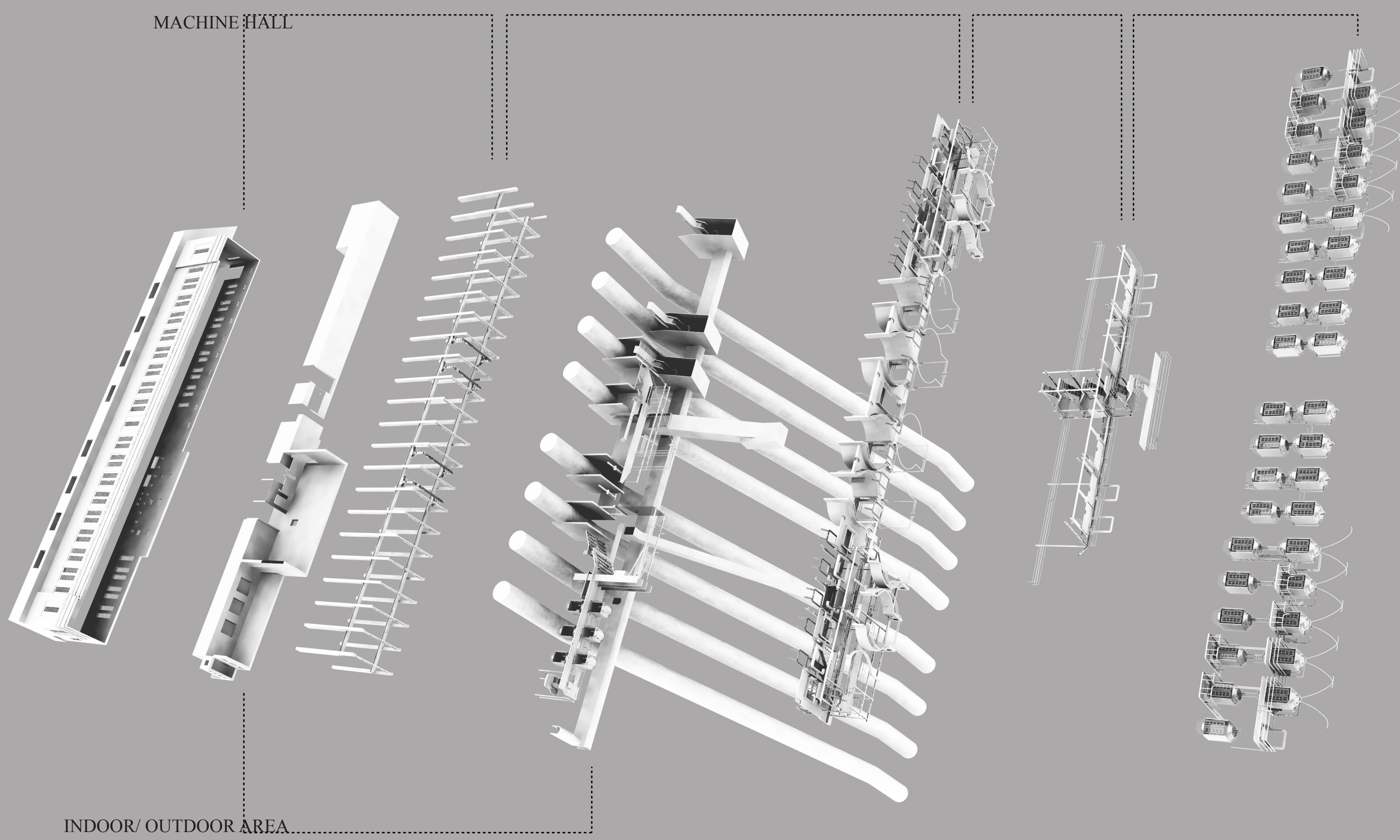




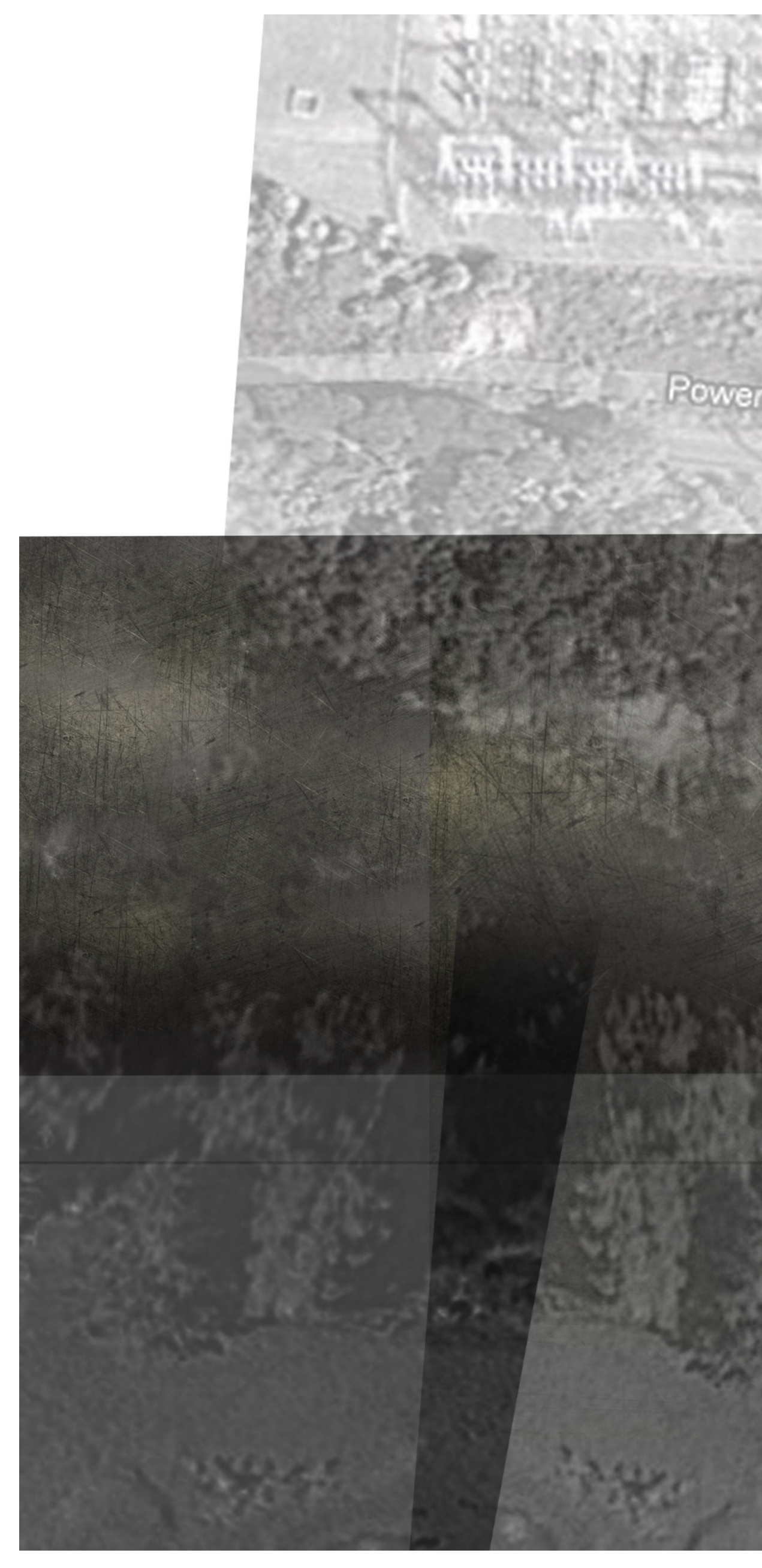

PLAN IN CONTEXT 


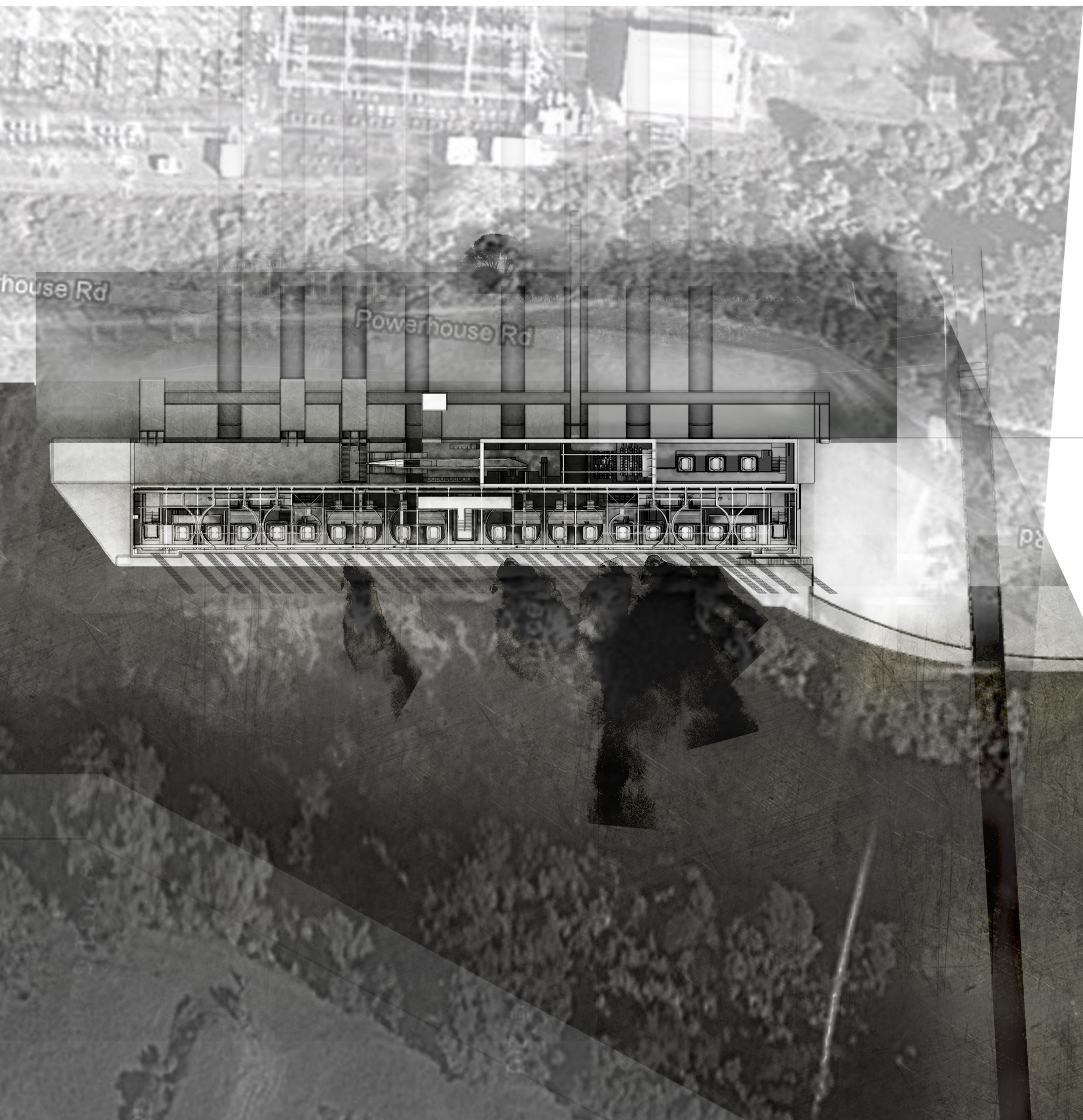




\section{LONGITUDINAL PERSPECTIVE}

Northeast Façade Removed

Capsule verticality to be read as freestanding

elements: building within the building. The

back can close but the front never has to.

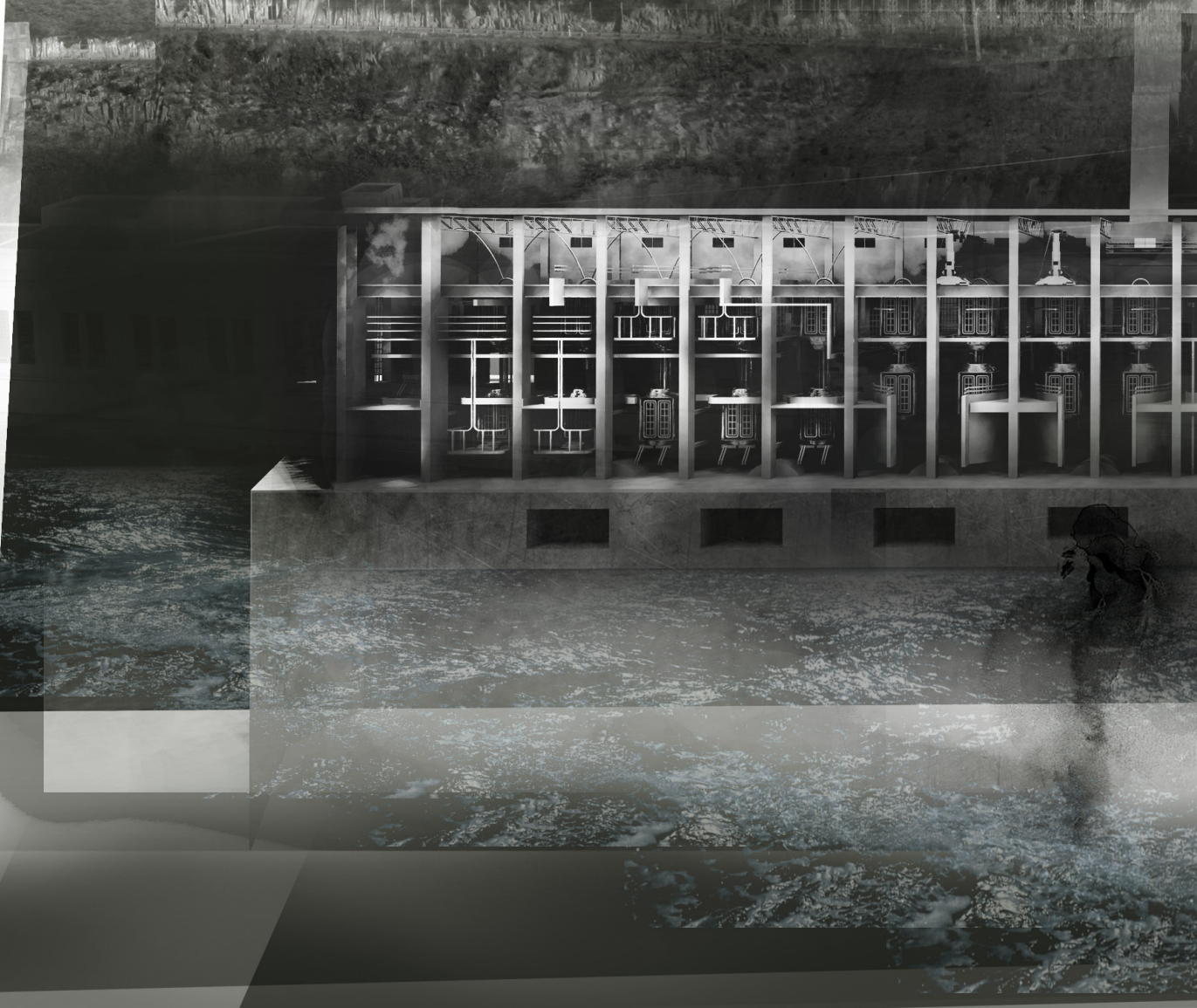




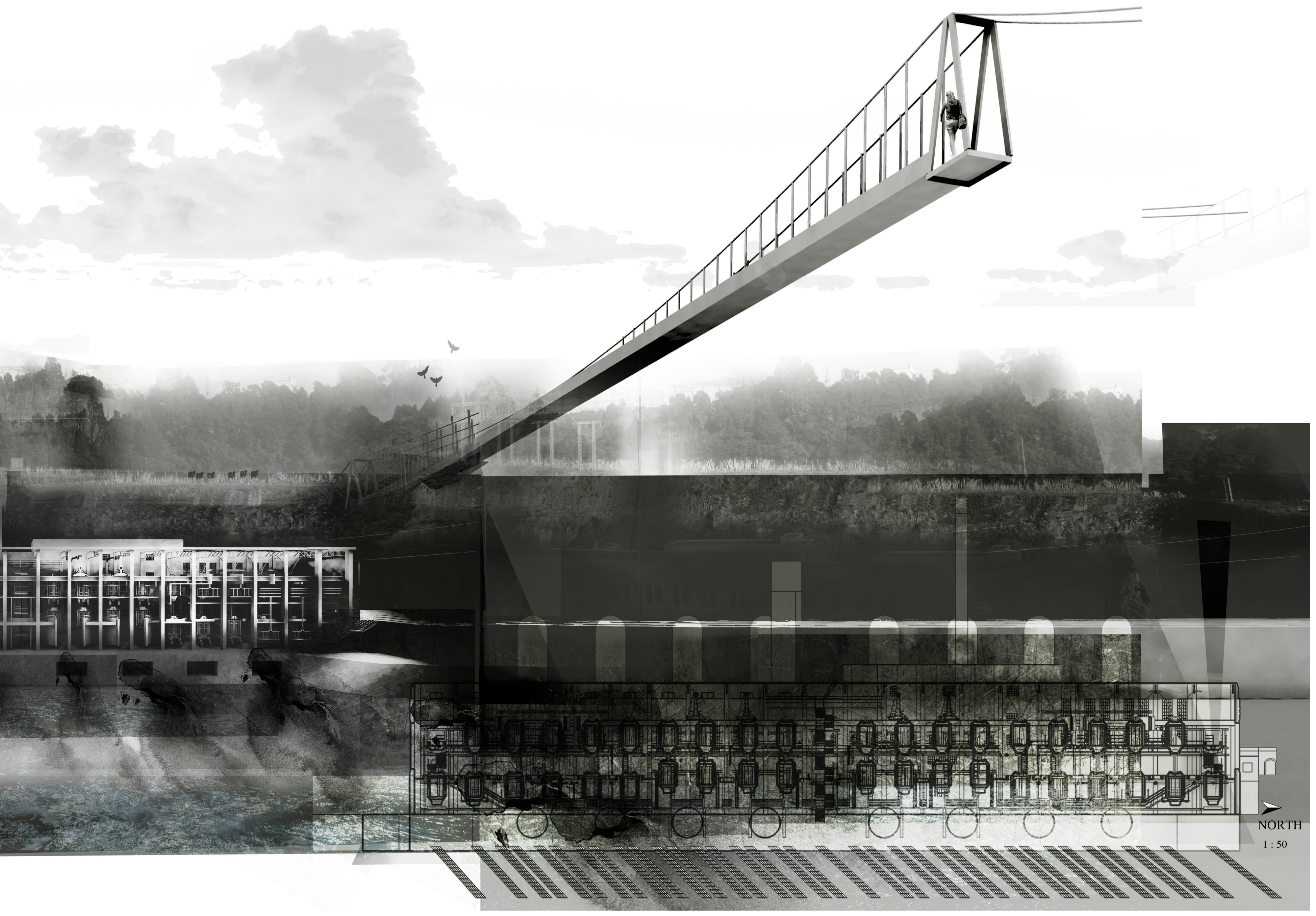


1 MAIN ENTRANCE AND ACCESSIBLE STAIR

2 PRIVATE CAPSULES

\section{PLAN LAYOUT}

3 PUBLIC CAPSULE

4 PRIVATE CAPSULES

5 PRIVATE CAPSULES

$6 \quad$ PUBLIC CAPSULE

7 PRIVATE CAPSULES

8 SECONDARY ACCESSIBLE STAIR

9 INDOOR / OUTDOOR ACCESS

10 ACCESSIBLE STAIR AND VIEWING PLATFORM

11 BATHROOM / SHOWER FACILITIES

CINEMA RECREATION

13 COMMON ROOM FACILITY

14 OUTDOOR COOKING FACILITY

15 OUTDOOR RECREATION SPACE: BARBEQUE TABLES, ETC. 


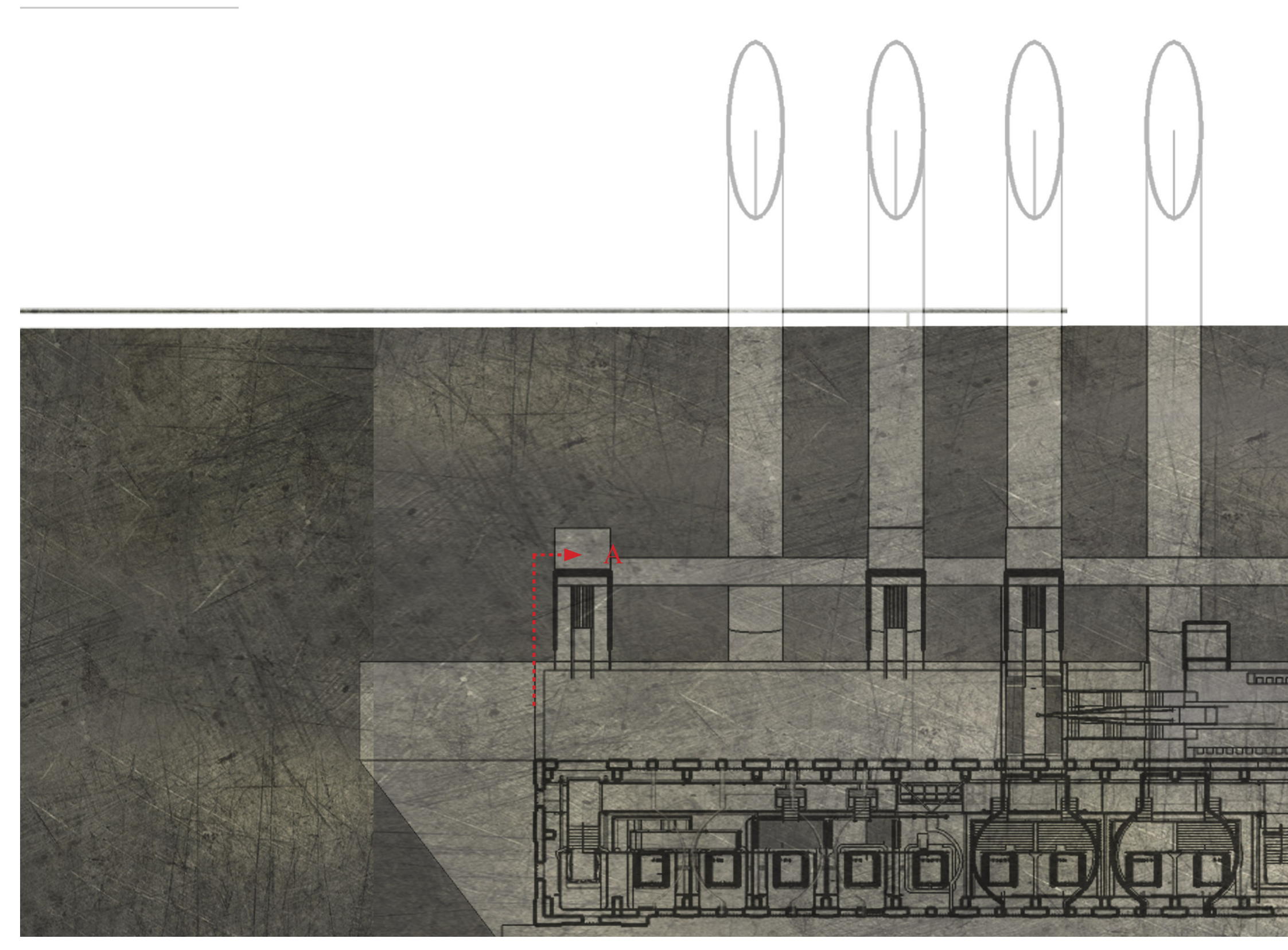





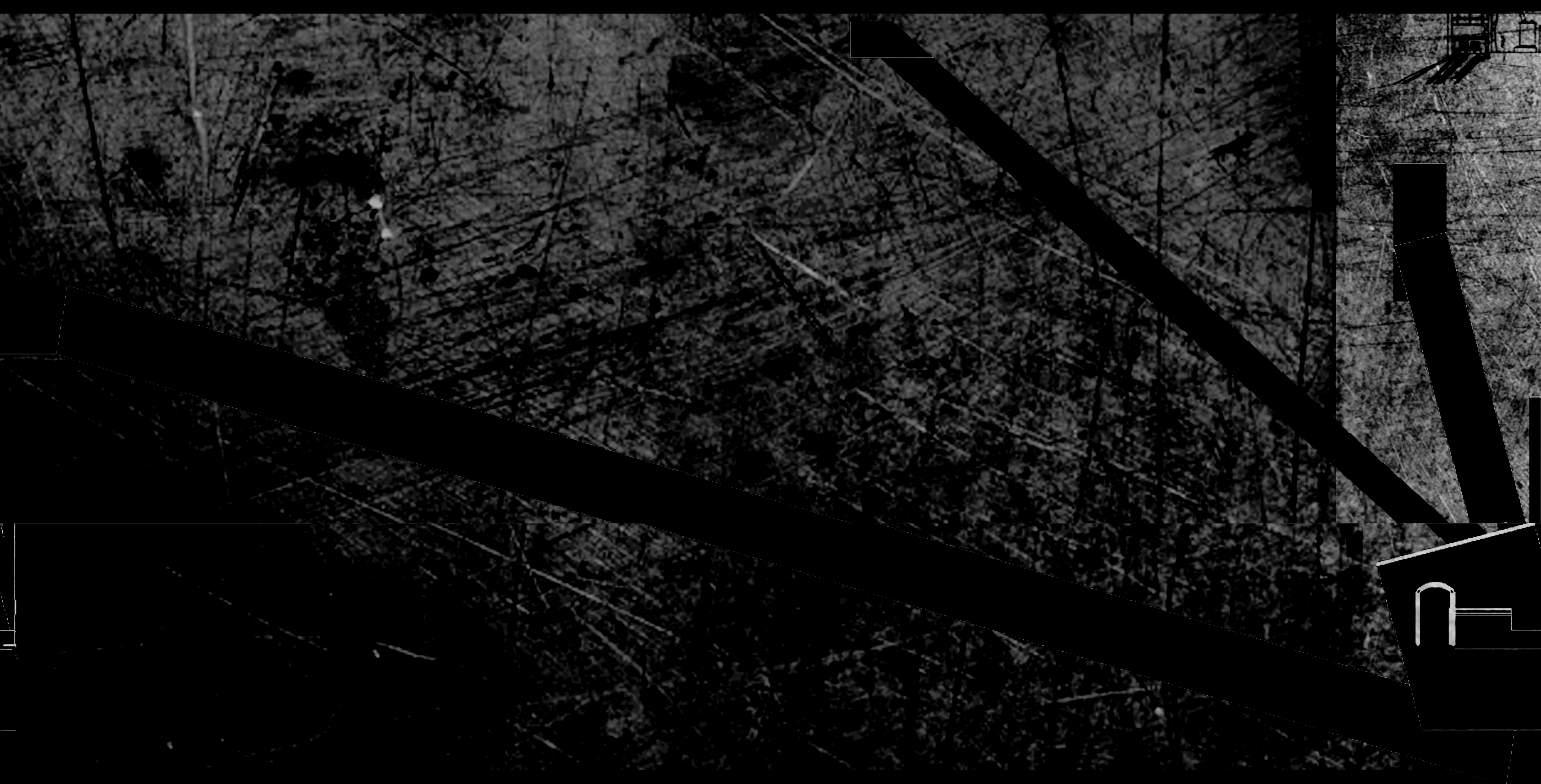



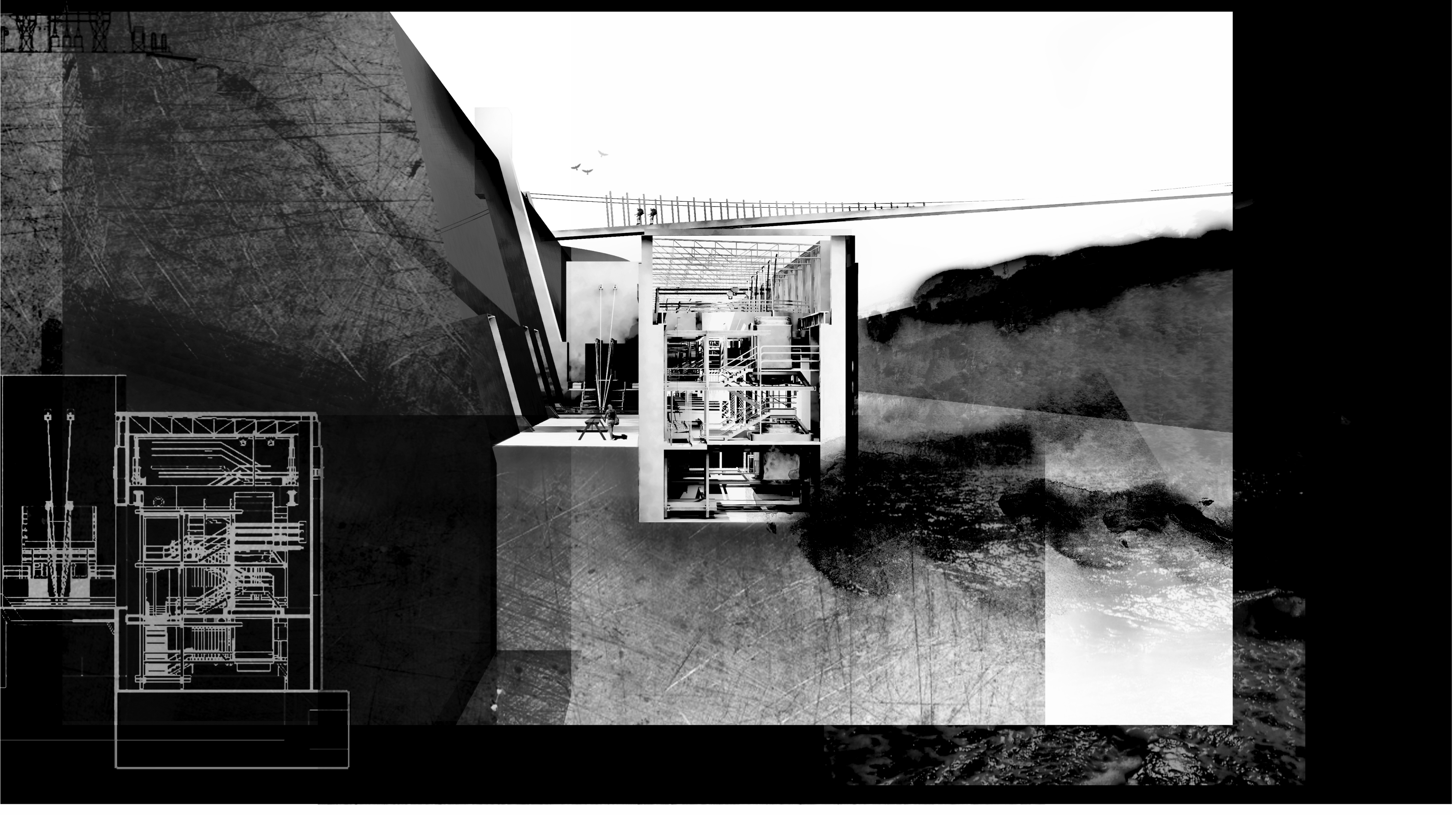

SHORT SECTIONAL PERSPECTIVE - A 


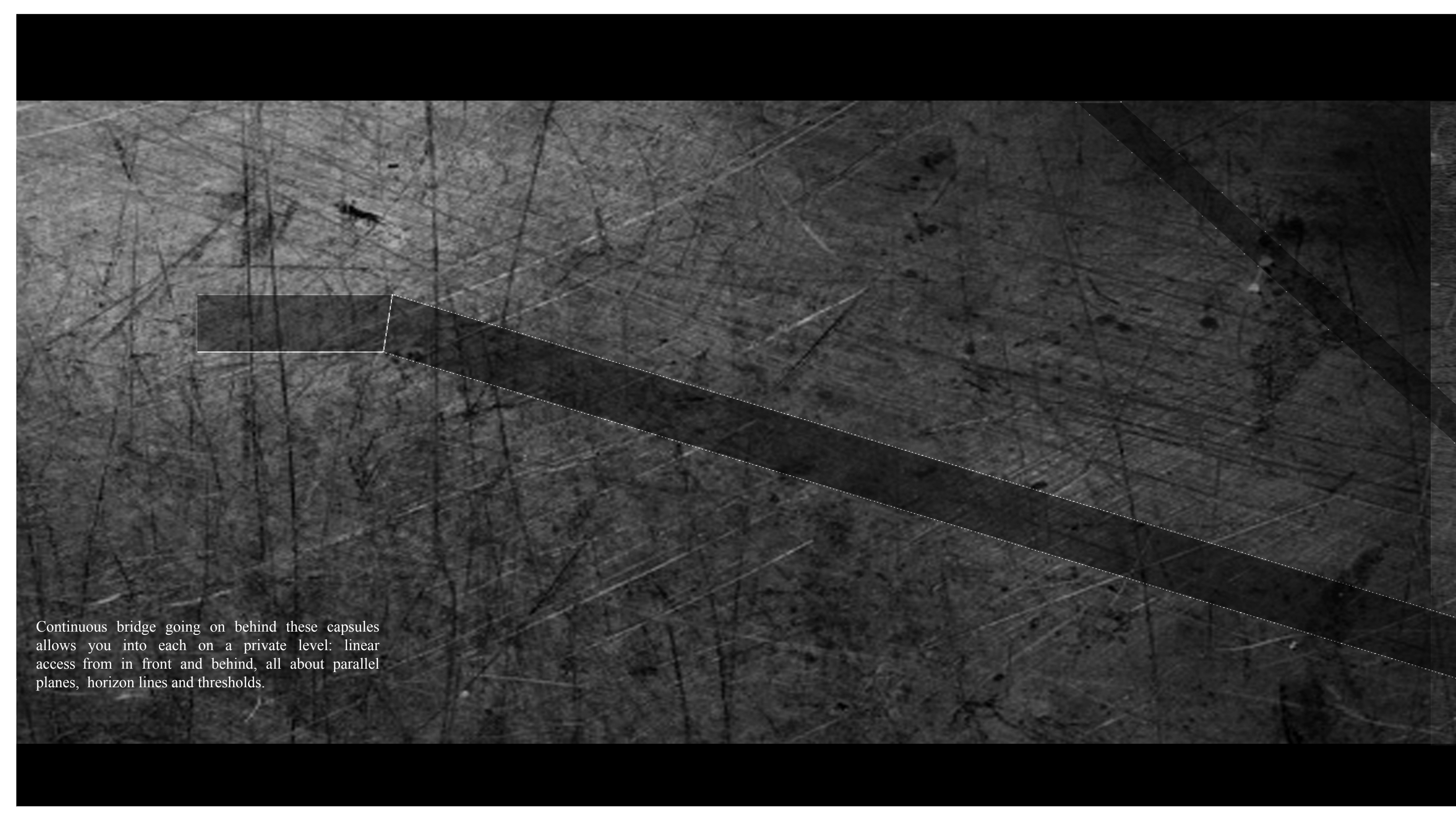




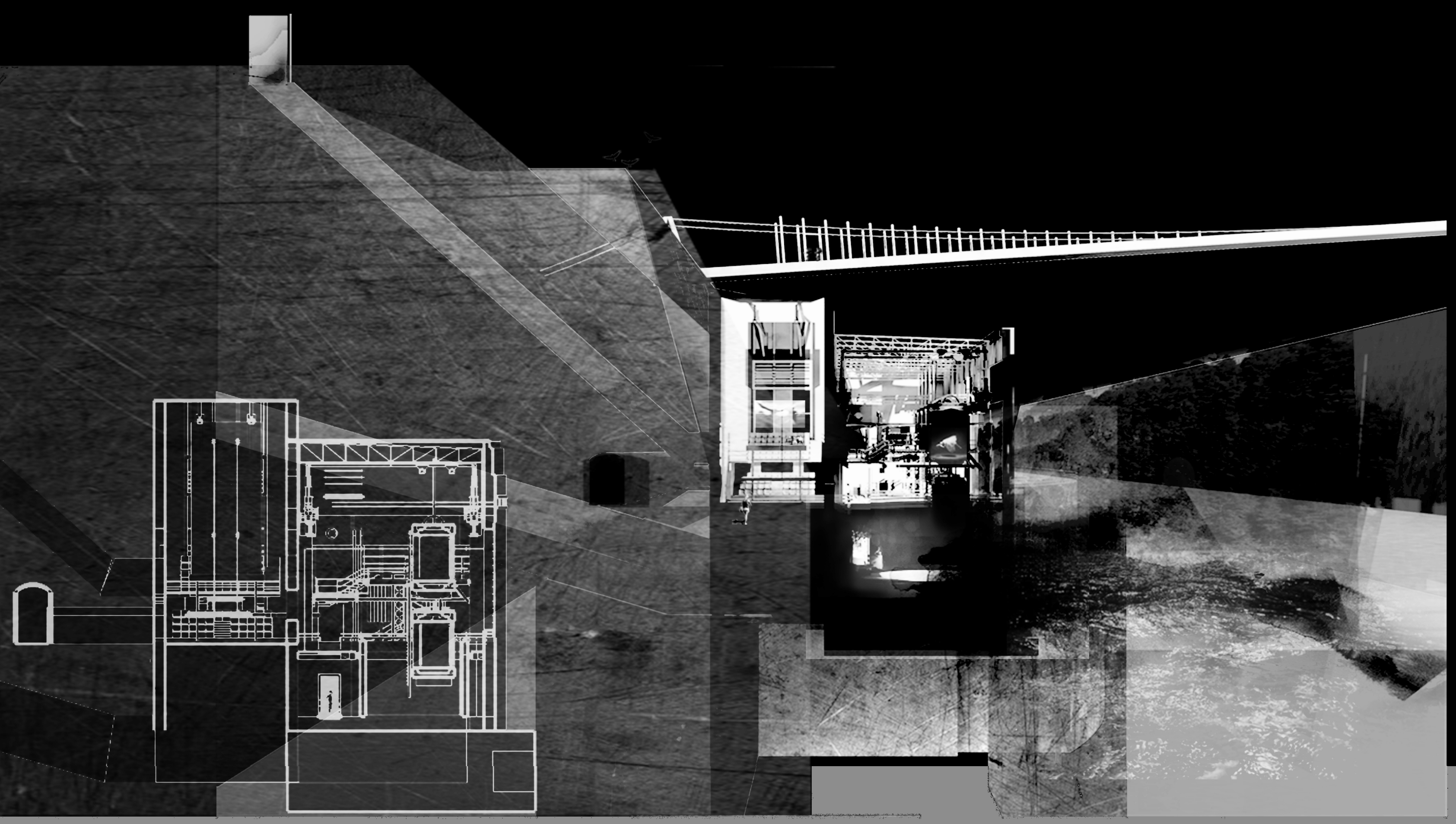




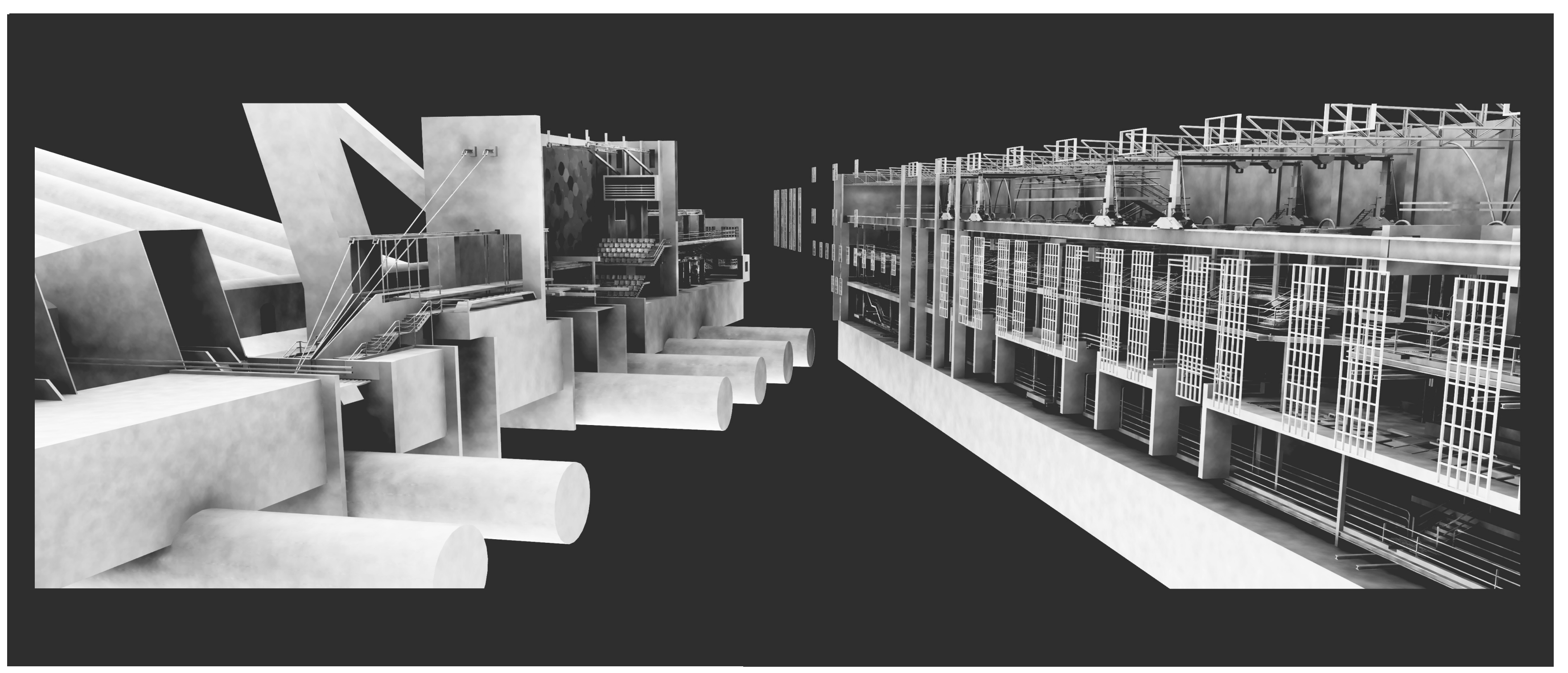




\section{Building Codes}

The third significant way humans have related their bodies to shape the designed world as we know it today is by:

"Developing rational and repeatable systems of measurement. The process began with the conversion of irregular, human-based units to standard units, and continued with the creation of classifications, like the metric system, that were ultimately detached from human experience. This rationalisation of dimensions eventually led to standardised measurements for the human body, for use by designers" (Caan 54).

It is ironic that there is so much talk of designing with fluidity to capture the entirety of human psyche as the design and building around human proportion has over the years led to an uncompromising rigid set of rules known as building codes today. Understandably, they are in place to make life easier to navigate, an uninterrupted journey at best. Absolute comfort should not have to be recognised in every applicable design or we will lose any sense of shock and excitement.
Although space is a reality, it is also a perception. Like the standardised third system noted previously which was developed to aid the rapid manufacturing process with the need to run efficiently, my chosen site is a hybrid of coordinating machinery and repetition. The site is largely hidden to the visitor's eye and from initial encounter would fit the predetermined, standard shape of most design we experience on a regular basis: a rectangular void. As the site was designed for largely mechanical purposes it is standardised and detached from human experience. 


\section{INTERIOR SCENE ONE}

When I am walking back and forth I get it, I get that I am in a continuous cycle of time. I start to recognise similarities when passing through reflective spaces, a module I have seen before. When I am in my module I get it, I am looking out into the starry night, watching time go by through the change of natural light to artificial. The view is never hampered. I am watching time pass by from the outside-in. I understand time architecturally one way and naturally the other. 


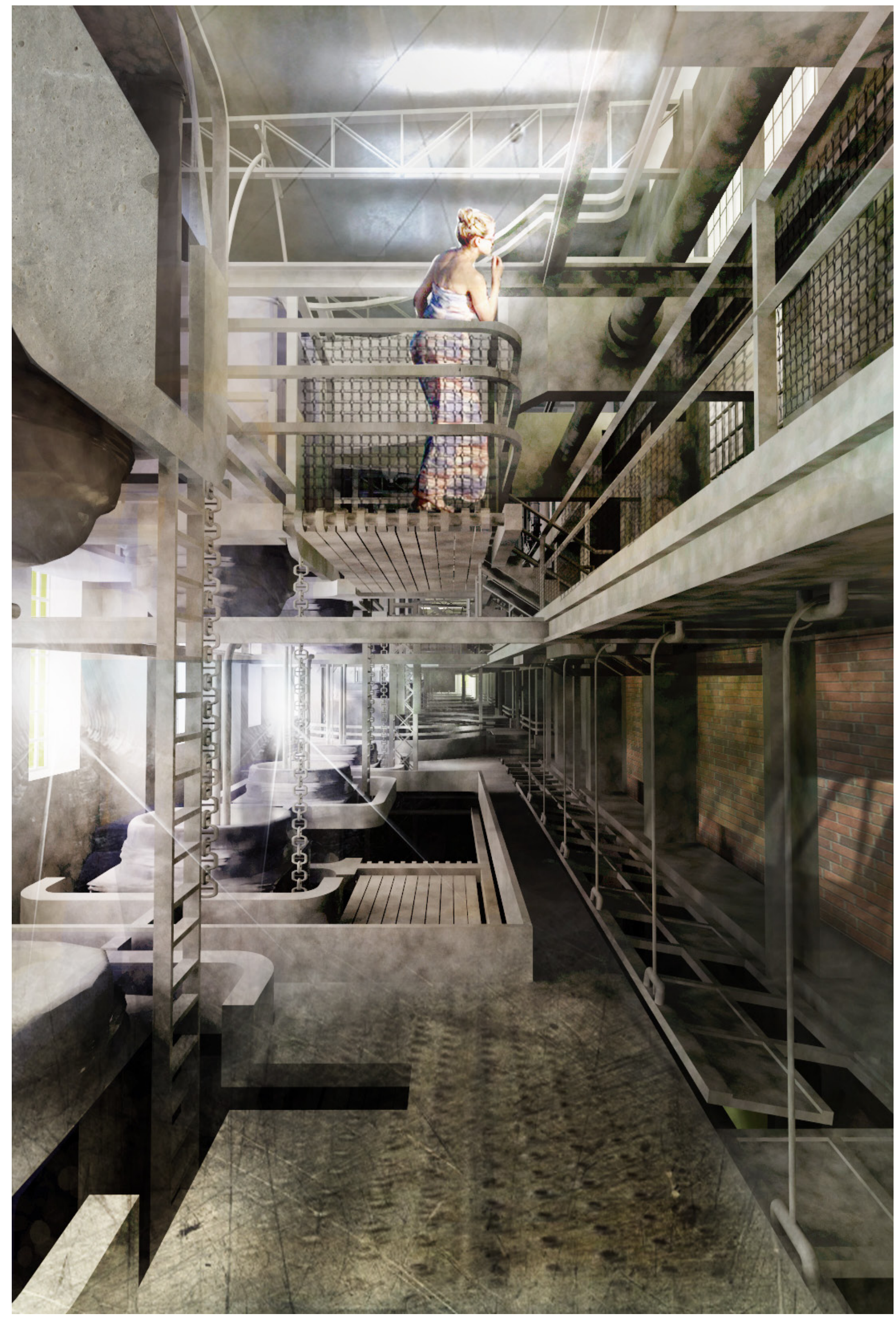


INTERIOR SCENE TWO

The access bridges allow the capsules to gain a sense of isolation. This creates a duality between vulnerability and protection in a visual rather than physical way, solving various issues of privacy, which makes a statement about the public nature of circulation as ultimately being about the private. 


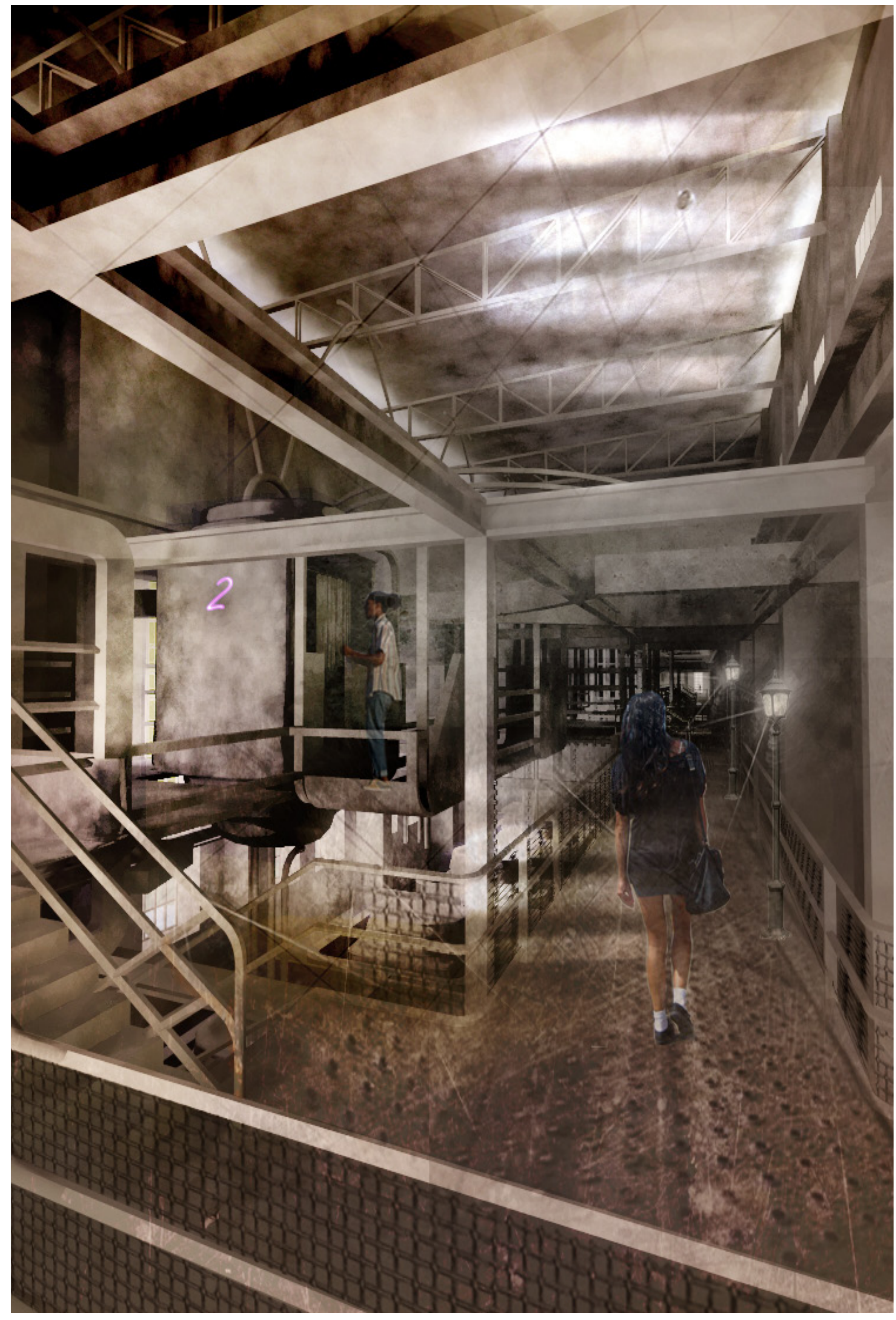


INTERIOR SCENE THREE

Module, Module, Module, then suddenly two modules link, then Module, Module,

Module, and you realise the last one is the beginning of the link which is not built yet.

- Approaching the evolution of time: the dream cycle. 


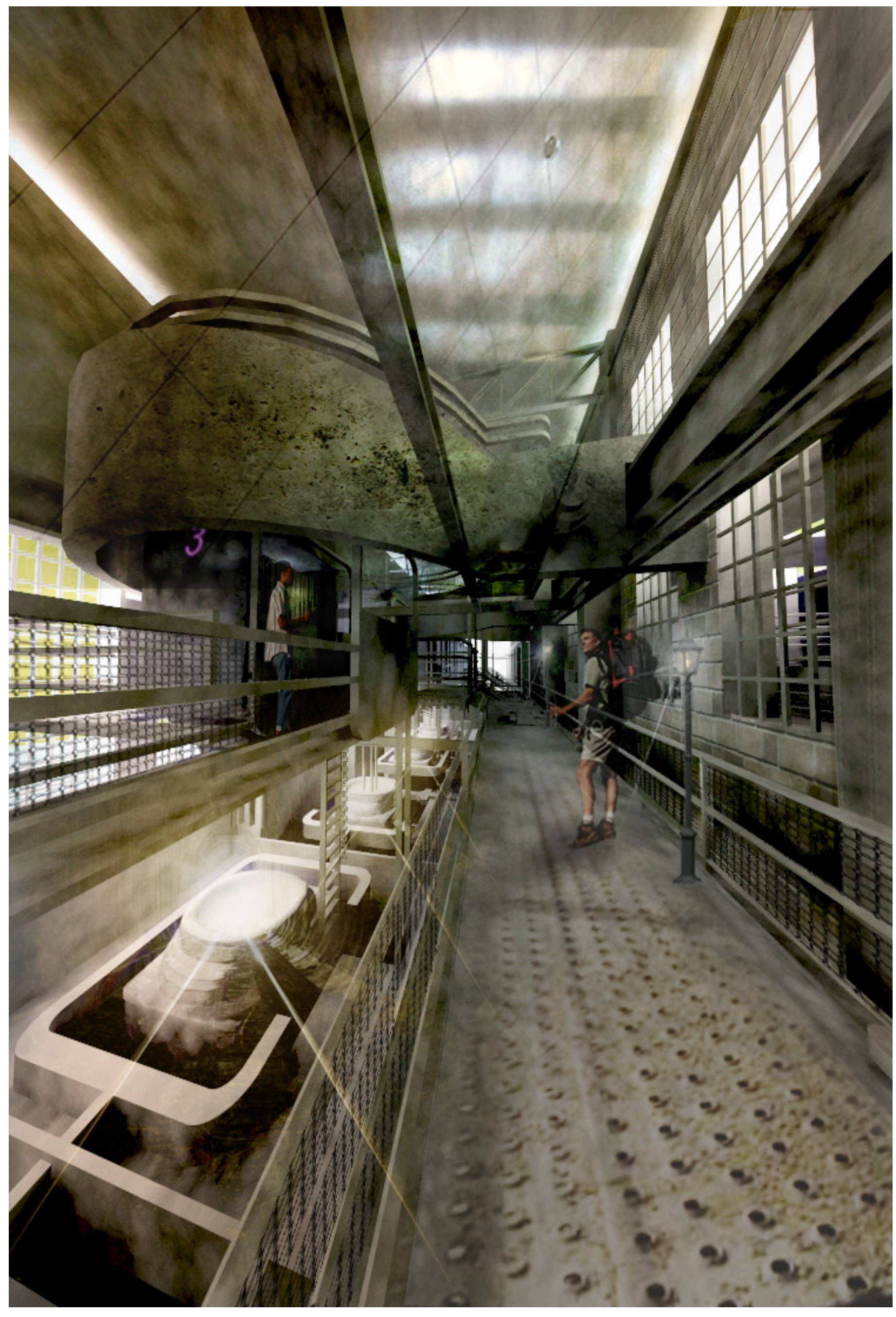




\section{INTERIOR SCENE FOUR}

Separate bridges with gaps controlling the intimate privacy or access to individual capsules. Even the original ground plane is invited to become a bridge. 


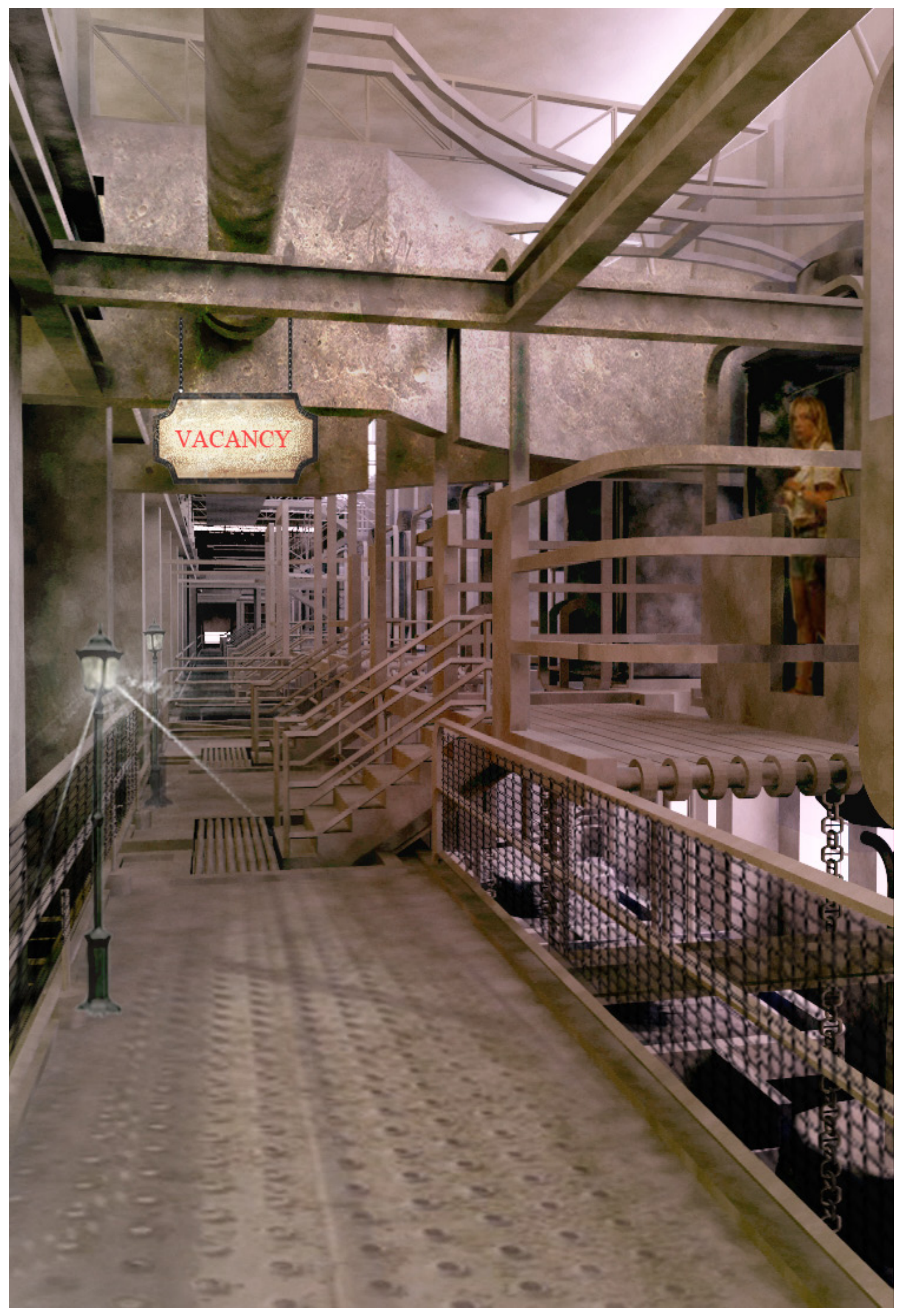


INTERIOR SCENE FIVE

Observation and witnessing. The place of witnessing or the place of being watched. 


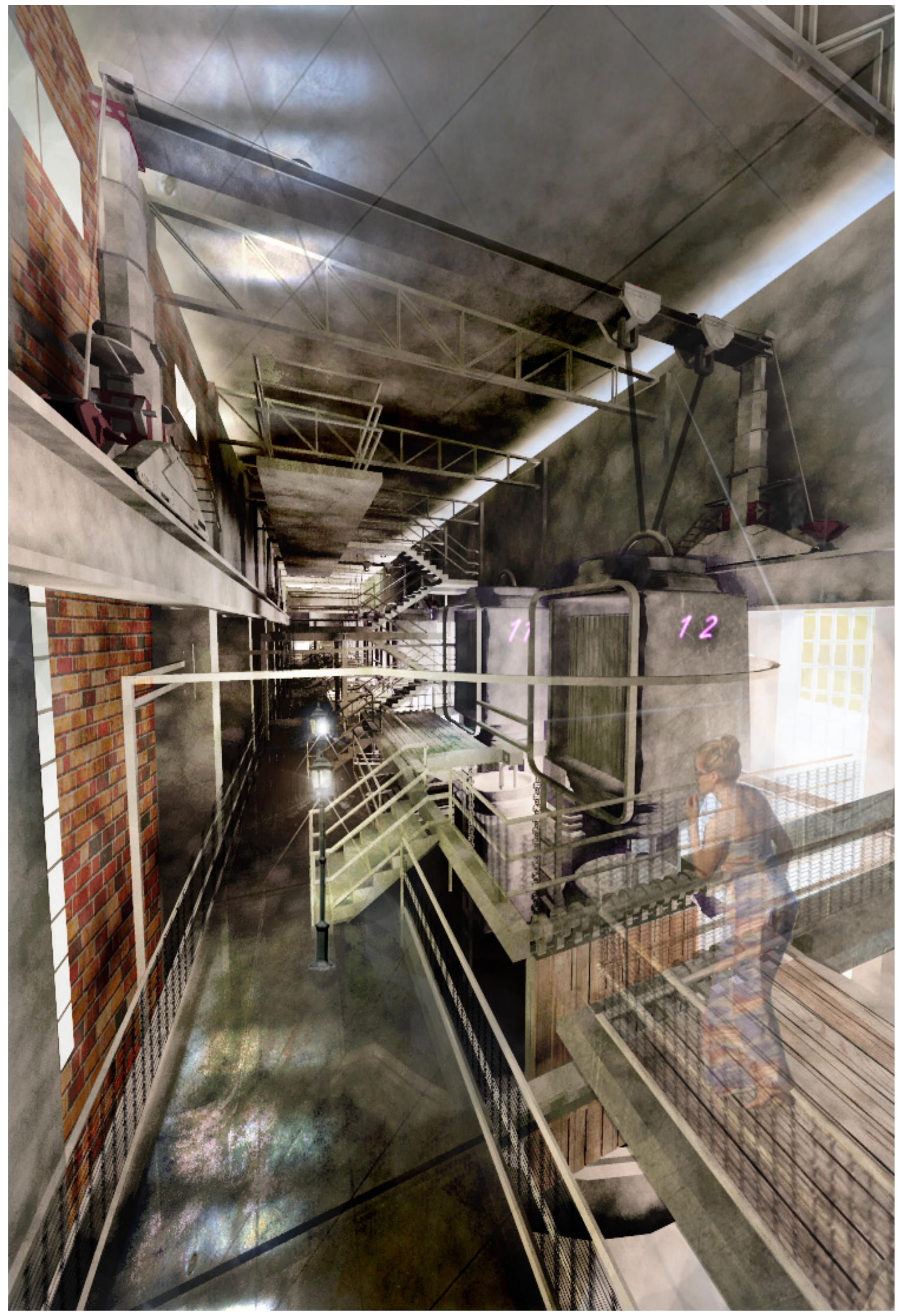




\section{INTERIOR SCENE SIX}

There is a change in rhythm whilst still allowing for the notion of an architectural cycle to unfold. You realise that these capsules cannot in fact go on forever, but instead are a moment caught in time, leaning towards a future.

The building of the bedroom and the modular elements of the bedroom each become different participants of living space, inviting each capsule to be a different point in time, or a shift in time. 


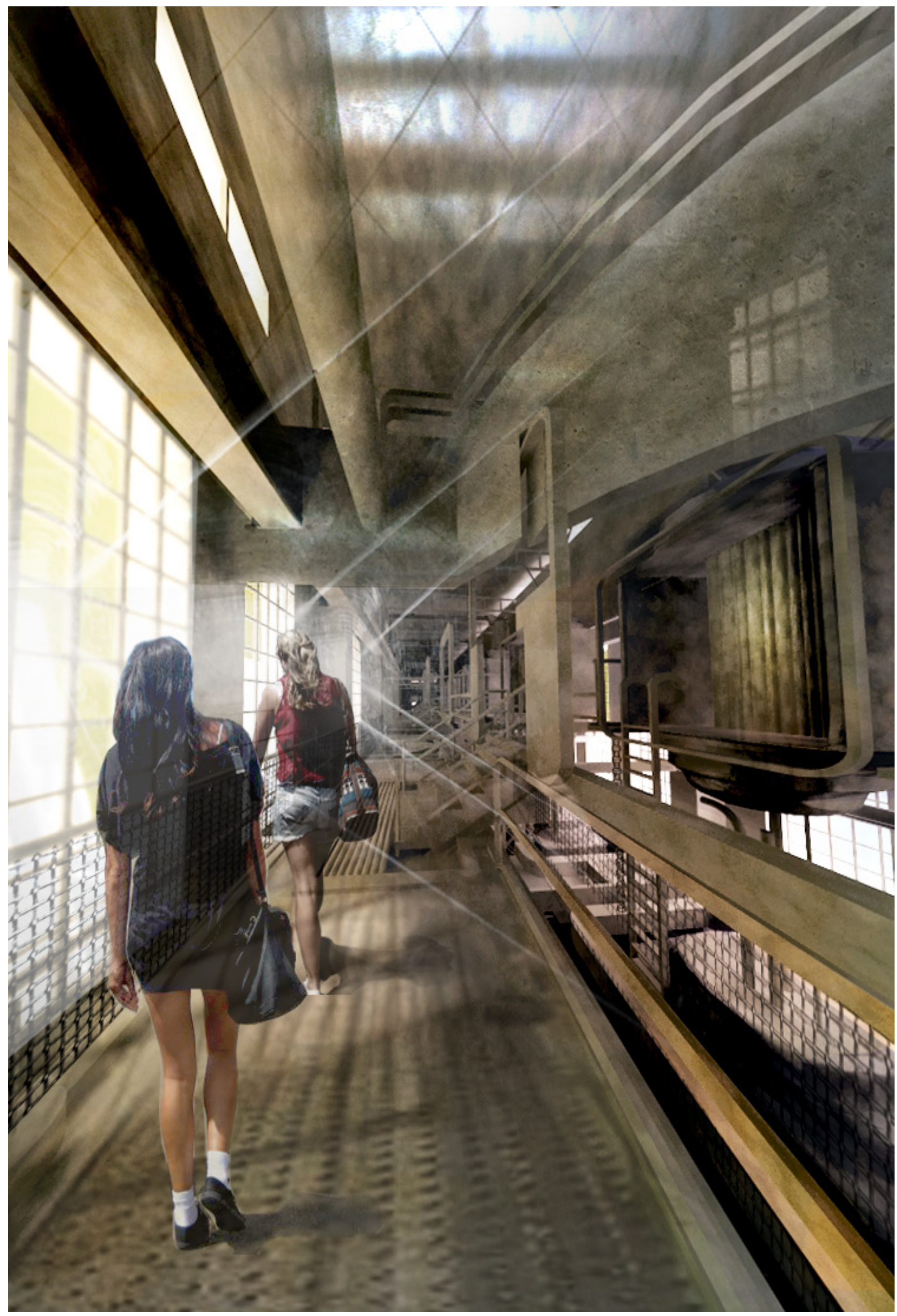




\section{INTERIOR SCENE SEVEN}

What could happen in the direction in which I have just walked? We have surfaces of glass and transparency, and alternatively we have surfaces of opacity and blockage.

We sleep in the transition between the blocked and the transparent.

Between the perpetual day and the perpetual night. The natural and the artificial.

Between illusion and reality.

Everything is constantly in transition. Never static. Just like your mind. 


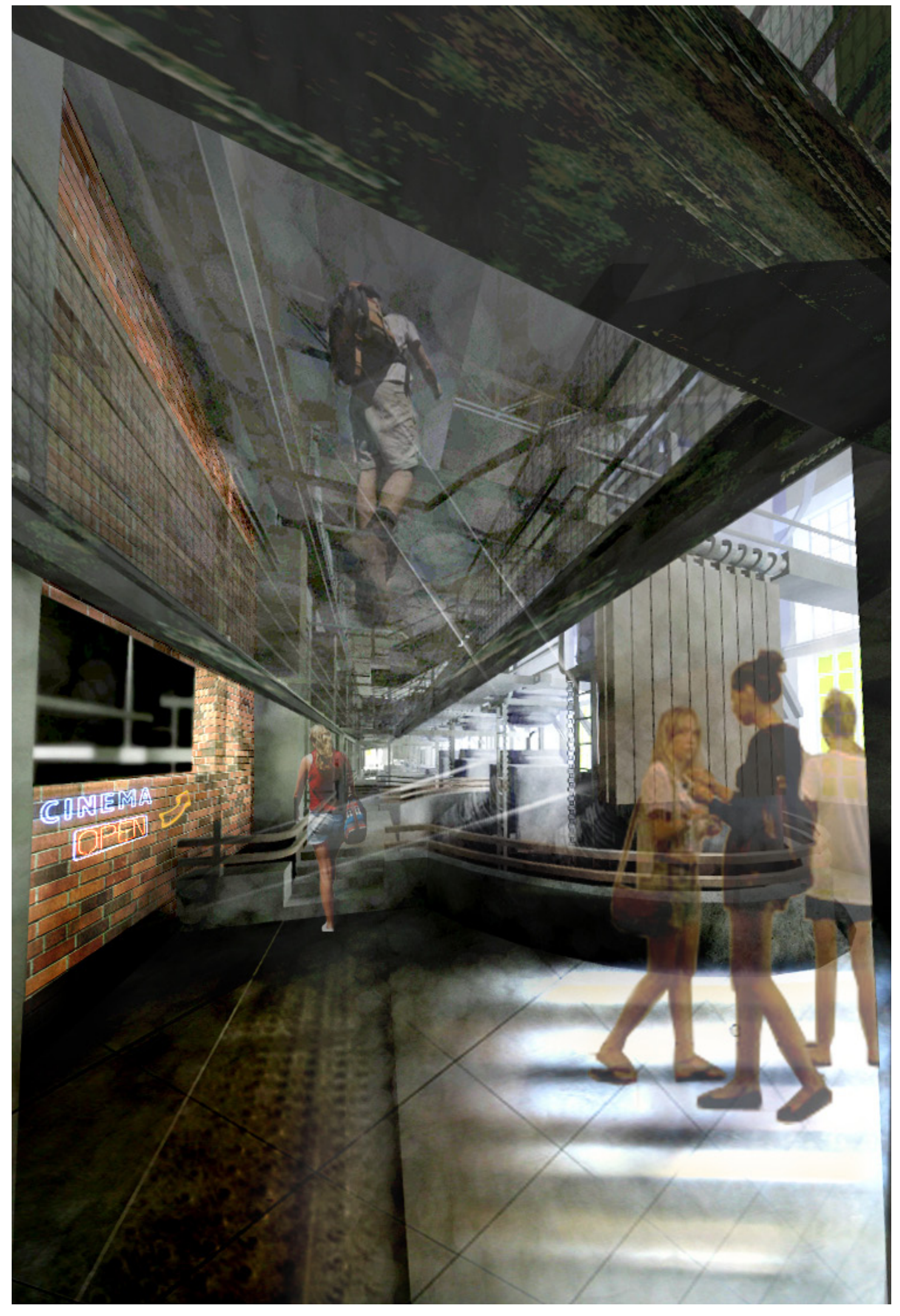


INTERIOR SCENE EIGHT

You are sleeping in there, and you know that you control that footpath. 


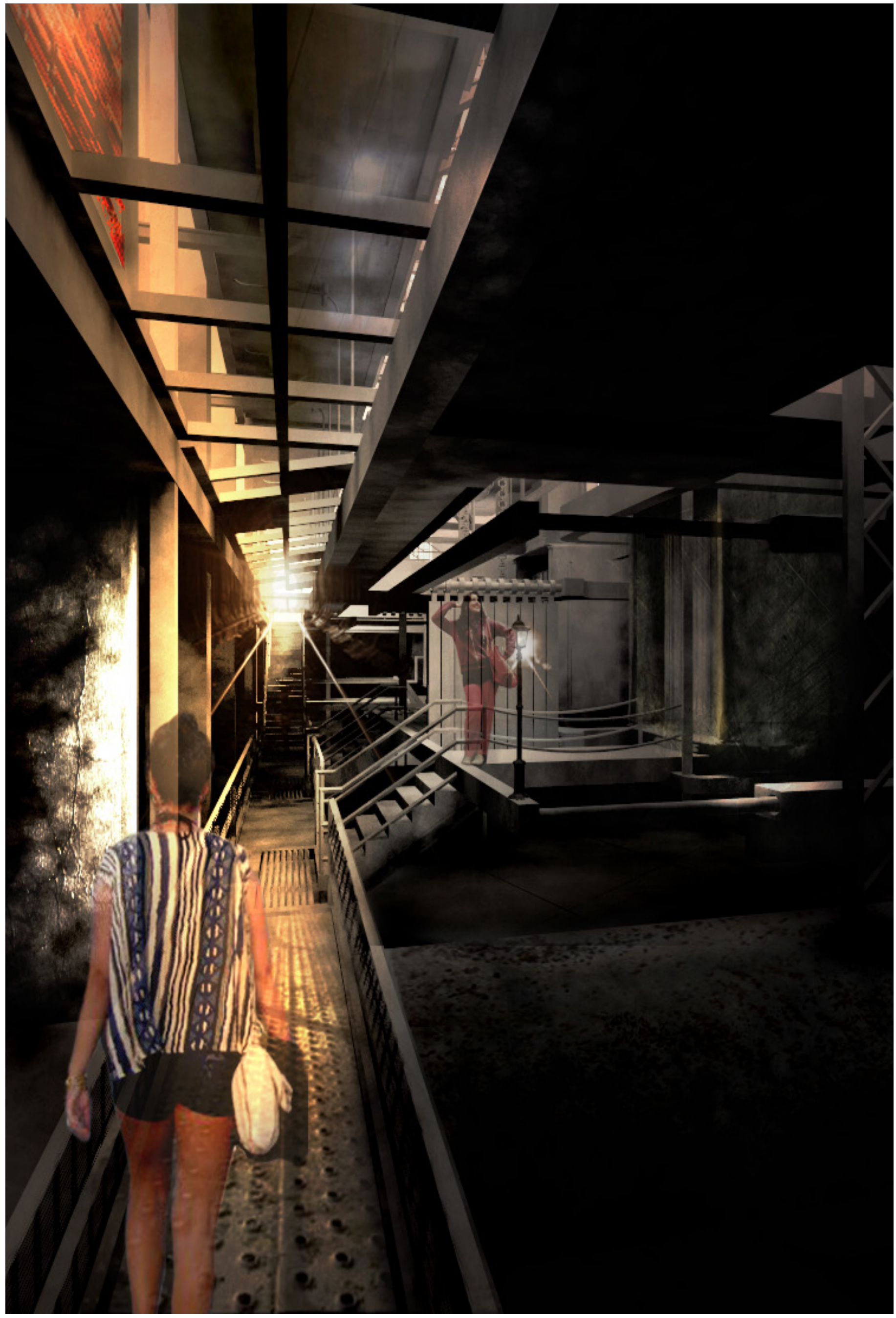




\section{BIBLIOGRAPHY:}

Abraham, Raimund. [UN] Built. New York, Wien Springer, 1996.

Academy Group, ed. A Guide to Archigram 1961-74. London, Academy Editions, 1994.

Archer, B.J. Follies: Architecture for the Late Twentieth-Century Landscapes. New York, Rizzoli International Publications Inc. 1983.

Bachelard, Gaston._The Poetics of Space: The Classic Look at How We Experience Intimate Places. Paris, Presses

Universitaires de France, 1958.

Beal, Justin. Oil and Water: Offshore Architecture. New York, Taylor \& Francis Inc, 2006.

Bollnow, O.F. Human Space. London, Hyphen Publishers, 2011.

Boultan, J.T. A Philosophical Enquiry into the Origin of our ideas of the Sublime and Beautiful. London, Routledge and Kegan, Paul1958.
Caan, Shashi. "Human Beings in the Built Environment". Re-thinking Design and Interiors. London, Laurence King Publishing Ltd, 2011.

Crompton, Dennis, ed. Concerning Archigram. London, Cornerhouse Gallery, 1998.

Darden, Douglas. Condemned Buildings. New York, Princeton Architectural Press, 1993.

Davidson, Cynthia, ed. Anybody. New York, Anyone Corporation, 1997.

Davidson, Cynthia, ed. Anytime. New York, Anyone Corporation, 1999.

Deleuze, G. and Guattari, F. A Thousand Plateaus: Capitalism and Schizophrenia. Minneapolis, University of Minnesota Press, (1987).

Gander, Phillippa. Sleep in a 24Hour Society. Auckland, The Open Polytechnic of New Zealand, 2009.

Hall, Edward \& Mildred. Ed. The Fourth Dimension in Architecture: The Impact of Buildings on Man's Behaviour. Santa Fe, New Mexico, Blue Feather Press, 1975. 
Hall, Edward, T. The Hidden Dimension. New York, Anchor Books, 1966.

Holl, Steven. Colour Light Time. Zurich, Lars Muller Publishers, 2012.

Krondenburg, Robert, ed.

Transportable Environments 3. New York, Taylor \& Francis Inc, 2006.

Myers, Tracy, Woods, Lebbeus, Harries, Karsten. Lebbeus Woods: Experimental Architecture. Pennsylvania, Carnegie Museum of Art, 2004.

Ostwald, Micheal, J. Tucker, Chris, Chapman, Michael. Residue:

Architecture as a Condition of Loss. Melbourne, RMIT University Press, 2006.

Rendell, Jane, Hill, Jonathan, Fraser, Murray and Dorrian, Mark. ed. Critical Architecture. New York, Routledge, 2007.

Southwood, I. J, "Golden Jubilee of the Arapuni Hydro-electric Power Station June 1929-1979." The History of Arapuni. Arapuni, 1979.
Sykes, Krista A. ed. Constructing a New Agenda: Architectural Theory 19932009. New York, Princeton Architectural Press, 2010.

Taylor, Mark, Preston Julieanna, ed. Intimus: Interior Design Theory Reader. Chichester, Wiley-Academy, a division of John Wiley \& Sons Ltd, 2006.

Terzidis, Kostas. Algorithmic Architecture. Oxford, Architectural Press, 2006.

Terzidis, Kostas. Algorithms for Visual Design using Processing Language. Indianapolis, Wiley Publishers, 2009.

Van Der Laan, Architectonic Space: Fifteen Lessons on the Disposition of Human Habitat. Netherlands, E. J. Brill. 1983.

Warlamis, Efthymios. Poetic Architecture. London, New Architecture Group Limited, 2005. 